Portland State University

PDXScholar

1995

\title{
We are the Vanguard, Not the Norm: Stories of Successful Minority Students in Predominantly White Graduate Teacher Education Programs
}

Leslie Rennie-Hill

Portland State University

Follow this and additional works at: https://pdxscholar.library.pdx.edu/open_access_etds

Part of the Teacher Education and Professional Development Commons Let us know how access to this document benefits you.

\section{Recommended Citation}

Rennie-Hill, Leslie, "We are the Vanguard, Not the Norm: Stories of Successful Minority Students in Predominantly White Graduate Teacher Education Programs" (1995). Dissertations and Theses. Paper 1315.

https://doi.org/10.15760/etd.1314

This Dissertation is brought to you for free and open access. It has been accepted for inclusion in Dissertations and Theses by an authorized administrator of PDXScholar. Please contact us if we can make this document more accessible: pdxscholar@pdx.edu. 


\section{DISSERTATION APPROVAL}

The abstract and dissertation of Leslie Rennie-Hill for the Doctor of Education in Educational Leadership: Postsecondary were presented April 28, 1995, and accepted by the dissertation comrittee and the doctoral program. COMMITTEE APPROVALS:
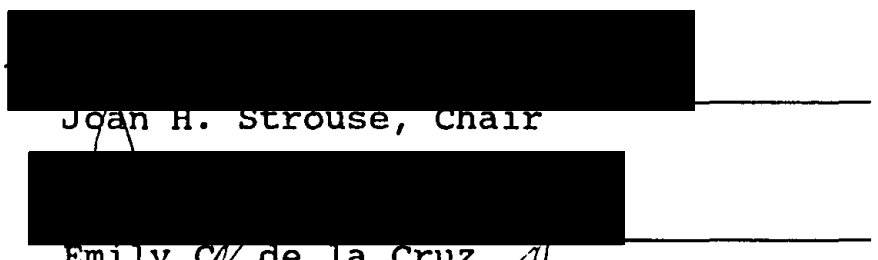
Emily of de la cruz $f$

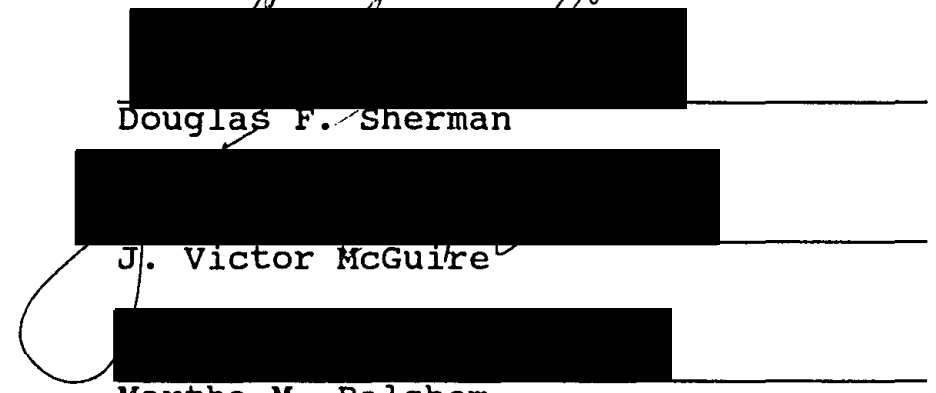

Martha M. Balshem

Representative of the office of Graduate studies

DOCTORAL PROGRAM APPROVAL:

Robert B. Everhart, Dean

School of Education

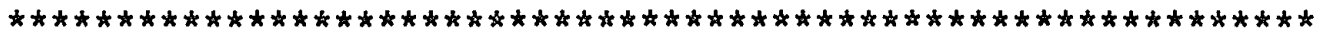
ACCEPTED FOR PORTLAND STATE UNIVERSITY BY THE LIBRARY by on $y+2 \pi x$ 


\section{AIRSTPACT}

An abstract of the dissertation of Leslie Rennie-Hill for the Doctor of Education in Educational Leadership: Postsecondary presented April 28, 1995.

Title: We Are the Vanguard, Not the Norm: Stories of Successful Minority Students in Predominantly white Graduate Teacher Education Programs

Minorities stand increasingly under-represented in the teaching profession; they continue to be under-represented in graduate teacher preparation programs. Despite calls for increased numbers of minority teachers, despite countless well-intentioned recruitment and retention programs, the relative proportion of newly prepared minority teachers is in fact decreasing (Carter \& Wilson, 1992).

Literally hundreas of studies examine retention programs, identifying the deficits of minorities, noting what program elements work, and establishing characteristics of supportive institutional environments. Unfortunately, knowing what can be done to/increase persistence does not yet translate into doing it.

By focusing on a positive correlate--those minority students who successfulty complete their programs--this 
study contrasts with the deficit approach. Employing a critical analysis and feminist and ethnic interpretive perspectives, this qualitative study investigates the experiences of minorities who did complete graduate teacher education programs at 10 predominantly white, public and private, urban, suburban, and rural instirutions in the Pacific Northwest. Specifically, the study examines how these minority students understand and interpret their experiences, which events they perceive as enhancing their successes and which ones they know interfered.

All minorities who had completed graduate teacher preparation programs at the 10 institutions since 1990 were surveyed. Sections of the survey correspond to categories previously found to correlate with persistence (AME/OMHE, 1992; Attinasi, 1989; Pascarella \& Terenzini, 1990; Tinto, 1987). Of the 728 who returned the surveys $(\underline{N}=61), 838$ asked to be interviewed. Subsequently, seven respondents representative of the surveyed population each participated in two face-to-face interviews.

Ethnographic methods were used to inductively analyze the empirical materials gathered in the research study. Content analysis of the subjects' journals combined with their interview transcripts and surveys enabled triangulation within three different sources of the respondents' own words. 
Results confirm that minorities see themselves as outsiders within predominantly white institutions. Belonginy, or not, frames their institutional experience and mirrors their everyday lived realities in mainstream American culture. Respondents attribute their achievements to individual persistence; examples of persistence cited align remarkably with psychological profiles of resiliency (Benard, 1991). Retention program components are viewed as less significant than the personal resiliency each respondent evidenced. 
WE ARE THE VANGUARD, NOT THE NORM: STORIES OF SUCCESSFUL MINORITY STUDENTS IN PREDOMINANTLY

WHITE GRADUATE TEACHER

EDUCATION PROGRAMS

by

LESLIE RENNIE-HILL

A dissertation submitted in partial fulfillment of the requirements for the degree of

\author{
DOCTOR OF EDUCATION \\ in \\ EDUCATIONAL LEADERSHIP: \\ POSTSECONDARY
}

Portland State Univarsity
01995 
UMI Number: 9532759

Copyright 1995 by Rennie-Hill, Leslie

All rights reserved.

UMI Microform 9532759

Copyright 1995, by UMI Company. Al1 rights reserved.

This nicroform edition is protected against unauthorized copying under Title 17, United States Code.

\section{UMI}

300 North Zeeb Road Ann Arbor, MI 48103 
DEDICATION

Dedicated to my grandmother, PATTI RENNIE. 


\title{
ACKNOWLEDGEMENTS
}

\begin{abstract}
I have been bliessed with remarkable comrades and collaborators: together we organize our world for ourselves, or at least we organize our understanding of it; we reflect it, refract it, criticize it, grieve over its savagery, and help one another to discern, amidst the gathering dark, paths of resistance, pockets of peace and places from whence hope may be plausibly expected.
\end{abstract}

Marx was right: the smallest divisible human unit is two people, not one; one is a fiction. From such nets of souls societies, the social world, human life spring.

Tony Kushner, Playwright

During the course of my study, I gained an enhanced appreciation for the sensitivity and depth of the topic of diversity in contemporary American culture. Most everyone has strong, personal feelings about the topic--personal experiences, some extremely poignant or painful--and personal desires and hopes for changed outcomes. Navigating these tricky currents of the Pacific Northwest renowned for their submerged snags was a constant learning experience for me, especially when my sight was drawn to an attractive vista downstream rather than the immediate waters ahead. Thus, I feel particularly fortunate to have had such a wonderful "net of souls" cast around me: I couldn't have done this research project without them. 
I owe a special debt of gratitude to my dissertation committee, a group of people who critically guided the research process while never wavering in their collective support for the importance of the topic. To Professor Joan Strouse, mentor and committee chair, and Professors Martha Balshem, Emily de la Cruz, J. Victor McGuire, and Doug Sherman, I offer my appreciation.

Secondly, I must mention the "D-Group": a group of four women who conversed, critiqued, cajoled, and cooperated to support one another throughout the development of their dissertations. Thanks to Gloria Gostnell, Lorna Kern, and Penny Poplin-Gosetti. I cannot imagine having done this without you all.

Another invaluable help came from Sandra steward who transcribed the interviews with a sensitive ear and a lot of heart.

A circle of women friends and colleagues prompted much discussion about privilege and marginality. They know how to approach a serious subject with the balance and humor that let us continue to face issues of discrimination with a realistic optimism. Thanks to: Susan, Stephanie, Nancy, Lucile, Gene, Marcia, Katie, Nancy, Judy, and Beliz.

A very special man, Dr. Harvey Horne, talked with me about resiliently walking on the fault line. His insistence as to the importance of this research topic spurred me on; I'll never forget him. 
And finally, a heartfelt thanks to my partner ken and my patient family--Amy, Jon, and Jeanene. We did this together. Tharks. 


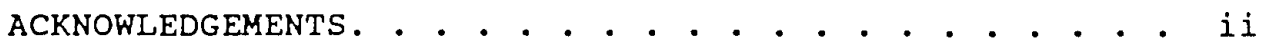

LIST OF TABLES. . . . . . . . . . . . . . . . . . . ix

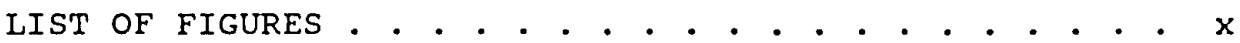

CHAPTER

I INTRODUCTION • . . . . . . . . . . . 1

America's Shortage of Minority

Teachers: Framing the Problem . . . 1

Current Demographic Trends in Teacher Preparation. . . . . . . . . . 3

Research Questions . . . . . . 8

Importance of the study. . . . . . . 9

Historical Background: Mixed Messages. . 11

Contemporary Context of the study. . . 18

Definition of Terms. . . . . . . . 23

Approach to the study. . . . . . . 25

Introduction . . . . . . . . . . 29

Discussing the Need for Teachers of color. . . . . . . . . . . . 34

Models of Retention and Attrition. . . 37

Institutional Responses: Recruitment and Retention Programs . . . . . . . 42

Environments of Support 
Barriers and contributors to

Persistence. . . . . . . . . . 44

Considering Perspectives from the

Margin... . . . . . . . . . 49

Feminist and Ethnic Perspectives

Exploring the Effects of Embedded

Racism. . . . . . . . . . 59

Summary: What Is Known and what Is

Not. . . . . . . . . . . . 62

II METHODOLOGY. . . . . . . . . . . . 65

Introduction . . . . . . . . . 65

Purpose of the study and Basic

Assumptions. . . . . . . . . . . . 66

Theoretical Framework. . . . . . . 70

Locating Myself as Researcher. • • . . 77

Research Design. . . . . . . . . 80

Research Questions

Subject Recruitment

Survey Intent, Construction, and Review

Survey Distribution

Survey Response and Interpretation Results

Development of Interview Instrument

Selection of Interview Participants conducting the Interviews

Collection of Additional Empirical Materials

Data Analysis. . . . . . . . . . 107

Limitations. . . . . . . . . . 108

DATA ANALYSIS. . . . . . . . . . . . . 114

Introducing the cast: The Characters

Present Themselves . . . . . . . 116

Joe

Ada

Sam 


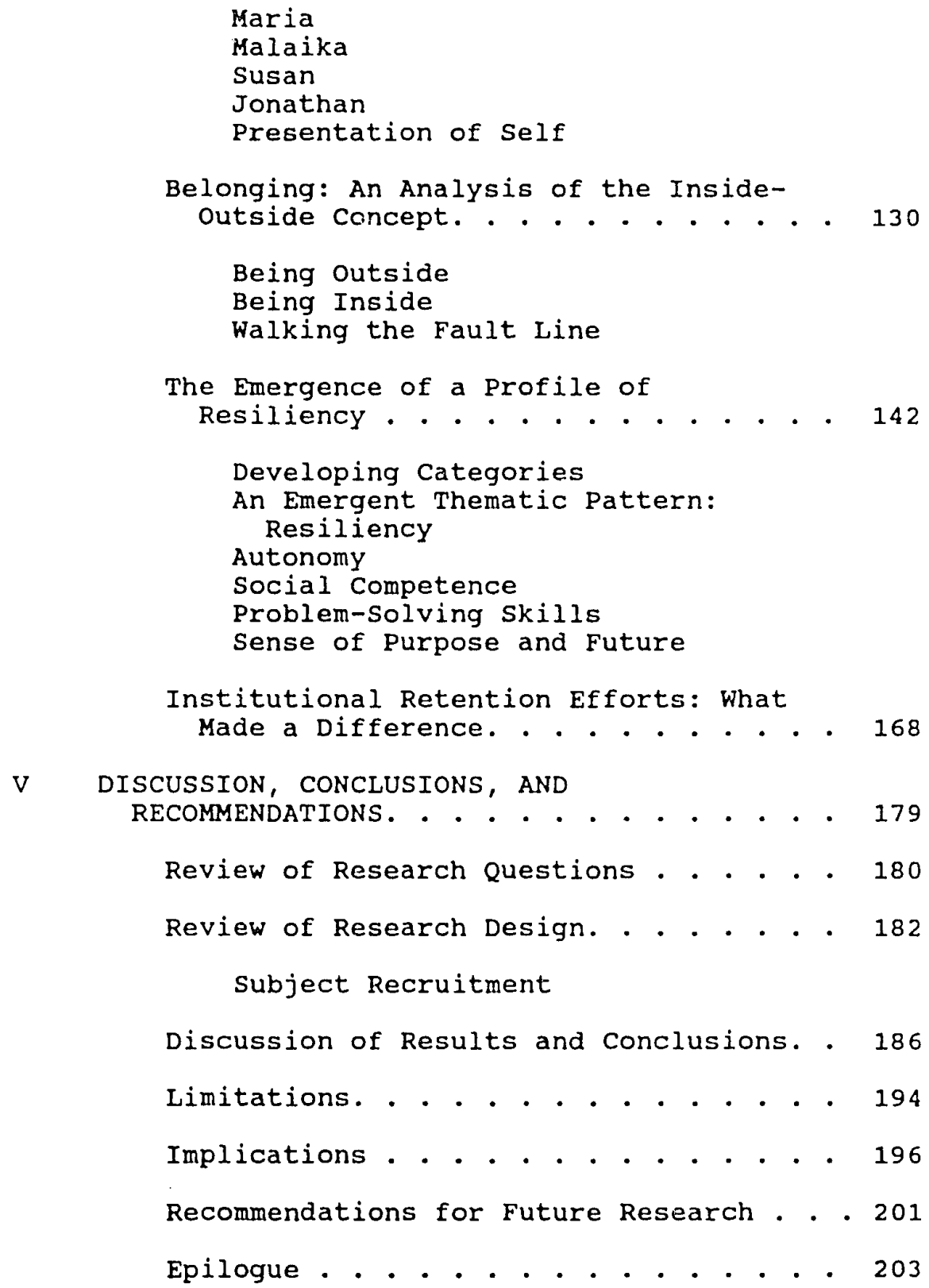


viii

B CORRESPONDENCE ............. 216

C SURVEY . . . . . . . . . . . 221

D INTERVIEW QUESTIONS. . . . . . . . . 225 
LIST OF TABLES

TABLE

PAGE

1. Total Master's Degrees for Education, 1981 and 1990.. . . . . . . . . . 63

2. Master's Degrees for Education by Minorities 1981 and 1990... . . . . . 63

3. Distinctly Different Self-Identification of Respondents' Race and Ethnicity . • . 93 


\section{LIST OF FIGURES}

FIGURE

PAGE

1. Race and Ethnicity of U.S. K-12 Teachers, 1990 . . . . . . . . . . . . . 4

2. Comparison of Predicted Changes in Numbers of $\mathrm{k}-12$ Minority Teachers and Minority Students Under Age 17 as Percentages of Total Teacher and student Populations. . . 5

3. Interviewees' Self-Reports of Location on Inside-Outside Diagram. . . . . . . 133

4. Jonathan's inside-outside diagram. . . . . 140 
CHAPTER I

INTRODUCTION

\section{America's Shortage of Minority Teachers: \\ Framing the Problem}

Melting pot. Salad bowl. Stir fry. Mosaic. The race relations metaphors change, but the underlying demographic reality persists: The United States is a culturally pluralistic society. The specific make up of the population of the United States varies in response to socio-economic and geo-political factors which alter the relative proportions of racial and ethnic groups, yet the fundamental diversity of the U.S. population remains one of its primary characteristics. In the face of such variation of heritage among its people, many Americans adhere to a belief in the ethos of an over-arching and inclusive American culture which binds the country together, whereas others argue that such cultural glue no longer suffices or even exists, if indeed it ever did. As the complexity of American demographic change intensifies, so does debate regarding the true cultural ethos of the United States (Hirsch, 1987; Ravitch, 1990; Simonson \& Walker, 1988). What constitutes American culture? Is there a singular American culture? What are its essential elements? Who are its legitimate 
members? How should that culture be passed on? And, who can or should best convey that culture to America's children?

Since public school teachers serve as primary agents in the transfer of cultural norms and beliefs, these fundamental questions about contemporary American culture surround the issue of the preparation of American minority teachers. At times the questions sharply frame the subject; at other times they fog it, playing tricks with one's eyes as issues move in and out of focus. On its surface, the need to prepare and employ a greater number of minority teachers can seem to be a straightforward, easily adjusted function of shifting demographics: as proportions within the population shift, so should the need for and realization of higher percentages of minority teachers. This functionalist hypothesis presupposes that with individual efforts by minorities to access to higher education and professional training, a sufficient number of minority teachers should become prepared and enter the teaching ranks. The addition of recruitment and retention programs targeted for minorities should ensure the achievement of demographically proportional adjustments. Yet, after decades of such programs, the relative proportion of newly prepared minority teachers is in fact decreasing (Carter \& Wilson, 1992; McGuire, 1991). 
Espousing a desire for more well-prepared minority teachers is an accepted and valued position to hold in many arenas. Media sources frequently mention the need for minority teachers. Mission statements of many school districts and higher education institutions speak to comitments to diversity. Nevertheless, assuming that this is a widely accepted problem demanding resolution may be naive. One can question: Is a lack of minority teachers a problem? For whom? Why should the number of minority teachers be increased? Who will benefit? Who will be limited? What might those benefits or limitations be?

\section{Current Demographic Trends in} Teacher Preparation

The United States Office of Minorities in Higher Education reports the number of students of color entering the teaching field declined steadily during the seventies and eighties and began only a minor upturn since 1989 (Carter \& Wilson, 1992). As of 1990, almost 9 of every 10 teachers were White, Blacks constituted 8.6 \& of the teaching force, and Hispanics formed 1.8 of those $\mathrm{K}-12$ teachers. Numbers of Asian-American and American Indian teachers were too few to mention by percentage. Concurrently, minority enrollment (i.e., where minority signifies the sum of the marked categories of AfricanAmerican, Asian-American, Hispanic, and Native American typically used by the U.S. government) in public schools 
measured 21.7 \& and growing (U.S. Department of Education, $1992)$

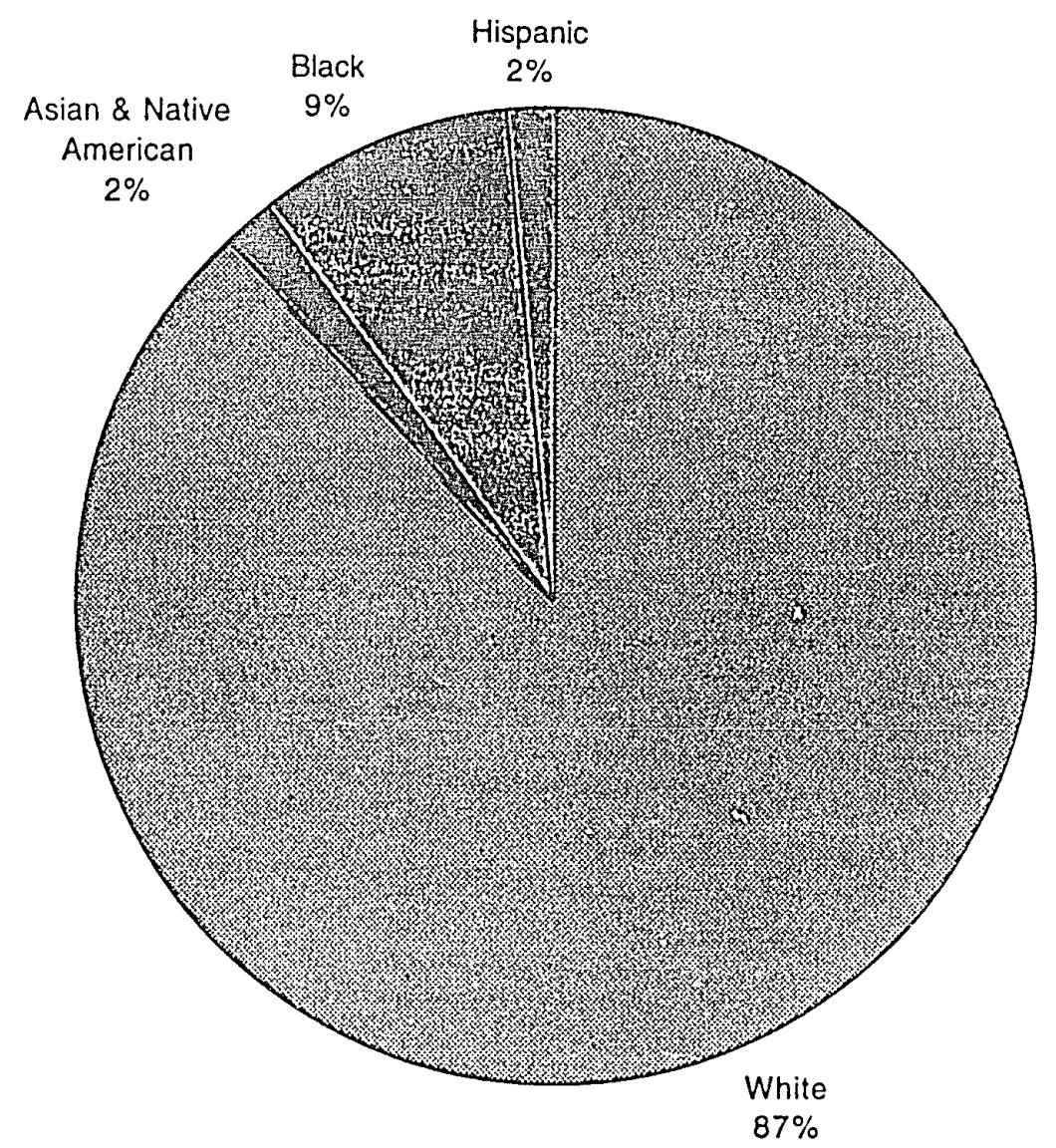

Flgure 1: Race and ethnicity of U.S. K-12 teachers, 1990.

U.S. Department of Education (1992b) statistics confirm that the U.S. witnessed a 35.78 drop in the number of minorities receiving bachelor's degrees in education between 1981 and 1990. Detailed Department of Education results indicate that 13,633 minorities received education degrees 
in 1981; that number fell to 8,771 by 1990. These Department of Education reports predict increases in minority populations and also anticlpate concurrent declines in the higher education achievement of those minority populations. If the sorecasts bear out, then the percentage of all teachers of color will shrink from 12 to less than 5 by the year 2000 .

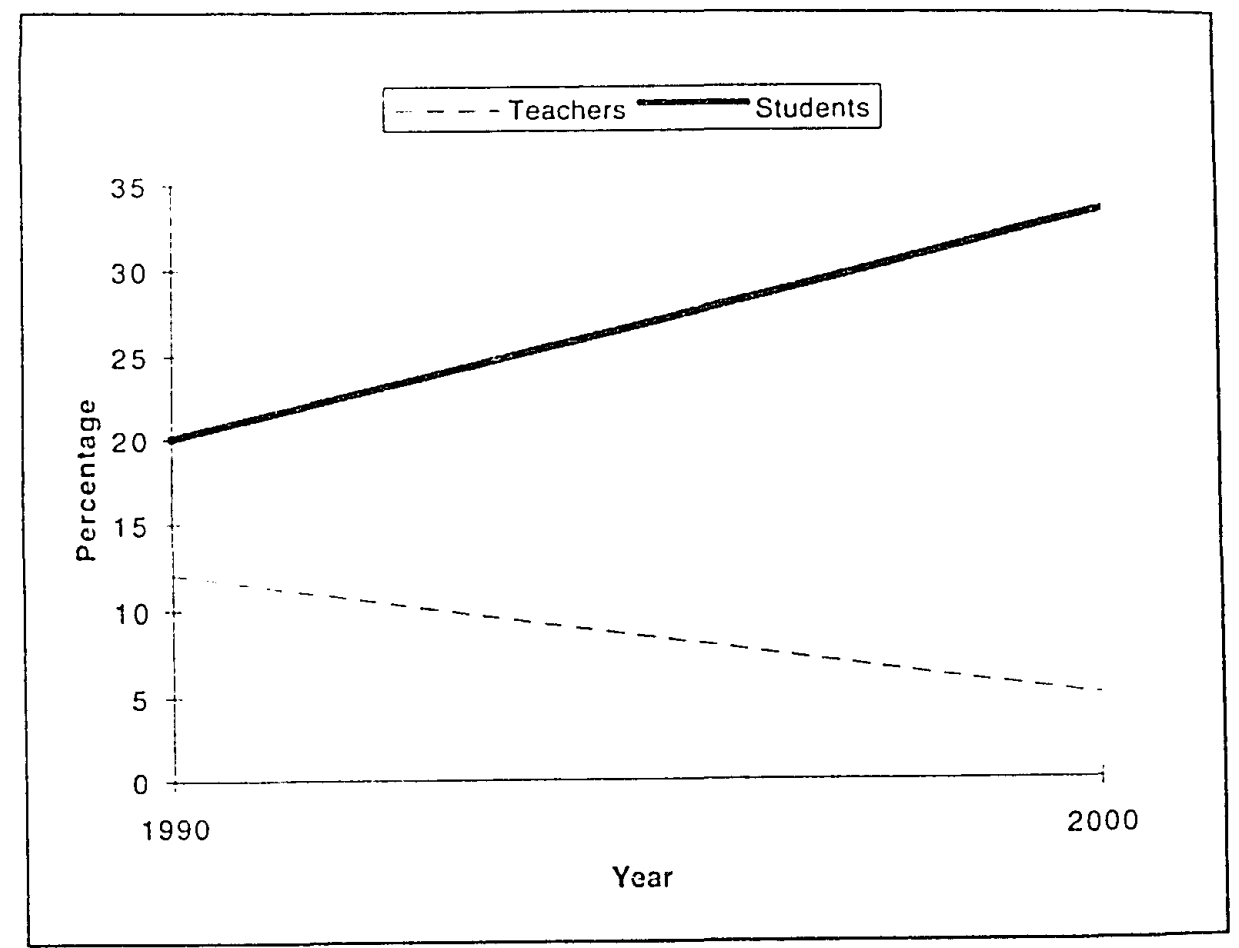

Figure 2. Comparison of predicted changes in numbers of K-12 minority teachers and minority students under age 17 as percentages of total teach:i and student populations.

According to the American Council on Education/ Education Commission of the states (ACE/ECS) (1988), over 
148 of all U.S. adults-and $20 \%$ of children under 17--are Hispanic, American Indian, African-American, and AsianAmerican. By the year 2000, one third of all school-age children will be children of color. Between 1985 and 2000, workers of color will make up one third of the net additions to the U.S. labor force. The Hudson Institute reports consistent estimates predicting that 21.8 million of the 140.4 million people in the labor force will be non-white (Johnston, 1987). Given these trends, economists and policymakers recommend concerted efforts to integrate workers of color into the economy and to improve the educational preparation of all workers in order to meet the higher skill demands of a more sophisticated, technological, service-based economic system (The Secretary's Commission on Achieving Necessary Skilis [SCANS], 1990).

Despite individual efforts via recruitment and retention programs at many colleges and universities, students of color are not enrolling or graduating in numbers representative of current demographic figures. Relatively small, isolated successes are not turning the national tide. Unfortunately, equity in postsecondary educational opportunity continues to be more a goal than a reality. students of color remain under-represented in American higher education based on their share of state populations. Despite some headway in areas of recruitment of students of color, retention figures remain low, 
particularly at predominantly white institutions.

Considerable research cites numbers for documentation:

students of color categorized by race and ethnicity who are recruited to programs, students of color who complete programs, grade point average (GPA) entering, GPA leaving, family income, age, etc. These quantifiable data confirm the current output of the teacher preparation system: The shortage of teachers of color is abundantly documented (ACE/ECS, 1988; Carnegie Forum on Education and the Economy, 1986; King, 1993).

The reasons behind the shortage are less understood. Studies of retention programs list institutional remedies whereby the institution is the actor and the student of color is the direct object, or receiver, of the action (American Council on Education/Office of Minorities in Higher Education [ACE/OMHE], 1992; Garibaldi, 1989; Martinez, Durham, Philbrick, \& Melenez, 1992; Noel-Levitz Centers, Inc., 1992). Additional research investigates the characteristics of students of color, particularly of those who choose to leave a program, and other studies cite socioeconomic and cultural factors which inhibit the success or explain the failure of students of color (Attinasi, 1989; Cibik \& Chambers, 1991; Kinnick \& Ricks, 1992). 
Research Questions

The primary purpose of this research is to gain a fuller understanding of the experiences of graduate students of color who complete teacher certification programs at predominantly white institutions. Specifically, efforts are made to learn how these more successful students interpret their experiences, which events they perceive as enhancing their successes and which ones they know interfere.

Minorities who have succeeded in their graduate studies at predominantly white institutions may possess characteristics and enjoy circumstances which allowed them to achieve their goals where others have failed. Thus far, most data collected have focused on the deficits of those who have not been recruited or retained in a program; a dearth of knowledge exists about their positive correlate-those who have completed programs of study. More qualitative data need to be gathered from the players who hold the keys to understanding their successes.

The broad research questions guiding my study are:

1. What are the experiences of students of color at predominantly white graduate schools of education?

2. What do these students of color perceive to have been contributors or hindrances, to their academic persistence and subsequent program completion? 
3. What, if any, commonalities of experience or interpretation of experience exist among the students of color?

Importance of the study

This research explores the current/decrease in the proportion of teachers of color in the public school teaching force, despite continuing rhetoric that strongly encourages their recruitment and preparation and some practical efforts to increase their number. I believe U.S. society does need teachers of color in proportion to the changing national demographics, and that teacher preparation programs need to recruit, retain, graduate, and place more minorities in the public schools. I also believe that leaders within the dominant culture do not fully understand why such goals, when they are set, have not yet been realized. By affording a clearer view of the experiences of a minority who is negotiating an institution normed by the majority, I hope that my study will add realistic insights and new information to guide decision makers toward a more expeditious achievement of a diverse teaching force.

At this point in time, people of color stand increasingly under-represented in the teaching profession; students of color continue to be under-represented in teacher certification programs. The scope of this problem is national. Given the contradictions between stated 
intentions to increase the number of American teachers of color and demographic and statistical evidence of widening disparities, the question "Why?" is raised by policy makers and minority parents alike:

- Why is the proportion of teachers of color relative to the number of European-American teachers decreasing in the face of general demographic trends to the contrary? - Why do proportionally fewer students of color than European-American students complete teacher preparation programs?

- Why can't my child have just one teacher who looks like she does?

Although many aspects of minority student failure are documented and explained, knowledge about the positive correlate, what works, is lacking. Information of depth and specificity is sparse with regard to those students of color who do complete programs at predominantly white institutions. By examining the perspectives of successful students of color who do complete teacher preparation programs, quantitative research on retention can be augmented with lived examples of that which has contributed to successful program completion according to experts--the minority students themselves. This information needs to be obtained. Without it, the picture is incomplete. These minority students who have persisted at predominantly white institutions and completed their academic programs are the 
ones who know why they have succeeded, what it has taken, and what they have done. Their voices, often silent or ignored, add an essential piece to the dialogue about this problem.

\section{Historical Background: \\ Mixed Messages}

By scanning the legal history of the United States, guideposts which legitimize membership in the society can be found. Such markers include significant imperatives for educational equity (Terrell \& Wright, 1988). Framers of the U.S. Constitution and Bill of Rights strived to establish and preserve principles of democratic equality while at the same time legalizing the institutional exclusion of Indians, slaves, and women. This conundrum of seeming contradiction threads its way throughout American history as the democratic value of individualism, which honors the right of each citizen to equal opportunity, abrades the democratic right of inclusion which values the equitable welcoming of groups under the aegis of the U.S. government.

Examples abound throughout American history where leaders have made the assumption that legislated equality of opportunity would produce equitable outcomes. Abraham Lincoln upheld equal rights for slaves in the Emancipation Proclamation of 1863 . Over 100 years later, the voting Rights Act of 1965 was intended to ensure the right to vote 
for all citizens and particularly strengthen protection for black voter registration.

The Brown $v$. Board of Education of Topeka (1954) decision denied the legitimacy of the "separate but equal" doctrine when it reversed plessy v. Ferquson (1896) and ordered the states to desegregate schools with "all deliberate speed." The Civil Rights Act of 1964 prohibited segregation or denial of access to public and tax-exempt institutions on the basis of race, creed, or national origin. By empowering the Department of Education to withhold federal funds from educational institutions that fail to comply with antidiscrimination laws, the civil Rights Act of 1964 was used to encourage the integration of previously all-white colleges (Terrell \& Wright, 1988). With the advent of the Higher Education Act of 1965, significant federal financial support became available to students of color and low-income students. Those monies alleviated a major stumbling block to the integration advocated by the Civil Rights Act of 1964 .

The Adams V. Richardson (1973) Supreme Court decision reconfirmed the Brown (1954) decision as it applies to higher education, namely that states cannot operate dual systems for whites and people of color. The supreme court decision in Regents of the University of California $v$. Bakke (1978) upheld race and ethnicity as factors appropriate in 
admissions decisions although it struck down the use of quotas.

These aforementioned legal landmarks, when taken together, paint an overly rosy and incomplete picture of American efforts to ensure and practice policies which deliver equal rights and opportunities for all citizens. The spaces in between these landmarks are pocked with incidents and policies which serve to protect the privileged, white, middle and upper middle classes. The dilemma is basic: American institutions grant legal rights to individuals, but political power comes through group membership. In the public arena, rights are protected; in one's private life, fair treatment and respect are dependent on the voluntary actions of those who make up the members of one's socio-cultural milieu.

A legal imperative to establish equal access and opportunity for education does exist in the United states. The evolution of that imperative with its concomitant incongruities can be traced from the U.S. founders' efforts to ensure equality--despite the fact that such equality was reserved for all landed, white men. The Constitution's inclusive language established the democratic ideals for our society, but its fine print legitimized the practice of excluding from democratic participation, or even rendering invisible, some segments of the population, e.g., women and people of color. The legal milestones cited previously 
represent legal efforts to extend democratic membership and its inherent rights and opportunities to a broader crosssection of the U.S. population. However, these legal protections presuppose a class-less society in which anyone can realize political or economic success by making the most of the equal opportunities provided and insured.

Although U.S. laws seem to be moving toward a legislated inclusivity, the attendant moral values and attitudes which could breathe life into those laws appear to be following a more complex and contradictory path. If the maintenance of the status quo within U.S. society is predicated on the tension between the ideals of equity and practices of exclusion, then uncovering and solving apparently simple problems of inequity will, be difficult indeed. Myths of equality and myths of a class-less society can hamper realistic identification and resolution of problems of incongruence between rhetoric and practice. To what extent is the egalitarian aspect of U.S. democratic institutions a myth? Might the embedded privilege and legitimized political power of white males, which were deemed normal in the late eighteenth century, still be factors today? To what extent can democratic rhetoric be congruent with real life events?

Throughout U.S. history contradictory forces spawn a cognitive dissonance: the legal imperative to extend an equal opportunity for individual success to members of all 
groups is countered by the political or attitudinal roadblocks which interfere with the receipt of equal opportunity. The result of such dissonance is unequal outcomes such as those indicated by the under-representation of some groups in what had been thought to be legally guaranteed capacities. A look at the changing roles of women in twentieth century American society furnishes many anecdotal examples of the confusion this dissonance causes (Rose, 1993; Valli, 1983). Despite the knowledge that women could vote and behave as equal citizens, school children of earlier decades accepted as normal that girls should be helpmates (nurses, secretaries, etc.) and boys could be leaders (doctors, lawyers, senators, etc.). Sometimes the inequities and discrepancies between rhetoric and real life are so embedded that they go unrecognized until a startling perspective is highlighted. Quindlen's (1993) New York Times essay described the enlightenment engendered by a reversed perspective:

Life magazine last year ran a photograph of 98 women and two men on the steps of the capitol to make concrete the unequal composition of the Senate in a clever and vivid way.

It took some time to find the men in that photograph. They were insignificant.

- . We are talking about the sense of universal possibility that should be inherent in democracy, the sense a little girl gets now when she sees the official portrait of the supreme court and realizes that girls can be justices, too. (p. B6) 
If society fails to integrate key population groups, the representative balance derived through the legislative and electoral processes of a democracy becomes sliewed by continuing to disenfranchise minority groups and limit their socio-political influence. Power is retained by those currently favored by the status quo. Citizens too disenfranchised to perceive themselves as stakeholders in this nation or take effective political action suffer undue limitations and hardships. If a system does not include a group, then that group may naturally recognize a heightened need to fight for its self-interest; society's majority is then perceived as an adversary; democracy's promise of social justice sounds hollow.

The argument which holds that a historic democratic value is inclusion, as evidenced by the growing contemporary acceptance of American cultural pluralism (Nieto, 1992), runs counter to the longstanding American "culture of inequality" explained by Lewis (1978). In his article "Inequality and Equalitarianism: The Individualization of Success and Failure," Lewis cited the institutionalized exclusion of Indians and slaves and their descendants as a paradoxical democratic tradition. When combined with the resilient "individual-as-central" notion (commonly touted in the American admiration for rugged individualism or Horatio Alger-like success stories), Lewis argued that an American 
culture of inequality is insured. He described such a culture as:

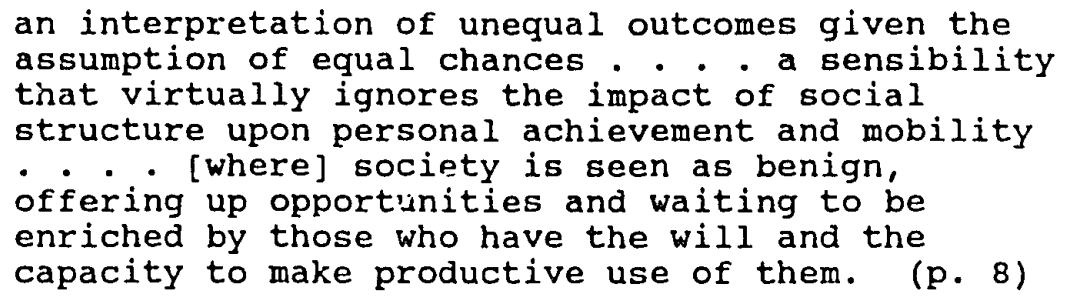


Contemporary context of the study

On its surface, the phenomenon of the relative scarcity of teachers of color seems simple to rectify--and it appears prudent to do so. Realization of a diverse teaching force appears consistent with widely accepted tenets of democracy; maintaining, either covertly or overtly, a predominantly white teaching force appears contrary to established egalitarian principles. Then again, those who maintain that democracy is color-blind see no need to diversify the teaching force along racial and ethnic lines because they suppose that an equitable American teacher can teach all American children equally well and provide those children with the equal opportunity each needs to succeed. Nevertheless, adherents to both viewpoints agree that unintentional de facto exclusion of minority teachers would be embarrassingly questionable if discovered, and intentional exclusion would be at odds with the U.S. Constitution and federal laws.

The desirability of a diverse, competent teaching force, which is empowered to socialize and educate America's young people, stands in keeping with espoused tenets of democratic inclusion and is advocated by many educators (King, 1991; King, 1993; Ladson-Billings, 1994). Teathing is a position of leadership and influence. School experiences socialize all children, allowing them to integrate into the culture and participate in the workforce. 
What happens to those children is far more powerful than what they are told. When children of any color learn from almost exclusively white middle class teachers and administrators, they understand unmistakably and implicitly who is capable and who is not, who is worthy of authority and who must defer, who is inside and who is outside. I believe this research study adds insights and information that strengthen the likelihood that efforts to diversify the American teaching force will succeed. Such efforts are critical steps toward ensuring equal opportunity for all individuals regardless of which group they are members. our cultural tendency to sort based on obvious visual cues like color, places people along a continuum from white to black. Even popular periodicals are grappling with the meaning of this color line. Newsweek (Staff, 1995) devoted an entire issue to its title: What color is Black? science, Politics, and Racial Identity, and its writers explored to what extent the term "person of color" is merely a euphemism for "black" with all of its pejorative implications (Morrison, 1993). Xes, attention to the actual numbers of people of different colors who achieve certain positions or awards affords a symbolic measure of progress relevant to issues of discrimination. However, by talking about numbers in color shade categories, are discussions avoided about underlying issues of power, privilege, or the maintenance of the status quo? Does the use of a shade of 
color as a defining characteristic mask more complex differences and divergent interests such as those of class?

Ogbu $(1978,1992)$ contended that the United States operates on the basis of an unacknowledged caste system where the relationship between minority cultures and the American mainstream culture is key. Ogbu distinguished between different types of minorities, particularly those which are voluntary (e.g., immigrants) and those who are involuntary (e.g., those forced through slavery, conquest, colonization, or forced labor to a marginal position vis-avis mainstream American culture). Ogbu believed that involuntary minorities are the ones who usually experience more difficulties with American institutions including schools. His introduction of class issues into the discussion of minority-majority relations added a much needed economic perspective to conversation of color. Dichotomous thinking reduces the naturally complex variations of life to either/or categorization: either you are white or of color, in or out. Who benefits from such simplistic sorting? In a creative writing anthology edited by an English teacher in Portland, Oregon, a Jefferson High School student gives us a glimpse of this oversimplification through her own lens. She speaks eloquently when she spurns the black/white sorting and its implications in her poem. 
"Nothing Is So Simple"

by Deanna Wesson

"What do you mean?"

"Are you mixed?"

"With what?"

"Black and White?"

"Is anything that simple?"

"Well, I don't know."

"I'll tell you, nothing is."

"So what are you?"

"An American."

"You know what I mean."

"Yes, yes, I do."

"So, what are you?"

"Do you really want to know what I am?"

"Yes, what are you?"

"I am a young American woman,

with high expectations of herself

and the people around her,

a Jefferson High School student,

the youngest in a family of four,

the tallest in my family,

a christian,

a teenager with a messy room,

a member of the National Honor Society,

a fourth year television student.

oh yes,

I am German, West African,

French, Swiss, and Choctaw Indian.

When you ask me, 'What are you?'

You are asking a lot.

Nothing is just black and white.

Nothing is so simple."

(cited in Christensen, 1992, p. 4)

Some people perceive no inherent problems if members of

the dominant culture continue to teach or lead in numbers

disproportionately higher than their percentage of the

population. However, others argue that children intuitively

assume an affinity for "their own kind" and will be more

likely to achieve if a mentor or exemplar like themselves

can guide the way. According to people with the latter 
point of view, a diverse society critically needs diverse role models in positions of cultural authority (King, 1993). Donald Sands, the University of Kentucky's vice Chancellor for Academic Affairs, finds links between democratic principles and teachers who are representative of the general populace. With a comment indicative of many current policymakers, he succinctly states the need for more American teachers of color:

As Americans, we live in a heterogeneous society. That, I think, is the special strength of our country. This nation cannot prosper and may not survive, however, unless all groups, races, and cultures participate in its most important work-the education of its youth. Black children need black teachers and white teachers. And so do white children. Teachers are the role models, the patterns of success, the images of respect. They are also the bridge to cultural understanding, which is so vital to whether or not such a diverse society as ours can endure. (Sands cited in Middleton \& Mason, 1988, p. vii)

Sands suggested that when people of color teach, benefits extend to all children, not just minority children.

Excerpts from the following essay by Quindlen (1993), printed in the New York Times shortly after clinton's inauguration, reflect on this issue and give it merit:

The children watching the inauguration being replayed on tape grew silent as Maya Angelou began to recite her poem. Then midway through they began to cheer, not for her words, but for themselves, as though she were calling the roll: So say the Asian, the Hispanic, the Jew, The African, the Native American, the sioux, ...

They each cheered the group to which they belonged in the poet's litany. There was even one faint little "yea" after the words "the homeless." one girl stood up in the Brooklyn classroom and 
read her own poem as though there were a hundred thousand watching her. And the teacher felt it was no accident that, like Angelou, the girl was black . .

"If there's nobody who looks like you, you have the sense that you can't do it." . . " "If there's somebody who's something like you, it seems possible," [a student said] . . .

(Thurgood) Marshall told columnist Carl Rowan several years ago that segregation still existed in America. "Clubs here in this (Washington, DC) town," he said, "they invite everybody else but me." Maybe that's how that little girl felt, until she saw Maya Angelou--everybody else but me. "Lift up your eyes upon this day breaking for you," the poem said. Welcome to the club. ( $p$. B6)

Which "clubs" of education should offer truly open access to all? Why? Which ones do? Is this a zero-sum game where if one group wins, another automatically loses? Is it time to delve beneath the surface of democratic platitudes to determine the complexities of this issue?

\section{Definition of Terms}

Particular terms are defined below that have specific meanings commonly understood in the education literature

that are distinct from their everyday connotations.

Attrition: withdrawal from a college or university program prior to completion for reasons other than administrative sanctions.

Graduate Student: A student who previously has completed an undergraduate program and earned a Bachelor's degree and who is subsequently enrolied in a formal course 
of graduate study. The profile of such a student is usually more akin to that of a nontraditional college student than that of a traditional one.

Minorjty: Used frequently in the literature to refer to non-white, non-Euro-American populations in the United states, the term may refer to people who are Black or African-American, Hispanic or Latino, American Indian or Native American, Asian-American, or other people of color. All of these populations are under-represented in the teaching profession.

Nontraditional college Student: A student primarily interested in an institution's academic offerings and significantly less involved in the social environment. May be older than typical undergraduate college students (over 24), live off campus, and/or attend school part-time (Metzner \& Bean, 1987).

Persistence: Successful continuation in, and completion of, an academic program. Usually used in reference to student actions or attitudes.

Privilege: Unearned and often invisible advantage conferred upon a person due to one's social status or group membership, i.e., who one is rather than what one has done. Receipt of privilege confers a measure of dominance and can afford additional choices, opportunities, and control over one's life (Bohmer \& Briggs, 1991; Gosetti \& Rusch, 1993; McIntosh, 1988). 
Retention: Continuous enrollment culminating in program completion. Usually used in reference to institutional goals or efforts.

Students/Teachers/People of color: Used to refer collectively to individuals who identify themselves or are identified as members of racial or ethnic groups other than white or Euro-American, e.g., Black or African-American, Asian-American, American Indian or Native American, Hispanic or Latino, and/or mixed.

Traditional college student: Students who are under age 25 , enrolled full-time, and residing at their college (Metzner \& Bean, 1987).

\section{Approach to the study}

For over 30 years, political and educational leaders have espoused the need for more minority teachers, and many have sought to understand and address our unsuccessful attainment of such a goal. Unfortunately, our collective lack of success in this regard is well documented: A great deal is already known about what does not work. Nevertheless, settling for well-intentioned expressions of frustration and unintended retreats to blame like this comment by a colleague, "I don't know what we can do. Our hands are tied. Our minorities just don't seem to make it; something always seems to happen," is no more acceptable 
than it ever was. We need to keep investigating this phenomenon in order to act effectively to rectify it. This research examines the under-representation of minority teachers by applying a critical analysis and feminist and ethnic perspectives to an investigation of successful minorities who complete teacher preparation programs at predominantly white institutions. Critical theory aids in the identification and potential redirection of the forces which systematically act to reproduce the domination of the majority (Thomas, 1993). Feminist and ethnic perspectives urge us to assume alternative standpoints, especially those of marginalized people, and to walk the high-pressured fault lines between minority and majority worlds (Collins, 1992; Smith, 1987). These nontraditional perspectives impel us to give voice' to those more typically silent or silenced.

since this study focuses on minority-majority interactions, I purposely chose to avoid an emphasis on the distinctions between different racial and ethnic groups. While I recognize the significant differences experienced and valuec by people of different racial and ethnic backgrounds, I believe that the experiences of a minority acting within the dominant culture are characterized by some commonalities which cut across racial and ethnic boundaries and which are worthy of study in and of themselves. 
Instead of supposing what might or should help a person of color succeed in a predominantly white environment, this research lets us listen to minorities' own voices describing what has actually worked for them. The real life examples provided by these educators offer insights which may assist graduate schools of education to more successfully meet their societal responsibilities to support the development of educational leaders who are also people of color. Their stories enable us to make progress in the areas of equity and diversity, and to better understand how inequities and discrimination manifest themselves in our lives and institutions.

In sum, my study gives fuller resonance to heretofore whispered, unheard, or silent voices. It examines the issues of persistence and achievement by listening to the stories of minorities as they relate their experiences at predominantly white institutions. Typically, the voices of these people are silenced or at least unheard. By listening to these minority teachers, I want to add dimension to established understandings of the phenomenon of underrepresentation and accepted theories explaining student persistence. I do not believe it is acceptable to appear to know more about these people's lives and motivations than they do themselves. I believe we have much to learn from their stories and their insights. By listening to each minority as the unique individual he or she is, rather than 
only as a representative of a racial or ethnic category, I hope my study gives pause to re-think the familiar and raise more questions than it answers while also offering guidance for the actions we need to take to remedy this situation. 
CHAPTER II

REVIEW OF RELATED LITERATURE

Introduction

Delineating the boundaries of relevant literature on the topics of the need or not for more minority teachers and the explanation of the persistence of graduate minority teacher education students proved surprisingly complicated: The subjective answers to the questions of relevancy are open to debate depending on one's political philosophy, perspective, proximity to the minority graduate students, degree of exposure to today's school children, and sense of personal responsibility for action fostering more equitable numbers of minority teachers. In fact, the phenomenon evidenced by the low numbers of minority teachers and the assumptions which are used to explain it strongly influence the way this problem is viewed, whose problem it is, and even if it is deemed a problem at all.

The downward trend in numbers of minority teachers coupled with the rising diversity of both school age children and the entering workforce alarms policy makers and business leaders (Johnston, 1987). Basically, the numbers and their unknown ramifications raise concerns. Yet, the perceived urgency of those concerns seems to vary with one's 
proximity to children of color. Government publications name the problem demographically and stress the need to address it. An unscientific scanning of authors' race or ethnicity suggests that it is primarily educators and researchers of color (although by no means only they) who describe this problem, name the pros and cons of diversifying the teaching pool, and advocate the incorporation of multicultural curriculum. Community leaders of diverse populations, especially in urban areas, stridently call for immediate action. Many parents of color express their desire for comfortable access to schools and diverse role models for their children. The degree to which members of the dominant culture own this as their common problem or perceive its resolution as in their self-interest is difficult to assess. Some questions remain open: If these trends hold, who will be affected and what will the impact be? For whom is this truly a problem?

Particularly challenging to grasp is the embedded nature of discrimination and its unacknowledged presence in our language, culture, and institutions. It can be experienced and felt, yet due to its embeddedness its point of origin is next to impossible to identify and whether or not it stems from purposeful intent remains open to question. King (1991) referred to this embeddedness as:

dysconscious racism [which] tacitly accepts dominant white norms and privileges [and is] not the absence [italics added] of consciousness (that is, not unconsciousness) but an impaired [italics 
added] consciousness or distorted way of thinking about race. (p. 135)

If dysconscious racism is not deliberately intentional, then the frequently offered excuse for embedded racism which argues that a lack of intent mitigates its existence becomes irrelevant. Regardless of intent, results indicate adequate numbers of minorities do not complete programs at predominantly white institutions. Why does this outcome persist? Could it be racism? If so, what might that racism look like or sound like to a person of color? Does the person of color who does persist label any institutional or socio-cultural obstacles or supports as indicative of racism or of unearned privilege? Or, does the person of color deem these topics irrelevant to his or her persistence and success at a predominantly white institution? These questions nagged at me as I anticipated this literature review and they continue to do so.

Given my own sense that the low number of minority teachers is problematic for American society today, I focused this literature review on information sources which were likely to add to our ability to contextualize this phenomenon, to guide our efforts to fully understand it, and possibly to learn new skills and attitudes in order to ameliorate it.

In this chapter I divide the literature about this phenomenon into several broad categories. First, I attend to discussions of the need or not for more teachers of 
color. Here the references to recent government publications citing demographic changes confirm the national context of this situation. Next I explain models of retention and attrition which are generally respected in higher education circles. The institutional responses in the form of recruitment and retention programs logically follow. Since these programs have been less successful than institutional leaders had hoped, I sought to broaden the understanding of the topic by introducing recent studies which look more deeply into the barriers and contributors to persistence. It is in this section that a marked shift occurs from a focus on quantitative analyses of relatively easily obtainable numerical data (e.g., grade point average, financial aid, etc.) to more recent qualitative studies. These studies reflect epistemologies that favor nontraditional standpoints, and they form a natural springboard to the next two sections: considering perspectives from the margins and exploring the effects of embedded racism. The ethnic and feminist theorists mentioned in these sections offer new ways to understand a phenomenon, ways which stem from the assumption of alternative standpoints and allow us to study, from other perspectives, the everyday realities that serve to preserve the status quo. I conclude this literature review by summing up what is known and what is not known about the low 
number of minority teachers and our inabilities up until now to substantially affect those numbers.

Much of the literature surveyed in this review places the boundaries of the persistence problem at the walls of the college or university and examines the progress of the minority student once access to that institution has been achieved. The literature specifically related to students' higher education experiences reveals little or no attention to the perspectives of the students themselves or their own analyses of their experiences as minorities in predominantly white institutions or in a predominantly white culture-atlarge. What information there is from the student perspective is also analyzed in this review.

Since the research design of this study is to engage people of color in meaningful conversations about their educational experiences in minority situations, it seemed critical to seek to understand some of the subtler facets of minority-majority interactions. In the hope of achieving new insights into the dynamics of persistence, this literature review ventures into wider contextual territory. The map is unclear. New landmarks, including some sociocultural and political signs normally raised only in a noneducational milieu, may or may not provide pivotal direction. This literature review scans the traditional territory previously mentioned as well as the broader one suggested. By melding what is known about minority 
persistence in predominantly white educational environments with what have been considered peripheral matters (privilege, power, embedded institutional racism, and marginality), this literature review paves the way for different understandings of the phenomenon evidenced by the low number of minority teachers.

\section{Discussing the Need for} Teachers of Color

A myriad of reports (ACE/ECS, 1988; ACE/OMHE, 1992; Carnegie Forum on Education and the Economy, 1986; Carter \& Wilson, 1992) decry the diminishing numbers of teachers of color and call for urgent attention to rectify the situation. The reports' formats generally follow a pattern: demographic information is sandwiched between philosophical essays--bookends which address issues of democracy and equity by calling for changes and sometimes suggesting courses of action. At the 1993 national conferences for ATE (Association of Teacher Educators) and AACTE (American Association for Colleges of Teacher Education) similar admonitions to lead the charge to diversify the teaching force were issued.

In-depth analyses probing reasons for the lack of teachers of color occur far less frequently than the simple citing of demographic trends. One of the few researchers to extensively frame the problem, King (1993) presented a cogent discussion of the limited presence of African- 
American teachers including why and for whom AfricanAmerican teachers make a positive difference and what factors appear to foster the downward trend. King's thinking is enlightening because it moves beyond the typical, easily drawn conclusions that all children need teachers with whom they can identify.

King (1993) listed several reasons scholars recommend increasing the presence of African-American teachers: (a) the high expectation that every child can succeed is central to African-American teaching philosophy and its pedagogies have been shown to employ a variety of strategies to build community, instruct while accommodating diverse learning styles, foster socio-political action, and involve family; (b) all children benefit from representative role models; and (c) changing societal demographics and teacher supply and demand trends indicate a growing need for academically able teachers of color. King cautioned against assuming a universal African-American type of teacher or style; rather she draws from a broad research base to cite individual examples to support her premises. In an effort to explain her attention to only African-American subjects, King noted the preponderance of studies of African-American teachers as compared to a lack of study of teachers of other ethnicities or races. Although King believed many parallel experiences exist among all teachers of color, she suggested a research 
agenda should address this deficit and explore the different experiences of teachers of other ethnicities.

King (1993) also offered a discussion of factors which limit the presence of African-American teachers.' Suggesting the role of historically black colleges and universities (HBCUs) and the impact of school desegregation are of significant influence, King cited that college enrollment trends have remained relatively stable while career choices for teaching have declined in light of increased access to other professional fields. As a result of affirmative action, the civil rights movement, and state and federal legislation, more African-Americans are able to enter more prestigious or lucrative professions. King discussed Darling-Hammond's 1990 research on teacher education when she explained:

If past attractions and conditions of teaching continue, it is probable that teaching will continue to attract primarily first-generation college students from low- or moderate-income families. Yet, recently, these students have had fewer opportunities to go to college due to less available financial aid and tuition increases. (p. 139)

overall school enrollment trends including decrelasing high school completion and graduation rates form parallel patterns to college enrollment and degree trends and combine to decrease the potential African-American teaching pool. Lastly, King underscored the significant impact of teacher competency testing: lower pass rates for individuals of color mean fewer are admitted to, or complete, teacher 
preparation programs. My own experiences as a faculty

member in a graduate teacher education program align tightly with King's explanation for the low number of minority teachers; her words ring true for me.

of all of the literature I studied about this topic, I found King's (1993) writing to be the most comprehensive/and thought-provoking. Her sensitivity to the distinctive value and style of an African-American teacher is echoed by Ladson-Billings (1994) in her recent qualitative study the Dreamkeepers: Successful Teachers of African American Children. Both King and Ladson-Billings are in the forefront here. I expect that we are just beginning to see interest in the research focus chosen by these women; clearly there is much more to learn and understand in this area .

Models of Retention and Attrition

Study of the complex decision-making process affecting whether or not a student persists in a higher education academic program is guided by two major models. Both of them incorporate psychological, environmental, economic, and organizational variables and evaluate the interaction of these variables.

Tinto (1987) pioneered the examination of categorical theories contributing to persistence decisions, most recently proposing his Student Integration Model. Tinto 
identified five key constructs that are linked causally to persistence: background characteristics, initial commitments by the student toward his or her goals for program completion, academic integration, social integration, and later student commitments toward personal goals and to the institution itself. He suggested that attrition is a function of the degree to which a student is integrated into the institution, and therefore effective retention lies in the college's commitment to students and its ability to foster social and academic integration. Since Tinto's model reflects the lives of full-time traditional students, his conclusions are based upon the decisions of people immersed in collegiate life and to a certain extent insulated from demands of family and job responsibilities. Consequently, social integration plays a more significant role than it might for urban commuters or graduate students.

Another significant limitation of Tinto's (1987) model is its proposition that college-going is a societal rite of passage whereby cultural beliefs and norms are transferred. An unacknowledged assumption of such a rite of passage is that a student's full membership in common culture is present, and consequently, that goal attainment is universally rewarding. If the common culture is based exclusively upon the norms, values, and mores of middle class white society, then students of color may experience 
dissonance arising from their desire to complete the "rite of passage" without suffering a sense of alienation or distancing from their own backgrounds. Tierney (1992) went so far as to suggest that this required separation from or subsuming of one's personal or familial culture and the full embracing of the dominant culture could be harmful for racial and ethnic minorities. By devaluing one's actual cultural heritage, dissonance is created between what one is and what one appears to be. To what extent such dissonance affects self-esteem, identity, or efficacy remains open to speculation.

Rodriguez (1982), author and National Public Broadcasting essayist, wrote eloquently of the cultural dissonance caused by a minority's success in acquiring higher education. The personal price he himself paid for such mainstream academic achievement, the unanticipated alienation from his family and the culture of his youth, is well documented in his book, Hunger of Memory: The Education of Richard Rodriquez.

Perhaps not surprisingly, Rodriguez' (1982) sentiments were echoed by an Hispanic student I taught recently in a teacher education program. When asked to explain his philosophy about multicultural education, Monteblanco (1994) wrote:

As I begin to write my personal multicultural philosophy, I just can't stop thinking about a book that I recently read and the words of the author that so eloquently described his personal 
need to learn about himself and who he represents. victor Villasenor in his most recent book Rain of Gold explains it this way: "As time went by, the stories of my parent's past grew distant and less important, and as I became more and more Anglicized, I reached the point where, regrettably, I didn't want to hear about our past because I couldn't really believe in my parents' stories any more." The primary| reason for trying to define my multicultural philosophy is therefore one of personal need. I want to avoid the frustration that this Hispanic author was relating in his book. Becoming Anglicizled is a feeling that I am trying to control, (p. 1)

A second, commonly-referenced model for explaining retention and attrition is that of Metzner and Bean (1987) who altered Tinto's (1987) model to explain the attrition or decision to leave college of nontraditional students who are defined as older than 24, living off campus and/or attending part-time, and primarily interested in the college's academic offerings. Using a path model of analysis, Metzner and Bean identified four sets of variables:

1. Background and defining variables: age, hours enrolled, educational goals, high school performance, । ethnicity, and gender;

2. Academic variables: past GPA, study hours , study skills, academic advising, absenteeism, major and job certainty, and course availability;

3. Environmental variables: finances, hours of employment, outside encouragement, family responsibilities, and opportunity to transfer; and

4. Intent to leave (influenced by academic variables and psychological outcomes). 
These variables may be affected indirectly by social integration variables such as memberships, faculty contact, and school friends.

According to Metzner and Bean (1987), the complex interaction of these variables produces two categories of outcomes which influence the decision to leave:

1. Academic: Grade Point Average (GPA);

2. Psychological: utility (practical and personal value of the education), satisfaction, goal commitment, and stress.

Metzner \& Bean's research points to the psychological outcomes as keyl. Their model outlines two compensatory interaction effects assumed to impact the decision-making of the nontraditional student. One is the preeminent need for environmental support: academic support will not compensate for weak environmental support although the reverse is true. The second effect shows the complicated interplay of academic success confirmed through GPA and psychological outcomes. If the student perceives a high personal payoff by attending or completing school, s/he will continue to attend despite low grades, but if stress is too high or practical educational value too distant, s/he is apt to withdraw despite high grades.

Both Tinto (1987) and Bean and Metzner (1987) studied within the context of undergraduate institutions. Graduate students, especially those pursuing a professional degree 
like education, may or may not fit the models. In general, they are more apt to resemble nontraditional students, but their environmental variables and psychological outcomes may differ and should be explored to obtain an accurate picture of those forces influencing a student's decision to complete or withdraw from an academic program.

Another slant worth considering is the focus of the retention models. The research gives significantly more attention to the decision to leave college; detailed examination of the evolution of the decision to persist would illuminate to what extent it is a function of the student's resilience and/or to what extent it is a function of supporting academic and environmental variables.

\section{Institutional Responses: Recruitment} and Retention Programs

When investigating this topic, I read literally hundreds of ERIC (Educational Resources Information Center) references describing institutional efforts to design and implement programs which have succeeded in recruiting and retaining minority students in higher education. While some common themes and findings will be outlined here, a perhaps more significant conclusion begs to be aired: Despite intensive commitments and individual successes, the numbers of recruited and retained students of color in predominantly white institutions continue to be low and to be decreasing at an alarming rate. Examples of model programs with 
documented results do exist. Nevertheless, the problem of minority under-representation continues to persist more than the students of color themselves. One can question whether the underlying causes of the under-representation have yet been identified or properly addressed.

\section{Environments of support}

A comprehensive survey by the American Council on Education's office of Minorities in Higher Education (1992) described nationally recognized efforts yielding positive results in the preparation of under-represented groups for the doctorate. Titled "Environments of support," the document lists the common components of such environments (pp. $2-3)$ :

- Aggressive and targeted recruitment efforts that incorporate personalized outreach;

- Substantial, multi-year fellowships and assistantships that allow graduate students to focus on their academic studies;

- A locus of academic and social support services: a special office of minority graduate programs associated with or part of the graduate dean's office, and a minority leader of stature (ideally an associate dean or professor) to lead the recruitment and environmental support efforts;

- An atmosphere of /expected success;

- Department culture that encourages and supports mentoring by faculty; 
- support groups that allow minority students to share life experiences and academic work, as well as other activities;

- Curricula that encompass the new scholarship on ethnic, racial, cultural, and gender dimensions; and - A "critical mass" of minority students and minority faculty within individual departments. These factors align with the elements cited in many other publications (Garibaldi, 1989; Martinez et al., 1992; NoelLevitz Centers, Inc., 1992). With minor variation, the consistency is remarkable. Unfortunately, knowing what to do to increase persistence does not yet translate into doing it.

\section{Barriers and contributors to Persistence}

Mestas (1990) drew from his practical experience directing college retention programs and ruefully cited the gap between rhetoric about minority under-representation and everyday specifics to rectify it. He noted "a nagging paradox: we know so much, but we know so little" (p. 1). Mestas challenges higher education to: precisely define the problem; ensure that incentives are not at cross purposes with goals; and accept that retention efforts must be intrinsic to the academic function of the institution in order to succeed. 
When Mestas (1990) spoke of problem definition, he touched upon an issue raised by other researchers (Attinasi, 1989 ; Cibik \& Chambers, 1991; King, 1993; Love, 1993) which may be providing a skewed view of this issue. The underrepresentation of people of color in higher education is a problem defined and discussed in terms of race. Since race is the organizing feature around which the problem is studied, other possible determinants like socio-economic status or family education can be minimized or ignored. Even the collection of demographic data is coded for ease of analysis rather than accuracy of real life ancestry. What box should a person mark if his mother is from Mexico and his father is African-American? Are Chicano, Latino, Hispanic, and Mexican-American interchangeable? What if one's father is Euro-American and mother is Native American? Which parent's heritage counts more? And which provides more valid data to use when analyzing problems of retention? Categorizing by race and assuming color to be a primary determinant of persistence may blind the researcher to other compelling data by feeding stereotypes and self-fulfilling prophecies. To maintain an appreciation for and curiosity about the unique characteristics of an ethnic group and yet remain sensitive to the likelihood of superficial and stereotypic categorization by color is to achieve a delicate balance of perspective. 
Cibik and Chambers (1991), King (1993), and Love (1993) all found persistence factors to match to a large degree the features of an environment of support noted by ACE/OMHE (1992): If present, they contribute; if absent, barriers arise. King delved into the impact of teacher competency testing and asserted that it serves to decrease higher education admission to and graduation from teacher education programs. Citing figures from the Education Testing Service, the National Teacher Examinations, and the National Center for Educational Statistics, King questioned the widely different passing rates for Euro-Americans and people of color and suggested the possibility that the tests may discriminate unfairly and/or deter candidates from considering the teaching profession at all. Love contrasted the experiences of Black students at historically Black institutions (HBIs) with those of Black students at predominantly white institutions (PWIs), noting that Blacks at HBIs and white students at PWIs enjoy similar levels of persistence and achievement while Blacks at PWIs are more apt to withdraw. Love described the Black experience at PWIs as:

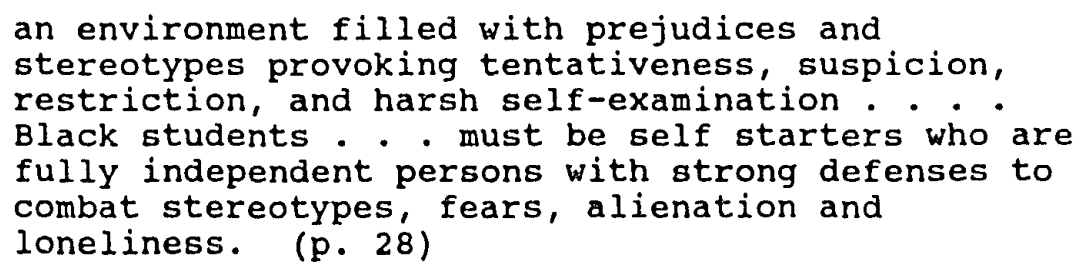


She catalogued seven factors identified in retention literature that should be addressed to ensure program success. The factors included: (a) White racism; (b) institutional leadership; (c) finances; (d) social interaction, cultural dissonance and environmental incongruence; (e) interaction with faculty; (f) student services; and (g) student characteristics. Love spoke boldly where others hinted at difficult issues like racism. of particular interest is her national survey of retention program characteristics which were cross-matrixed with the seven factors listed above. Rarely in her survey of programs does she find the first four factors actively addressed, whereas almost every program provided compensatory offerings for factor seven. Love's conclusion that most retention strategies focus on correcting or changing black students is provocative.

Steele (1992) deduced from the enrollment data that "something depresses Blacks' achievement at every level of preparation, even the highest" (p. 70). He attributed the failure of Blacks to thrive in American educational institutions to what he called "stigma (italics by author), the endemic devaluation many blacks face in our society and schools" (p. 68). Steele (1992, 1994) made a provocative argument. Citing his own persistence research data, he convincingly demonstrated that a Black student's strong academic ability and mentored institutional socialization 
are repeatedly overshadowed by the stigma of subtle and overt messages of the student's expected incompetence. students pick up the message that they are deficient: they are not where they are supposed to be, not where they belong, and consequently they drop out of college.

When the problems of student retention involving people of color are addressed, those explaining the problem usually search for deficiencies in the students themselves (Clewell, 1987; Steele, 1992). Essentially, the person who is different from the dominant culture is studied, and at times blamed. Tukufu (1991) suggested that expectations which evolved during the advent of affirmative action compel the person of color, once admitted to an organization, to adjust to that organization's norms and practices. When an organization's standards are perhaps unwittingly drawn only from the norms of the dominant culture, members of the dominant culture can enjoy an embedded privilege of familiarity and practice, whereas members of minority cultures must learn new ways and become bicultural in order to succeed. The dominant cultural mores are viewed as right and usual; those of the minority are wrong and can be construed as "not the way things are done around here." Affirmative action programs of predominantly white institutions and organizations which created increased access for people of color, presupposed that, once inside, people would behave in keeping with dominant cultural norms. 
Alternative ways of operating, perhaps more in keeping with minority cultural norms, were not legitimized. Thus, affirmative action programs could create the appearance of diversity while maintaining the status quo with regard to actual day to day actions and behaviors within the organization. Diversity, under such constraints, becomes something to be tolerated; the promise or opportunity to promote different ways of acting or thinking becomes moot. Tukufu recommended a more equitable remedy to this practice; he suggested that the time has come for mutual adjustments on the part of both the individual and the organization which will afford mutual benefits in this age of increasing diversity.

\section{Considering Perspectives from the Margin}

In order to understand the interplay between the cultural minority and majority, it is helpful to open up one's perspective to other views--to notice what typically might be ignored or to consider what else might be significant. Literature often provides a vehicle through which to open up new perspectives. Eliot's (1950) play the Cocktail party served up a striking literary example of outsider/insider dynamics and exposes some of the subtler meanings people can attribute to their minority or majority experiences. It is especially illuminating for Americans because this example from the British theater uses class 
rather than race or ethnicity as the defining characteristic to distinguish those with the power to act and control (the majority) and those acted upon (the minority). Dropping into the lives of upper class Britishers immersed in their social lives, Eliot gave the audience a peek at some essential elements of outsider/insider interplay: the insider's self-appointed exercise of power over others' lives "for their own good" while operating with the best of intentions, the outsider's establishment of a margin of safety, the outsider's intermittent craving for inclusion and power within the inner circle, the outsider's unique perspective. Eliot illuminated a fundamental dynamic between insiders and outsiders: Privilege as enjoyed by the insider confers a dominance which goes unquestioned--even unseen--by most people.

\section{Feminist and Ethnic}

Perspectives

Twentieth century feminist theorists have dealt with the issues of insider/outsider dynamics when investigating the role played by gender in American society. While not all feminist study is universally applicable to issues surrounding the experiences of people of color in predominantly white institutions, the examination of some commonly considered questions and elements relates to aspects of minority experiences heretofore discounted, ignored, or simply unrecognized as significant. Research 
from the feminist and ethnic perspective is particularly interesting for its attention to the constructs of legitimate membership, sanctioned knowledge, belonging, and personal efficacy.

Feminist scholar Smith (1987) described the juncture between her own lived experiences and the expected practices of her discipline, sociology, as a fault line. Just as an earthquake ruptures along a fault line when the internal pressures of the earth demand adjustment, so did she experience a parallel pressure when her world was at odds with her experience and sense of knowing. Smith went on to suggest that life along the fault line, although enlightening, can be extremely stressful. She drew an analogy with the awkwardness and frustration felt by the English working class when its members must act within the paradigm of the world of the ruling class in order to enact changes:

In the making of the working class in Britain, the conflict of silence with "their" language, the problem of paralysis and connection has been continuous. Every man who has worked up through the labour movement expressed this in some form. The embarrassment about dialect, the divorce between home talking and educated language, the otherness of "culture"--their culture--is intense and painful. The struggle is happening now every time a worker on strike has to justify his position in the alien structures of the television studio before the interrogatory camera of the dominant class, or every time a working-class child encounters a middle-class teacher. (p. 57)

Whether in the world at large or within the smaller world of a school, effective use of accepted language 
garners messages of competence, and ineffective use confirms incompetence, thereby affecting one's senses of efficacy and legitimacy. We need to question: What sorts of pressure erupt for those people of color who exist on the language/culture fault line--adept at more than one language while the dominant culture sanctions one and only one? What messages of general competence or incompetence do they believe they raceive?

In a similar vein, Grant and sleeter (1988) and Ornstein and Levine (1989) described research results that emphasize the tensions and an ensuing lack of academic achievement derived from the frequent class differences between the agents of the school system and the students themselves. Citing reasons for students' low achievement, Ornstein and Levine pointed to the significant difficulties which result when middle class teachers attempt to understand and motivate working and lower class students. Comments which the teachers find clear and compelling often simply do not make sense in the students' known world. Along the same lines, in their article "Race, Class, and Gender and Abandoned Dreams," Grant and Sleeter (1988) discussed their research results and explained some of the ways the dominant culture reproduces its domination:

Students who are white and middle or upper class tend to be taught better and challenged more, regardless, we suspect, of what role the parents might be playing. The higher the social class, the more actively demanding of the school the parents tend to become, but the more likely it is 
that the school will be trying to empower the students academically anyway . . . The problem was magnified at the school in this study: There was little home-school communication; the [lower class] parents gave their children what advice they knew how to give, and assumed incorrectly that the school was doing the rest. This is a problem that may well grow as teaching staffs become increasingly/white and professionalized and, in the process, increasingly removed from lower-class and minority communities. (p. 39)

Social class appears to be another fault line marker, another significant demarcation that, along with race, ethnicity, and gender, serves to establish who belongs and who does not.

Both Smith (1987) and Harding (1987), another feminist scholar, advocated more study incorporating standpoint theory where the researcher investigates from the standpoint of the subject. Both scholars insist that we need to question who can and should be deemed a knower, that is, one who not only knows but also interprets and makes meaning of information and events. Harding critiques established truths drawn from studies about women by emphasizing that the questions asked--and/those not asked--determine the accuracy and completeness of the total picture. Oversights of omission skew what might be discovered and serve to maintain the status quo. Smith suggested an inquiry process focusing upon a subject's experiences along a fault line, specifically as they connect to power and the maintenance of the status quo. To justify the promise of standpoint theory, Smith drew an analogy with copernicus' discovery 
that the sun, not the earth, is the center of the solar system: when the position of the observer was no longer assumed to be fixed, then the observer's position became essential to the interpretation of observations--and a whole new world of understanding and possibility opened up.

The dominant culture establishes the means to think about and imagine the everyday world. Smith (1987) believed its language and norms become "forced sets of categories into which we must stuff the awkward and resistant actualities of our worlds" (p. 55). Aspects of the dominant culture represent the positive and the neutral, whereas the minority culture can represent the negative or the other. If this is true, then what might this mean to a person of color operating on a fault line? Are situations of apparent neutrality actually covertly controlled? Must a person of color speak as a person of the dominant culture in order to be heard? Smith suggested that the common fixtures of the status quo are "a set of positions that manage, administrate, organize, and otherwise control," (p. 56) and she questions which social relations "organize and enforce the silences of those who do not participate in the process, who are outside it?" (p. 56).

Since the educational process (including the preparation and subsequent work of teachers) can serve to maintain the status quo of society, a doubly ironic situation can exist for a person of color living on an 
educational fault line. In order to succeed in the eyes of the dominant culture's educational and community leaders, a person of color may have to balance personal and professional needs for advancement which are achieved via approval by members of the dominant culture with his or her personal and professional desires to shift the status quo toward creating more equitable experiences for teachers and students of color. Then, again, the person of color may experience no dissonance whatsoever. This dilemma echoes back to the painful quandaries described by Rodriguez (1982) and Monteblanco (1994).

Smith (1987) identified a central question which must be answered by a person on the fault line: What constitutes the characteristics of a fully competent member? She summarized:

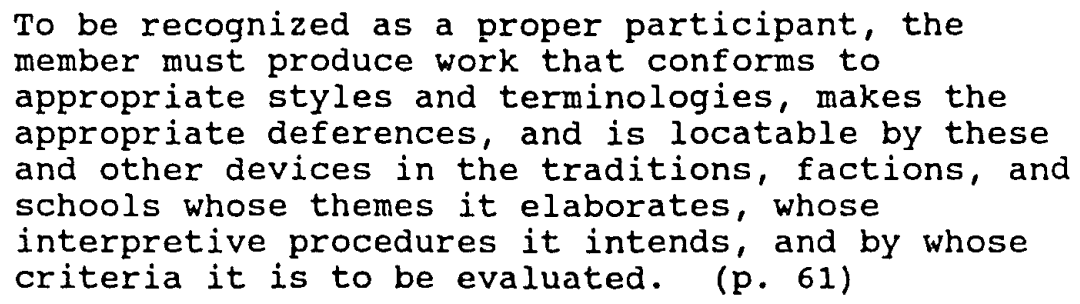

Messages of competence and signals conveyed to a person that she or he does or does not belong may be important determinants of persistence and success for the person on the fault line. The dominant culture establishes what in educational philosophy and practice is to be valued or deemed competent, and those values may not mesh with the values of people of color who have traveled different 
educational roads and perhaps are aiming toward slightly different end points.

Collins (1992) raised similar possibilities when arguing that Black feminist sociologists occupy rare marginal positions, an "outsider within" status, which affords them special vantage points from which to explore self, family, and society. Collins agreed with bell hooks, another Black feminist critic, when she cited some potential benefits of the outsider within status, particularly the ability of the stranger to see patterns which typically go unnoticed by those who fully belong. According to collins, much is to be learned by listening to the experiences and the insights of the outsider within. One can question the effects of operating from such a location: . Is outsider within status a painful experience? stimulating? Debilitating? Does it foster creativity or snuff it out? Do people of color who persist in predominantly white institutions do so on a fault line? How do they experience that unique yet precarious spot?

Collins (1992) elaborated on three themes which emerged from her consideration of outsider within status issues. The first theme spoke to the significance of one's ability to define and value oneself in the face of forces which stereotype and objectify one as the other. Embedded in this theme are elements of power and domination (the outsider can be defined in terms of his or her position versus the 
insider) and invisibility (the insider ignores or is indifferent to the experiences or inputs of the outsider). Collins stressed that in her opinion, self-definition and self-valuation were necessary for survival when living and working as an outsider within. In the elaboration of her second theme, that of the interlocking nature of oppression, Collins attempted to explicate the complexity of systems of domination which ensure the status quo. Collins attributed this construct to dichotomous oppositional differences which are central to American culture, and she explained that they derive from: (a) dualistic thinking which sets up people, things, and/or ideas in relation to their different counterparts (i.e., black/white, male/female, fact/opinion, reason/emotion); (b) the fact that those relationships are oppositional not complementary; and (c) the nature of those relationships as inherently unstable. The resulting instability must be resolved by subordinating one half to the other through subtle systems of domination and subordination. Collins identified a third theme worthy of investigation--the culture subsequently developed by outsiders within--which she believed is evidenced by the exercise of socio-political activism, a system of selfprotection, and a method to ease the tension caused when an individual's consciousness is at odds with the conforming behaviors demanded by the culture of the inside. 
Minorities who persist in predominantly white institutions can legitimately be described as being outsiders within who exist on a cultural fault line. Understanding how these minorities experience this condition and what it means to them relative to their persistence and success warrants further investigation.

Another feminist scholar, McIntosh (1988) of the Wellesley College Center for Research on women, also drew connections between gender studies of male privilege and racial/ethnic studies of white privilege. She identified correspondences between the two privileges starting with their descriptions as "an invisible package of unearned assets which I can count on cashing in each day, but about which I was 'meant' to remain oblivious" (p. 2). When discussing white privilege, McIntosh expressed frustration at its elusive nature for the person who is white. She attributed this slippery slope to her belief that to accept and recognize specific privileges, she must shed the myth of meritocracy and acknowledge the unearned aspects of some of those privileges which she has come to see as central to her continued success. McIntosh reported that people of color recognize such privileges with ease; to them, they are daily and obvious occurrences. If this is so, then it would logically follow that people of color may well be able to identify examples of privilege they encounter at 
predominantly white institutions and elaborate upon whether or not such privileges or their absence affects persistence.

Feminist and ethnic studies offer other lenses through which to view American culture and its institutions. These lenses can offer new clarity in previously dark or opaque spots, and they show promise for clarifying the subtle and systematic ways in which the dominant culture is able to reproduce its domination.

\section{Exploring the Effects of Embedded Racism}

When considering the existence of privilege or racism which unfairly advantages some at the expense of others, the research waters can quickly shift from calm and clear to roiling. Such topics can evoke strong emotional reactions among even the most dispassionate members of the majority and minority alike. The notions of privilege and prejudice run counter to American values of equal opportunity for all individuals regardless of their identifications as members of a particular group. The possibility of uncovering such aberrant attitudes (e.g., a tolerance for racism or a welcoming of privilege) within oneself is embarrassing at best, abhorrent at worst, to most Americans. Experiencing such discrimination, especially if it is denied or justified by the discriminator, is enraging. Thus, while the sociopolitical debate about affirmative action rages and the contemporary American media zooms in on racial incidents, 
many people continue to separate the personal from the political and deny that they themselves personally enjoy any privileges or express any racism. This is a vexing situation, one not easily contextualized in a literature review, yet one that influences the tenor of the times and the setting within which my study takes place. Because I believe it is important to draw in some alternative voices, I include the references in this section. They are another step toward adding depth to the broader cultural context within which a predominantly white institution operates and within which a minority exists in contemporary America.

In a series of American History lectures at Princeton University, Nobel Prize winner Toni Morrison (1993) questioned what it means to be authentically American and suggested that a real or fabricated "other" serves to define one's sense of Americanness:

As a disabling virus - . Africanism has become, in the Eurocentric tradition that American education favors, both a way of talking about and a way of policing matters of class, sexual license, and repression, formations and exercises of power, and meditations on ethics and accountability. Through the simple expedient of demonizing and reifying the range of color on a palette, American Africanism makes it possible to say and not say, to inscribe and erase, to escape and engage, to act out and act on, to historicize and render timeless. (p. 7)

Morrison identified the many ways throughout American history that the black man has served as the foil for the white man--ways by which the confirmation of the black man's deficits and failures sets off the white man's strengths and 
successes thereby defining the white man as good, right, and deserving of dominance.

Morrison (1993) subsequently elaborates upon the implications of the lack of discourse about race in America:

Evasion [of discussion about race] has fostered another, substitute language in which the issues are encoded, foreclosing open clebate... . the habit of ignoring race is understood to be a graceful, even generous, liberal gesture. To notice is to recognize an already discredited difference. To enforce its invisibility through silence is to allow the black body a shadowless participation in the dominant cultural body. According to this logic, every well-bred instinct argues against noticing [italics by author] and forecloses adult discourse. (p. 10)

By analyzing its evidence throughout Arnerican literature, Morrison (1993) uncovered the embedded American racism she believed to be the unacknowledged driving force perpetuating the inequities of the status quo. Bell (1992), Steele (1992), West (1993), and Zweigenhaft।and Domhoff (1991) added dimension and detail to the topic of racism and its effects on people of color and on members of the dominant culture. All of these authors demonstrated an unusual willingness to raise this difficult|subject: Like a shiny, wet stone spotted on the beach, they pick it up, hold it, look at it from different angles and watch its sparkle pale as it dries under the light of the sun. Why is it difficult for all people, but especially for members of the dominant culture, to investigate racism? These aforementioned authors all alluded to its connections to power, especially power over others, which is enjoyed by 
members of the dominant culture. Their identification and elaboration of power issues are consistent with McIntosh's privilege theory. Once these topics are broached, the discussion of minority persistence and success in a majority environment becomes complicated far beyond issues of institutional programs and retention efforts.

Summary: What Is known and What Is Not

A review of related literature confirms America's changing demographics and the lack of congruence between those changes in the population at-large and the continued decrease in the number of new teachers of color. Despite public rhetoric calling for more minority teachers and despite examples of recruitment and retention programs which do work, overall trends indicate proportionally fewer minorities enter or persist in teacher preparation programs at predominantly white institutions than ever before. Data from the U.S. Department of Education, National Center for Education Statistics, which were used to compile Tables 1 and 2, clearly confirm this trend (ACE/OMHE, 1992). The typically more intense focus of study around this issue of under-representation has zeroed in on students of color who leave school. By analyzing students of color who do not measure up, by examining those who do not persist, a deficit bias is perpetuated. Knowledge is growing with regard to who or what does not work, and that knowledge is 
often framed in light of differences from the dominant culture. The differences are often couched in negative terms measured against a preferred dominant cultural standard. At times the differences become rationalizations for continued subordination.

Table 1

Total Master's Degrees for Education, 1981 and 1990

\begin{tabular}{llll}
\hline & 1981 & 1990 & $\begin{array}{l}\text { of Change } \\
1981-1990\end{array}$ \\
\hline Total & 98,380 & 86,057 & -12.5 \\
Men & 28,079 & 20,834 & -25.8 \\
Women & 70,301 & 65,223 & -7.2 \\
\hline
\end{tabular}

Table 2

Master's Degrees for Education by

Minorities* 1981 and 1990

\begin{tabular}{|c|c|c|c|}
\hline & 1981 & 1990 & $\begin{array}{l}\text { \& Change } \\
1981-1990\end{array}$ \\
\hline Total & 12,902 & 9,548 & -26.0 \\
\hline Men & 3,380 & 2,230 & -34.0 \\
\hline Women & 9,522 & 7,318 & -23.1 \\
\hline
\end{tabular}


What is less understood with regard to the underrepresentation problem is why some minorities persist and succeed in a predominantly white environment. others have endeavored to explain their persistence for them. However, only the minorities themselves know whether they succeeded because, or in spite of, retention programs or other interventions. Only the persisters can tell us what their experiences at predominantly white institutions were like-what happened and what it meant to them. The time is ripe to listen to their voices--to hear them tell their own stories. 
CHAPTER III

\section{METHODOLOGY}

Introduction

In this chapter, I describe the challenging task of designing a study which first allowed me to find former graduate students of color who completed teacher preparation programs at predominantly white institutions in the Pacific Northwest and second, enabled me to engage in a meaningful dialogue with them. I begin the chapter by reviewing the purpose of my study and explaining the basic assumptions that underlie it. Next, I delineate the major paradigms and interpretive perspectives which guided my choice of methodology and design. Since I view qualitative research as an interactive process shaped by the personal biographies, gender, race, ethnicity, and social class of both the researcher and the participants, I also deemed it important to locate myself within the context of the study; I do so in the first section of this chapter. Then, I provide a detailed overview of the research design, elaborating upon its major components: survey construction, distribution, response and interpretation of results; development of the interview instrument; interview sample 
selection; interview protocol; and accumulation of additional empirical materials. I briefly outline the procedures I followed for data analysis and interpretation. Finally, I describe the limitations of my study.

\section{Purpose of the study and} Basic Assumptions

The goal of this research is to expand our understanding of the perspectives of minority students who have succeeded in predominantly white educational environments. Given the persistent proportional decrease in the numbers of America's teachers of color, despite governmental and community calls for more diversity in the teaching ranks, this research study starts with the premise that this widening numerical disparity presents a problem for American society--a problem that could be affected positively by a deeper understanding of the issues, including understandings from the standpoints of multiple perspectives. Therefore, a value-laden premise does underlie my study: the number of effective teachers of color ought to be increased and information which might expedite the achievement of that goal should be actively sought by those in a position to influence policy and practice.

As I noted in earlier chapters, too few minority students do succeed in such environments. Despite individual efforts via recruitment and retention programs at 
many colleges and universities, students of color are not enrolling or graduating in numbers representative of current demographic figures. Relatively small, isolated successes are not turning the national tide. Unfortunately, equity in educational opportunity continues to be more a goal than a reality. People of color remain under-represented in American higher education based on their share of state populations.

As explained earlier, the factors believed to contribute toward environments of support for minority students are well documented (ACE/OMHE, 1992; Garibaldi, 1989; Martinez et al., 1992; Noel-Levitz Centers, Inc., 1992). With minor variations, the consistency is remarkable. Unfortunately, knowing what to do to increase persistence has not yet translated into doing it. When confronted with the dilemma that we know the numbers are too few and we believe we know what constitutes an environment of support, yet we are not increasing those numbers of successful minorities, I asked myself, "What don't we know?"

While considerable attention has been paid to a deficit model which focuses on those students of color who fail, little research exists that expands our understanding about which students of color succeed and how and why $-3=y$ do so. In particular, we have not heard much from the students themselves; rather, we have heard from others who seek to 
explain or interpret the deficits or strengths of students of color based on an analysis of standard educational measures (GPA, attendance, financial aid, etc.) which are more readily available and relatively easy to quantify. This questioning and reflection led me to recognize a primary assumption guiding the planning and implementation of this study: A focus on the positive is apt to reveal new information which is not merely the reverse of that discovered in a deficit-model inquiry but is truly different.

I also worked with a second assumption: The experience of a minority person within a majority environment, while influenced by that person's specific racial and lethnic identification, is also markedly distinguished by experiences shared across different races and ethnicities when one is in a minority position. This assumption serves to place the emphasis of my study on minority-majority relations and the fault line walked on by any person of color who operates in a predominantly white world.

By making this second assumption, I do not want to diminish the significant differences experienced and valued by people who identify, or are identified, with distinct racial and ethnic groups. It goes virtually without saying that an African American female, a Japanese-American man, and a Nicaraguan immigrant enjoy different support systems and meet different challenges when they operate within 
mainstream American culture. Such differences are well elucidated (Gray, Hernandez-Gravelle, Lewis, \& Warren, 1992; King, 1991; Nieto, 1992). What is less clear is that is lost when these differences are the only or primary area of study.

After my review of the retention and persistence literature, I observed that an analysis of the low numbers of successful minority students frequently points to the influence of racial and ethnic factors to such a degree that the reader is blinded to the possible influence of other factors. Typically, race and ethnicity are viewed as an । excuse or a deficit; the lens zooms in on the details of the minority while the actions and effects of the majority culture blur. Thus, minority race and ethnicity are the marked categories. They are the noticed, the explained, the problematic. When the "explanation" is offered, the dominant culture is invisible. Ironically, despite the focus on minority status as explanation (prima facie), the minority point of view is neglected.

To effectively participate in contemporary American culture, we are expected to employ a common lens. When we do so, we come to know and interpret our world through the. images that reflect the deeply embedded values and beliefs derived from the dominant American culture. We also misconstrue, or simply miss, the images that do not focus in the cultural center; areas of margin and overlap are blurred 
or invisible; and the picture is incomplete. The lens of the dominant culture is the necessary lens of choice for the daily life and work of most minorities.

Dominant cultural lenses have traditionally been used to design, conduct, and interpret research as well. In the case of the problem outlined in this study, minority underrepresentation in teaching, those lenses have as yet proved to be inadequate. Therefore, I have chosen to use the lenses of non-dominant perspectives, in the hope that the gaps and invisibilities embedded in traditional ways of seeing, thinking, and knowing will come into a new focus and thereby new light can be shed on the problem.

Thus, a major goal of mine has been to design a study that keeps minority-majority relations in focus, inquires of those who have succeeded, and listens to the participants tell their own stories.

Theoretical Framework

The theoretical framework of this study speaks to the ironic contradiction between the typical research emphasis on minority race and ethnicity as marked categories used to explain phenomena and the de-emphasis of the minority point of view. It incorporates elements of several interrelated, nontraditional perspectives explicated in Denzin and Lincoln's (1994) comprehensive historical review of qualitative research. Their review described the evolution 
of the interpretive paradigms of qualitative research and situated nontraditional theories within the field. They characterized the mid-1980s to the present as "the fourth moment" in the history of qualitative research, a time of "profound rupture . . a crisis of representation . . . a time of blurred genres" (pp. 9-10) when new models of truth and method are sought. Denzin and Lincoln legitimized the trend in qualitative research to utilize overlapping theoretical paradigms and perspectives to guide inquiry and the interpretation of findings, and they encourage further exploration in this direction.

Guided by Denzin and Lincoln's (1994) criteria for categorizing forms of inquiry, I determined that the most appropriate paradigm for this study--and the most congruent with my philosophy also--is one of a postmodern, critical perspective. Such an approach demands a materialist/realist ontology that values multiple constructed realities where "the real world makes a material difference in terms of race, class, and gender" (p. 14) and where research results are evaluated in terms of their emancipatory implications.

I believe that the minority respondents in my study are the experts who knows their own life experiences and what they have meant personally, and therefore they can best tell their own story. Because of this belief, I chose to adopt an interpretive epistemology for my study, one that recognizes that as the knower and the known interact, they 
shape one another. This epistemology matches well with the interpretive, naturalistic methods I chose to adopt. After a review of feminist and ethnic models of inquiry (Belenky, Clinchy, Goldberger, \& Tarule, 1986; Collins, 1992;

Gilligan, 1982; Kincheloe \& McLaren, 1994; Lincoln, 1992; Olesen, 1994; Smith, 1987; Stanfield, 1994), I determined that such interpretive theoretical frameworks can be mapped into a critical paradigm, and I have done so in this study. A critical analysis of the structures and ideologies which serve to legitimize a group's lower status and power can only explain the under-representation of minority teachers to a limited extent. By restricting the study to a critical analysis, I feared I would risk not hearing the whole of what is happening with regard to this phenomenon. By adding interpretive perspectives, I believe a more powerful methodology is created. However, along with the advantages garnered from the combination, a puzzling problem arises. di Leonardo (1991) and O'Hanlon and Washbrook (1992) discuss what both consider a "conundrum" found in contemporary anthropological studies, i.e., the tension between committing to a political perspective and the recognition of multiple voices. di Leonardo particularly stresses that feminist and ethnic interpretive perspectives tend to ignore the existing, material world. She suggested adopting an epistemological orientation in which:

race and ethnicity are not [only] immutable characteristics of individuals but emergent and 
shifting social categories, categories that can and do become the objects of intense political struggle. (p. 29)

By recognizing the inherent and unavoidable tensions between the critical and interpretive perspectives, attention is directed to this ironic, yet not altogether unhealthy, research problem. Perhaps unresolvable, the contradictory tension should not be ignored. I believe that the way the problem of American teachen diversity is usually framed, i.e., as one in which the dominant culture is nonproblematic and the minority's race or lethnicity is viewed as the "explanation," calls for a critical perspective. However, since I also genuinely seek to base my study in minority voices, I was led to include the postmodernist interest in a multiplicity of voices. It is this appreciation for multiple perspectives that helps me separate my own self (and my desire for socio-political change) out of the data.

Both feminist and ethnic models offer a means by which to illuminate the landscape better known to women and minorities and also to observe the normally well-lighted world of the dominant culture from other standpoints. While contemporary feminism seeks to confront issues of oppression and inequity in any form, its touchstone is its focus on women and their experiences. By using this lens we can critically examine society, culture, and the world from the standpoint of being female. 
Feminist scholar Smith (1987) viewed the everyday world of women as problematic because it is created and shaped by external material factors, and she cautioned the researcher not to objectify those people who participate in a study. Smith identified "fault lines," points of rupture that exist between what traditional knowledge tells women they experience and what women actually experience in their everyday lives. Suggesting that the tension and disequilibrium felt by a person on a fault line exposes that which is problematic, Smith explained:

The concept of problematic is used here to direct attention to a possible set of questions that may not have been posed or a set of puzzles that do not yet exist in the form of puzzles but are 'latent' in the actualities of the experienced world . . . The problematic is . . . present in the everyday world as it is given to any of us to live... . for the everyday world is neither transparent nor obvious. (p. 91)

Black feminist sociologist Collins $(1989,1992)$ also urged attention to standpoint theory in the examination of local culture and local knowledge as a means to counteract the political and cultural hegemony of the American white middle class and its blindness to forces maintaining its hold on the status quo. Collins (1992) emphasized the importance of attending to the unique standpoint of women who experience dual social realities. She called their distinct vision that of the "outsider within:" a person who walks the fault line between the norms, expectations, and privileges of the dominant culture and her own experience as 
a woman in the margins. Collins suggested that an outsider within not only experiences a different reality than that of a member of the dominant majority, but also provided a different interpretation of that reality.

Elaborating upon the thoughts of Collins (1992) and Smith (1987), Black feminist bell hooks (1990) decried "the researcher's tendency to construct, speak for, and know us better than we know ourselves" (p. 22), and called upon researchers to interrupt such attitudes and replace them with approaches which centralize lived experience as a criterion of meaning and which value research ethics of caring, personal responsibility, and open dialogue. Ethnic models of inquiry parallel many of the elements espoused in feminist models and so are applicable to this study. Stanfield (1994) outlined the ways these models seek to address:

the ethnic hegemonic character of American and other Eurocentric traditions in the social sciences [that] has made quite problematic the legitimation of competitive, empowering research questions and strategies in work with people of color. (p. 177)

By grounding this study in theoretical perspectives which more adequately reflect the pluralistic character of American society, I believe the research framework is more legitimate. It places tnis study firmly in an established tradition of qualitative research. By aiming for more adequate knowledge production about the American minority experience, this study is designed to position those people 
typically filmed by others behind their own cameras where we can discover what they themselves deem worth a zoom shot and where they wish to stop and aim the lens longer as they pan across the dominant culture.

The other broad principles guiding this study align with those of the critical paradigm and also allow us to challenge traditional assumptions and beliefs about minority experiences in the dominant culture. Thomas (1993) suggested that a critical perspective:

is grounded empirically in explicit prior evidence of a variety of debilitating social conditions that provide the departure point for research - . and alerts critical thinkers that cultural forces may shape both the conditions and social responses that disadvantage some groups more than others. (p. 34 )

The critical lens focuses on the subtle and systematic ways that the dominant culture can reproduce its own domination. Therefore, by applying an additional, critical lens to this study, opportunities to consider the relationships among knowledge, society, and political action are enhanced.

Although the blend of critical and interpretive frameworks in my study creates the conundrum mentioned earlier, i.e., the tensions and limitations created by recognizing multiple voices while simultanosusly committing to a political perspective, many social thinkers are moving in this direction. I am one of them.

Together the feminist, ethnic, and critical perspectives provide high-powered lenses with which to view 
the problem of the under-representation of teachers of color. These combined philosophical principles create a solid framework by which to explore the lived experiences and self-understandings of people of color who have succeeded in predominantly white institutional programs; locate the fault lines they negotiate; maintain collaborative, caring, non-oppressive relationships between the researcher and the researched; and seek to understand how race, class and gender influence the problematic situation in order to interrupt and equalize it.

\section{Locating Myself as \\ Researcher}

For the past 20 years I've worked within the field of education in the roles of news reporter, public school teacher, school counselor, school administrator, and graduate school of education faculty member.| In recent years, I have taught Multicultural Education, served as a liaison between a graduate school of education and community organizations which primarily serve people of color, and advocated for students of color within educational bureaucracies. Over the course of my work I/ have become increasingly puzzled and troubled by our collective lack of progress in diversifying the teaching force of the United states. I am also troubled by my own misunderstandings and ineptitudes which continue to surface as I strive to ameliorate inequities in predominantly white। institutions. 
When I taught in a teacher preparation program at a predominantly white institution, a portion of my responsibility was to build a sense of community among the white graduate students and the very few students of color in the program. I often coached students as they negotiated the ins and outs of a big state bureaucratic institution. Most students of color made it; some did not. Many students of color appeared to struggle more than their white counterparts, and those struggles seemed to stem as much from outside forces as from personal ones. Throughout my tenure in the teacher preparation program, I was haunted by a sense of what went unsaid among us all-faculty and students alike. Increasingly, I felt we had much to learn from our students of color and about ourselves, yet it was difficult to create a safe space where that dialogue and reflection could occur. Many times, over coffee at a local cafe, students of color would allude to a problem or a coping strategy: a look, a laugh, a nod, a softly spoken comment provided the clue. My abiding recollections are of a subtle plea to understand combined with an admonition not to probe too deeply or of lightly veiled anger and resentment couched in a shoulder shrug. Upon reflection, I came to the somewhat embarrassing realization that probably neither I nor the program in which I worked had made as big a difference with regard to minority students' retention and achievement as I had led 
myself to assume. Some students of color succeeded and some did not; I was not sure why, but I was increasingly certain that the personal efforts of my colleagues and me and the implementation of minority student retention initiatives were not necessarily the primary determinants of the program completion of minority students. The questions have continued to nag at me: who completes and why? From such questions and personal experience, this research study evolved.

Given my interests in cultural pluralism and my sense of personal and professional responsibility to make progress in the diversification of teaching, I could not embark upon this study without locating myself within it. The objective, traditional/scholarly approach seemed to require a distancing that would interfere with inquiry efforts to preserve the authenticity of the subjects' stories and to understand the reality of their experiences. I feared that what I sought to find out would remain hidden if such an approach were applied. Therefore, I intentionally chose an epistemology which allowed me to integrate empirical tools I with my own knowledge of the culture of schooling.

I am a white, middle class, middle-aged, American, female educator; my voice springs from a life lived with such definition. My personal experiences as a woman connect me to the outsider within perspective described in feminist standpoint theory. My experiences as a white, middle class 
American can blind me to the very same perspective. My personal and professional voice, in dialogue with this inquiry's subjects, weaves in and out among the stories of the subjects themselves. Their voices rise and fall much like soloists featured in a choir; my voice is heard too, muted but not absent.

\section{Research Design}

The creation of a research design in keeping with feminist, ethnic, and critical paradigms posed many challenges in addition to those which must be resolved in any qualitative framework, e.g." gaining access to representative subjects, developing caring and credible rapport with those subjects which could support our dialogue, and increasing our collective ability to understand and realize the successful preparation of minority teachers (Collins, 1992; Ladson-Billings, 1994; Thomas, 1993). The additional scaffolding I built for this study employed design components drawn from ethnographic methodology (Atkinson \& Hammersley, 1994; Fontana \& Frey, 1994; Spradley, 1979). After determining the size of a potential sample of informants who were regionally accessible to me, I initially explored the social phenomenon of minority success in a majority environment through a survey. Respondents formed a pool of potential informants from which I selected a small number to study in detail, and 
respondents' survey comments guided the development of the question outlines used for the loosely structured interviews conducted later. Triangulation within three different sources of respondents own words--survey, interview, and personal journal--enriched the information received. Field observations in their own classrooms (now that they are employed as teachers themselves) and content analysis of papers written previously for graduate course work or for their current teaching positions added a legitimizing authenticity to their stories. Finally, ethnographic methods incorporating constant comparative analysis were used to categorize and cluster the empirical materials in order to better understand the informants' lives and the meanings they attributed to their successes in majority environments.

It is important to draw a distinction between a study which makes a claim to ethnographic authority and this one which incorporates ethnographic methodology. I do not claim that my study is a truly ethnographic one. It lacks the indepth, long-term fieldwork experience often marked by months of informal contact with people that comprises a full ethnography.

The intent of this research is to shed light in previously darkened space: to understand more deeply the experiences of people of color in the teacher preparation system in hopes of ultimately improving their level of 
representation in the teaching ranks. However, the degree to which the informants' interpretations of their experiences is endemic or pervasive should remain open to question. To generalize from their stories to other minorities is simplistic and inappropriate; the informants' voices can and do speak for themselves alone. What their stories can do is prompt our further investigation of this social phenomenon.

Most previous research on this topic stops with the establishment of the correlates of persistence. Few qualitative studies of higher education students of color exist (ACE/OMHE, 1992), and the ones that do typically focus on those students who do not finish, thus adopting a negative slant. Attinasi's (1989) investigation remains one of the few that has ventured into the qualitative arena. Based upon the richness and surprises Attinasi discovered in his interviews with Mexican-American college freshmen, he strongly advocated descriptive studies that emphasize the insider's point of view, especially using open-ended interviews. In keeping with Attinasi's recommendations, the cornerstone of my research was the in-depth interviews which followed the administration of the survey.

Informants were not the only subjects under examination; I also needed to practice reflective selfawareness as I engaged in conversation with them. Freire (1970) described dialogue as "the encounter between men, 
mediated by the world, in order to name the world" (p. 76). Freire's definition of dialogue as a horizontal A with B relationship matches the type of communication I aimed for in my relationship with the subjects. Kreisberg (1986) drew upon Freire's philosophy when he pioneered a new style of dialogic research in his empowerment study. Underscoring the need for a process of mutual adjustment, Kreisberg speaks to the critical distinction between the undesirable practice of squeezing participants' experiences into his framework for analysis versus the preferable researcher practice of gleaning more precise understandings of the phenomena in question by engaging in collaborative, reflective dialogue with the subjects. The dialogic ideas of both Freire and Kreisberg served as reference points guiding the evolution of this study.

Research Questions

The primary purpose of this study is to guin a fuller understanding of the experiences of graduate students of color who have completed teacher preparation programs at predominantly white institutions. specifically, this research design supports a focus on the subjects' interpretations of their experiences and their identification of events perceived to enhance or hinder their successful program completion.

The broad research questions guiding this study are: 
1. What are the experiences of students of color at predominantly white graduate schools of education?

2. What do these students of color perceive to have been contributors or hindrances to their academic persistence and subsequent program completion?

3. What, if any, commonalities of experience or interpretation of experience exist among these students of color?

\section{Subject Recruitment}

Primarily due to testing issues, state teacher certification is not always guaranteed when someone completes a teacher preparation program. Therefore, I could not recruit subjects through state certification records. Drawing upon the recommendations of clewell (1987) who suggested initial personal contact with each institution in order to obtain names and addresses will prove fruitful, I decided to contact teacher preparation institutions instead. I expected to find little difficulty identifying graduate students once assurances of participant and institutional confidentiality were given to the schools.

Due to Pacific Northwest state licensing changes aimed at increasing the professionalization of teaching (enacted just prior to 1990 ) that require completion of graduate level teacher preparation programs in order to qualify for certification, I limited my study to graduate schools of education. Although some undergraduate teacher preparation 
programs still exist in the Northwest, the number of students they serve is few and the number of minorities served is even fewer. By choosing to study students from graduate schools of education, I selected a potential sample population whose experiences are likely to be most reflective of minorities seeking teacher preparation in the region.

optimistically, I began my recruitment of subjects by phoning 14 public and private graduate schools/of education in the Pacific Northwest situated in urban, rural, and suburban locations to explore whether or not any minorities had completed their graduate level teacher preparation programs. of the 14 institutions contacted, representatives from 3 reported that no people of color had completed their graduate teacher preparation programs since 1990. Agents of the other 11 schools expressed their commitment to diversifying the teaching force and their consequent interest in considering participation in this study. Unfortunately, expressions of sympathy for the problem did not translate into easy access to the institutions and their former students. In order to meet the privacy requirements of the institutions regarding their students' records and contact procedures, I needed to locate an agent at each institution with whom I could work. In search of such colleagues, I traveled to each of the 11 institutions. Armed with a memo vouching for my integrity from the dean of 
the graduate school of education supervising my study, I routinely approached a school's office of the Dean first. At four schools I spoke directly with a dean or director who agreed to distribute my survey. Two of these school leaders were minorities themselves who expressed heartfelt appreciation for the opportunity to join the study because it freed them from enduring the expressions of annoyance and skepticism conveyed by their own faculty members when the leaders suggested such research be done on-site. They reported comments like: "Here we go again;" "That's your issue;" and "We can't solve society's problems." These school leaders of color clearly welcomed the opportunity to learn more about this phenomenon through a composite sample where findings might broaden the perspectives of faculty and lift the onus of self-interest from the administrator's back. At the other seven schools I was referred to a sympathetic faculty member or program administrator, a person who in five cases was a minority responsible for multicultural education. Ultimately agents from all 11 schools agreed to write a letter to their students espousing the need for such research and encouraging voluntary, confidential participation and each planned to distribute the surveys.

Another glitch arose shortly thereafter when some schools questioned the need to obtain individual approval from the Human Subjects Research Review Committee at their 
own institution. Concerned about this potential roadblock, I encouraged the representatives at each site to consult with their colleagues and administration prior to making a final determination in this regard. After thoughtful review of my own Application for Review of the Protection of Human Subjects in my proposed research, 10 schools decided that the approval from my supervising institution was sufficient, and 1 school insisted that the study be additionally reviewed by its own committee. Unfortunately, time delays from the on-site review committee prohibited inclusion of this last school's students in the study. Summarily, the number of institutions involved in the study rested at 10 . Their anonymity was assured. The graduate schools of education choosing to participate covered a range of urban, suburban, and rural locations; public and private funding and governance; and religious and secular philosophies. The schools are quite similar in many respects: situated in close proximity to urban areas of oregon and Washington, graduating very small numbers of minority students relative to their majority populations, and possessing both elementary and secondary teacher preparation programs. The potential subject sample at this point was estimated to be approximately 150 people of color who, since 1990, had completed teacher preparation programs at these predominantly white graduate schools of education in the Pacific Northwest. 
Survey Intent, Construction, and Review

Intent of the survey was three-fold: to elicit factual background information about environmental and personal factors likely to have impacted a student's lacademic work and program completion, to guide the development of the interview focus by gathering descriptive data that would begin to establish the contextual character of the inquiry, and to create a pool from which to select interviewees. sections of the survey correspond to categories previously found to correlate with persistence (ACE/OMHE, 1992; Attinasi, 1989; Pascarella \& Terenzini, 1990; Tinto, 1987): personal characteristics, including/demographics; family background; financial resources; recruitment; academic and support services; school culture and climate; curricula; and testing policies and procedures. Additional sentence stems lead respondents to comment freely or raise personally significant issues in their own words.

The survey is a straightforward, simple two-page instrument that takes no more than 15 minutes to complete. other than finishing the two sentence stems, respondents merely fill in a blank (e.g., race and ethnjicity) or circle yes or no. If students are willing to consider participating in a follow up interview, they are given the opportunity to share their address and preferred contact method. 
After designing the survey and evaluating its format for ease of response, I submitted it to selected people of color who work in the areas of graduate education and/or equity issues. Two African-American women, two AfricanAmerican men, two Hispanic men, two Hispanic women, an Asian-American man, an Asian-American woman, and a Native American man who collectively represent a variety of professional expertise and income levels voluntarily reviewed and critiqued the planned study, especially with regard to cultural sensitivity. Confidentiality was promised to the group of reviewers and it has been maintained. Since I am not a person of color, this review process provided invaluable information. The members of the panel agreed to study both the form and content of the instrument as well as my accompanying letter of invitation to participate and interview protocol. Well aware that every communication between the potential informants and me would either add to or undermine the rapport I sought to establish, I welcomed outside review. They critiqued the instrument and letter for indications of bias, offensive language, assumptions of privilege, and questions or comments apt to skew the type of information likely to be offered by respondents. All of the reviewers offered to consult as needed during the interview portion of the study as well. 
An unexpected side benefit occurred through my interactions with the reviewers: their enthusiastic encouragement to pursue the study spurred me on at a frustrating initial point in the study. After weighing and incorporating their suggestions, the survey and letter were placed in final form.

\section{Survey Distribution}

During June and July of 1994, a survey packet was mailed to each of the 10 institutional allies previously contacted. Each packet contained: the number of surveys requested by the institution based upon their estimates of students of color who had completed their teacher preparation program since 1990 (color coded by school to enable assessment of return (rate); an equal number of letters from me to the potential respondents explaining the study, referencing the support of their former school's faculty, and inviting their participation (hand-signed); self-addressed, stamped envelopes for survey return; blank, stamped envelopes for survey distribution; a sample letter encouraging participation for the distributor's reference; and a personal note of thanks for assisting in the distribution. The institutional allies agreed that letters were only to be sent to students who had identified themselves on school records as persons of color. By utilizing this method, it was assured that I would not obtain the participant's addresses until they returned the 
survey to me and voluntarily included their address and/or phone number.

Once each packet was mailed to the institutional ally, I had to wait to see what arrived back at my home address. Since the distributors were volunteering to do a somewhat tedious and time-consuming chore at an inopportune time when they were juggling their own teaching and administrative jobs, I hesitated to ask them to do reminder notices or any other follow up tracking.

I did, however, request that each institutional ally send me a note indicating the total number of surveys distributed and when they were mailed. Eight of the 10 school representatives did so and several sent copies of their individual letters of encouragement.

A surprising occurrence surfaced as a result of these confirmations of distribution. The total number of qualified potential respondents dropped from the original estimated total of 150 people to be surveyed to the actual total of 85 people. Although two schools were only minimally off their mark, most of the schools were grossly off in their predicted number of graduate students of color who had completed their programs. While some of the faculty representatives offered explanations ranging from overly optimistic projections to reliance on entry rather than completion figures, this disparity remains a puzzling yet potentially significant fact. 
Survey Response and Interpretation of Results

within two months from the mailing dates, 72 of of the surveys had been returned $(\underline{N}=61)$. In many cases, respondents used up most of the available blank space on the survey to write additional comments and notes of appreciation for addressing the topic. Their enthusiasm for the need for the study was far greater than I had anticipated.

since the intent of the survey was to contextualize the study, guide the construction of interview questions, and enable me to select interviewees, the survey was not designed for statistical analysis beyond the accumulation of descriptive data. The lower than expected number of surveys sent out confirmed that such analysis in fact would not be meaningful despite the acceptable return rate.

The richness of respondents' comments did prove enlightening and allowed me to create a profile of the sample group. When asked to indicate their race and ethnicity by filling in blank lines on the survey, 53 different combinations of descriptors appeared on the 61 surveys. In a rough categorization by the minority groups typically assumed to cover the diversity in American culture, the sample divided as follows: Asian - 37f, Hispanic - 36\%, Black - 16\%, and Native American - 10\%. However, a closer examination of the responses revealed that 418 of the total sample population was a mix of two or more 
racial groups and the percentage was even greater when

factoring in the multiple ethnicities mentioned (see Table 3).

Table 3

Distinctly Different Self-Identification of Respondents' Race and Ethnicity

Race

Ethnicity

Asian American

Eurasian

Asian

Asian-Japanese

(blank)

Japanese

Okinawan/Japanese

Asian

Amerasian

Oriental/Caucasian

Japanese American

Asian

Filipino/White

Asian

(blank)

Asian

Asian (Chinese)

Asian

Asian-American

Asian

White

Chicano/Mestizo

(blank)

Hispanic

Mexican-American

(blank)

Mexican

Hispanic

(blank)

Hispanic

Hispanic

Chicano/White

Hispanic

Mexican

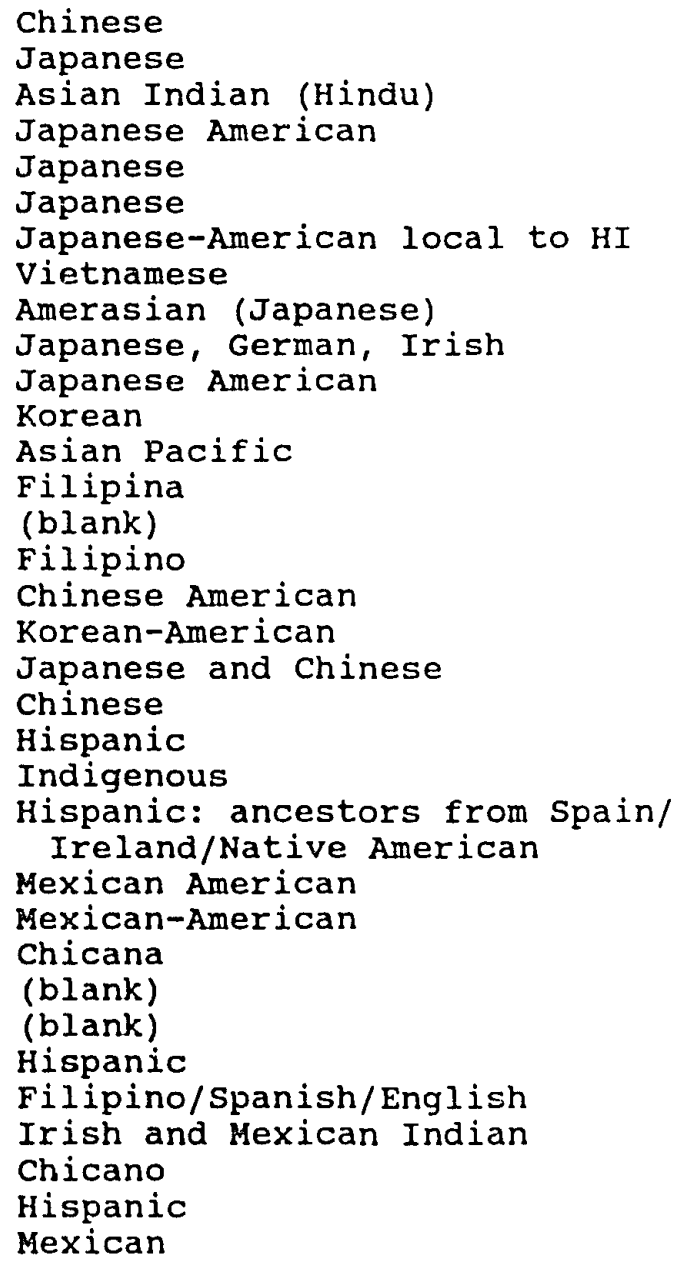

Chinese

Japanese

Asian Indian (Hindu)

Japanese American

Japanese

Japanese

Japanese-American local to HI

Vietnamese

Amerasian (Japanese)

Japanese, German, Irish

Japanese American

Korean

Asian Pacific

Filipina

(blank)

Filipino

Chinese American

Korean-American

Japanese and Chinese

Chinese

Hispanic

Indigenous

Hispanic: ancestors from Spain/

Ireland/Native American

Mexican American

Mexican-American

Chicana

(blank)

(blank)

Hispanic

Filipino/Spanish/English

Irish and Mexican Indian

Chicano

Hispanic

Mexican 
Table 3

Distinctly Different Self-Identification

of Respondents' Race and Ethnicity

(Continued)

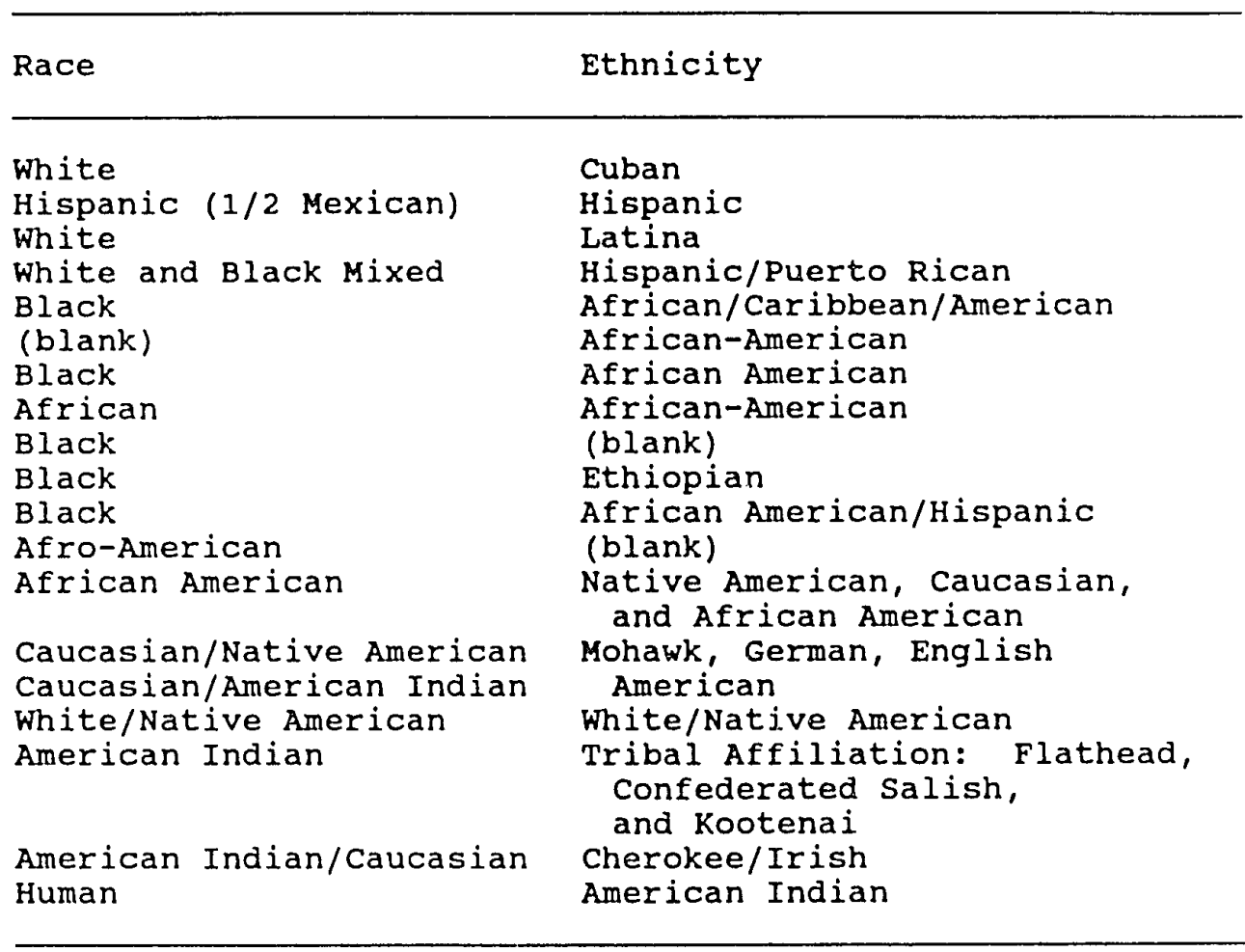

The wide variety of racial/ethnic identifications suggests the complexity of one's relationship to one's biological and cultural heritage. It also provides a pointed contrast to the superficiality of description that results from checking off one of five or six boxes on a standardized form. Respondents made conscious, thoughtful choices with regard to these information requests, and they 
often explained what they meant about their backgrounds by writing in the margins.

The majority of respondents (588) reported that they are able to speak, read, and write two or more languages. Specifically, 368 know two languages, 168 know three, 38 know four, and 18 know five. The most common language spoken other than English is Spanish; this is true across all racial and ethnic groups and is not limited to those of Hispanic background. For example, an Asian-American of Japanese ethnicity reported her ability to speak English and Spanish and a little Japanese--she was placed in the two languages group.

The entire sample population represents about two thirds women (67q) and one third men ( $33 \%)$. The ages of the respondents span all four categories with the highest proportion located in the 30 s age group. The breakdown occurfed as follows: $20-29,338 ; 30-39,448 ; 40-49,128$; and 50-59, 3\%. For those in their $40 \mathrm{~s}$ and 50s, the respondents frequently noted, in the margins, words to the effect that becoming a teacher represented the achievement of a lifelong dream rather than a midlife career change. Almost all of the respondents reported that they had received their home state's teacher certification $(898$ are certified; 118 are not). I did not explore reasons for noncertification on the survey. It is puzzling why someone who had successfully completed a state-approved program would 
not qualify for or seek certification. This figure may indicate personal preferences not to enter public school teaching or it may indicate the existence of additional barriers beyond the educational institutions (e.g., more stringent testing requirements) which inhibit the entry of minority teachers into the public school ranks.

Respondents' reported levels of teacher preparation and types of certification received were surprisingly comprehensive. While 54 \% chose only elementary level preparation, the remainder divided between secondary (25\%) and $\mathrm{K}-12$ (218). The majority of the new teachers reported having earned multiple endorsements, e.g., handicapped learner, special education, and/or additional subject areas. Parents' employment information gave some indication of class standing. Respondents reported a range of parents' occupations from homeless unemployed to upper and lower working class jobs (construction worker, waitress, migrant worker) to middle class (sinall business owner, secretary) to upper middle class and professional (physician, professor, chief financial officer, banker). An estimate of the total sample's categorization by class standing (based on their reports of parental vocations) divides as follows: lower working class, 25\%; upper working class, 38\%; middle class, $218 ;$ and upper middle/professional class, 168. For 258 of respondents, they were the first of their families to ever attend college. For another 25\%, they were the first of 
their families to have gone beyond "some" college to earn either an associate's or bachelor's degree.

Financial concerns surfaced as a significant issue for most respondents. Paying graduate school tuition while supporting self or family and/or not causing hardship to others by draining the family coffers appeared to be a major challenge. of the total sample, 87 i received some form of financial award: 648 earned a scholarship or outright grant, and 548 took out a graduate school loan. These percentages reflect the fact that some students accepted both kinds of financial aid. Only 138 of the respondents received no financial assistance whatsoever. While a few of the scholarships mentioned by name were based on academic merit alone, most noted were targeted for minorities. Three institutions appeared to have connections to a funding source (special community program or business partner) that allocated monies specifically intended to benefit minorities, because a majority of each institution's graduates reported scholarship awards from the same local funder.

of the $54 \%$ of the sample who reported working while in their teacher preparation program, $18 \%$ put in under 15 hours per week and 368 logged between 16 and 30 hours per week. Almost half $(468)$ indicated that they did not work during their program; this was largely true of those respondents who had received financial aid. 
Development of Interview

Instrument

The two sentence stems at the end of the survey

prompted some general responses that guided the initial

development of the interviews. After Question 28, "I

believe that a primary reason I successfully completed my

teacher preparation program is because . . ." some

representative responses often mentioned were: emotional

support of family and friends, prayer and spirjtuality, personal determination to achieve a deeply desired goal, encouragement from a faculty mentor, or the cheers and collegiality of fellow students. For Question 29, "I felt that the biggest obstacle which interfered with my work in and completion of the teacher preparation program was - . " respondents generally mentioned: lack of money, lack of adequate study time due to employment requirements, unexpected personal and family problems, racism, unmet concerns about student teaching placements, lack of minority role models, lack of minority students, and undermining of self-confidence after references by faculty or fellow students to the preferential treatment and lower expectations for minorities legitimized through affirmative action programs.

After reflecting upon the survey results in toto, I contrasted the responses with the retention and persistence literature and the descriptions of environments of support (ACE/OMHE, 19:92; Attinasi, 1989; Garibaldi, 1989; King, 
1993; Martinez et al., 1992; Metzner \& Bean, 1987; NoelLevitz Centers, Inc., 1992; Tierney, 1992; Tinto, 1987). Subsequently, I selected the following broad content categories for the first interview guide: construction of self, teacher education program experience, and role of the teacher. Because I wanted to organize a conversation which would support dialogue and disclosure, a seemingly tall order since I would be a complete stranger to the interviewees, I chose to begin with the personally familiar before moving to interpretive, philosophic and analytical territory.

I planned the first section, construction of self, to create a gentle entry into the interview where informants could share what they wanted about their family background, relevant life history, and personal reasons for choosing teaching as a profession. Given the survey responses to the race and ethnicity questions and the number of hand written notes added to the instrument, I wanted to be able to refer to the survey and ask for elaborations like "What did you mean here?" and "When you described yourself here, what was important to you about phrasing this comment in this way?" Even though I planned to prepare an interview guide, I believed that the informants should influence the course of the interview and the degree of disclosure and I wanted them to develop a sense that this was genuinely true. I hoped that they might venture off--telling stories about who they 
were and how they came to this point in time. During this section of the interview, I also planned to investigate Collins (1992) outsider within concept by asking the interviewees to locate themselves on a graphic representation and to discuss the rationale for their placements.

My readings of Attinasi (1989), Cibik and Chambers (1991), King (1993), and Love (1993) strongly influenced the outline of the second section of the interview, teacher education program experience. I hoped to hear about highs and lows, personal stories, and the everyday details which can serve to make stories identifiable to others. In particular, Love's analysis of significant dimensions of programs for minorities enrolled in predominantly white institutions offered what appeared to be a legitimate guide for the formation of this interview section.

The final section, role of the teacher, grew out of the respondents' answers to Question 28's call for reasons for program completion. At this point I was not sure, but I thought that many respondents had chosen teaching for reasons of the heart as well as mind. I wanted to explore their visions of teachers and their possible role in the creation of American culture now and in an idealized future.

A copy of the survey, interview outline, and sample letters to institutional allies and survey respondents are included in the appendix. 
Selection of Interview

participants

of the total number of survey respondents $(N=61), 83 \%$ indicated their desire to be interviewed. Many hand wrote comments like: "Do call!" or "I could talk for a long time about this!" or "I'm so glad someone is finally asking about this!" I determined that I not only had a sufficient pool from which to select representative interviewees, but also could look forward to at least some eager participants.

I first sorted the returned surveys based on the standard racial-ethnic groups used commonly in demographic studies, i.e., African-American, Asian-American, Native American, and Hispanic. Then, within each group, I sorted by gender, age, and likely social class based on parents' reported employment.

At this point, I reviewed each survey's hand written comments and eliminated a few that offered the barest minimum of response or contained a virtual diatribe against the system or a particular individual. I wanted to interview people who were willing and able to talk about their experiences, represented the profile of the sample, and appeared free of a major unresolved personal issue which would unnecessarily skew the conversations. This culling of the piles resulted in a final eligible pool of 45 potential interviewees.

From those eligible, I selected 10. After contacting each one to arrange an interview time, I found that three 
had conflicting work and travel plans which would have made the interviewing process too much of an imposition. Thus, the number of informants willing and able to participate ultimately rested at seven people of color who represented the following descriptive characteristics: four women and three men; two ethnically mixed Asian-Americans, one AfroAmerican, two of mixed Hispanic and African-American background, one of Native American/Caucasian mixed racial heritage, and one of African-American, Caucasian, and Native American mixed heritage; three English only and four multilingual speakers; three aged 20-something, two aged 30something, and two aged 40-something; two lower working, two upper working, two middle, and one upper middle/professional class members; five scholarship and financial aid recipients and two non-recipients; representatives from 5 of the 10 participating institutions ( 3 public and 2 private); and four who worked during their program and three who did not.

\section{Conducting the Interviews}

Face-to-face interviews were scheduled at a time and place convenient for each subject. Each interview lasted at least two hours, none longer than three and a half. Any conversation longer than the anticipated two hours was extended at the behest of the subject to continue our dialogue or finish the story.

Each interview was audiotaped and later transcribed verbatim. A transcript of each subject's interview was 
mailed shortly after the interview occurred with a request to review it for questions, comments, elaborations, and corrections. A sample copy of the letter accompanying a returned transcript is included in the appendix.

A second interview was scheduled within a month of the subject's receipt of the transcript. The purpose of this follow-up interview was to verify the accuracy of the informant's prior comments--to allow for any additions, deletions, or balancing of perspective deemed important to the subject. Originally I had expected that the first interview would be a time for me to establish rapport and legitimacy with the informants and that the second interview would be the one where they would volunteer the most information. Surprisingly for both the subjects and myself, the first interviews seemed more like the opening of a floodgate. The second interviews were universally characterized by opening comments like:

I meant every word of what I said before. It looked funny in print, and I didn't sound very eloquent, but it's all true. I've been thinking a lot about this since we talked. You know I've never said this stuff out loud before, at least not all at once, but now that I've started I think I want to keep talking. I think it's important. OK, what's the next question?

Rather than broaden the second interviews too much, I did try to keep the focus on the topics first raised in the initial conversations despite the subjects' tendencies to invoke examples from their present teaching situations or to elaborate on their broader life experiences as minorities in 
America today. I explored subjects' feelings about their first interviews and inquired as to whether or not they got across what they wanted to. I also shared the gist of some of the other informants' comments in order to foster the dialogic atmosphere I value.

By means of this interview process, I wanted to honor the ethics of inquiry called for by Collins (1989), Denzin and Lincoln (1994), hooks (1990), and Smith (1987) whereby concrete, lived experiences assume a central place in the content of the conversations and collaborative, caring, nonoppressive relationships develop between the researcher and the researched. Lincoln's (1992) admonitions as stated in her article, "I and Thou: Method, voice and roles in research with the silenced," are especially clear with regard to the prerequisites for open dialogue, She called for the establishment of a dialogic, power relationship between the researcher and the subject. Averaging one and a half hours each, the second round of interviews was also transcribed verbatim. Springing as it did from my hopeful plan that in-depth, multiple । interviews would yield rich qualitative data highlighting respondents' experiences and perceptions, this research design appeared as least quantitatively successful. Transcripts from the two rounds of seven interviews yielded 600 pages of data. 
Some process notes are relevant here. I always deferred to the subjects' preferences for meeting places and times. This required some flexibility: almost every interview was rescheduled at least once, often at the last minute. I often misinterpreted the scheduling difficulties as a hesitancy to participate. Upon our actual meeting, subjects would clarify that they were in fact cautiously eager to be interviewed. They reported having mixed feelings of uncertainty, especially with regard to talking about something so personal, and pride at being selected. overall, they all noted their desire to converse in a comfortable setting without the distractions of children, family, work, or impending commitments--a|setting personally familiar and safe. We met in their former graduate schools of education, their homes, my home, a public library, and a mutually agreed upon neutral location. Finally, after every single interview, the interviewees initiated some sort of personal, heartfelt thanks for the opportunity to talk punctuated with a hug, an extended handshake, a smile, and a reticence to finish the interview.

Collection of Additional

Empirical Materials

After the first interview and before/the second, the subjects were each given a spiral notebook in which to record their thoughts and feelings during! the interim. These personal logs were collected at the 
and served as a reference point for some of our

conversations at that time. In several instances, a recently experienced event served to concretize an idea previously discussed and helped to clarify the everyday subtleties of minority-majority relations. Sometimes such an event jogged a subject's memory of a prior school occurrence. In general, subjects reported that their desire to write was not commensurate with the actual amounts jotted down. Nonetheless, all seven expressed appreciation for the notebooks and the implied understanding that there would be more ideas and understandings to surface.

Three of the subjects voluntarily shared previously written papers as further evidence of their thinking. These included: lesson plans, reflective journals, and papers completed for academic course work in their teacher preparation programs. Five of the subjects allowed me to visit their classrooms and observe their teaching and interactions with children and colleagues. During these visits I was able to function as a participant observer and gather data that corroborated or contradicted the subjects' previous remarks. The accumulation of all of these additional empirical materials lent added authenticity to the study by providing a broader context within which to know the subjects. 
Data Analysis

Ethnographic methods were used to inductively analyze the empirical materials gathered in the research study. During the interview process itself, I listened for themes, concepts, and behaviors which seemed to stand out or recur. After all interviews were completed, I began a coding phase of analysis. At this point, interview transcripts were analyzed singly and collectively by searching for distinct conceptual categories which could be coded. Once a multitude of coding categories was identified from the texts, the categories themselves were reviewed to search for emergent themes and patterns. Periodic reflective steps backward helped to establish what seemed to be truly important. This constant comparative method enabled me to move from rough categories (e.g." choosing to speak) to higher order narrative elements (e.g., use of laughter after giving examples of unexpected boldness) and to uncover commonalities and disparities.

content analysis of the subjects' journals combined with their interview transcripts and surveys enabled me to triangulate within three different sources of the respondents' own words. This triangulation formed the basic core of data analysis. Additional data--notes about interview behavior, notes about phone calls, observations from classroom visits, and content analysis of academic papers shared--combined to enrich and deepen the emerging 
pictures of these successful people of color. The results of this analysis of empirical materials are found in chapter IV.

\section{Limitations}

The viability of obtaining an adequate sample size of survey respondents was of concern. Carter and Wilson's (1992) report of recent demographic data indicating low numbers of graduate students of color in predominantly white schools of education across the country foreshadowed the difficulty of obtaining access to potential study participants. My necessary reliance upon the cooperation of each institution to contact the subjects initially and the difficulty of sending follow up reminders contributed to the low numbers in the survey pool as did the institutions' overly optimistic estimates of students who had completed their programs.

Data obtained from public institutions differed with that from private ones. Disparities such as those found in amounts of financial assistance available, perceived status of the institution, and freedom to individualize for students may have subtly influenced the persistence and perspectives of students of color. Since the study relies to such a large extent on the subjects' own words, a more detached exploration of the possible effect of the institution's characteristics may elicit more information. 
Since subjects in this research recently completed teacher preparation programs, they worked at field placements in practica sites and public schools along with their completion of their course work at their chosen graduate schools of education. To demonstrate successful preparation, graduate students of education who seek state certification must teach in public schools. Thus, the teachers-to-be could conceivably have to navigate two predominantly white institutions, both the university and the public schools, where two opportunities for support or interference exist. Experiences at field sites may have been only peripherally relevant to the subjects' persistence; on the other hand, they may have directly affected students' successes. While care was taken to distinguish which experiences came under the aegis of the teacher preparation institution and which did not, this factor remains a complicating one for this study. I could not eliminate this confusion, I could only attempt to keep track of what was what.

Graduate level professional training demands an immediate career focus distinct from that required by undergraduate studies or the pursuit of advanced degrees. A teacher preparation program assumes such an immediate career focus, and a graduate program presupposes a track record of undergraduate success. What is discerned from people persisting in a graduate-level teacher preparation program 
may not be representative of, or generalizable to, other students of color who are studying other subjects or who are enrolled in other levels at predominantly white institutions. This is particularly relevant with regard to the perceived potential income of teachers compared to other professions. The rationale one or one's family accepts for incurring school debts and the ways that debt accumulation is mitigated by the profession's perceived status and projected salary very, are likely to influence persistence, yet they may be extremely difficult to measure or understand.

Initially I worried that subjects' positions within the public education system may have limited the degree to which they felt free to be candid and clear during interviews. since many institutions link graduate degree programs with teacher preparation, I was concerned that subjects still pursuing further graduate degrees through the institution which prepared them to teach might fear the consequences engendered by a loss of confidentiality or worry about reprisals if they had voiced negative comments about their experiences at their teacher preparation institutions. Naturally, preservation of confidentiality for survey respondents and interviewees was a must. After conducting the study, I now believe that while this situation should be carefully reviewed, it was not an issue for these subjects. In fact, I was far more concerned about confidentiality and 
possible negative repercussions than any of the interviewees. They wanted their stories told and told often: "It's time we started talking about this and got the issues out in the open," was their unanimous refrain. In fact, the study participants would like to meet each other and have proposed a dinner to celebrate the completion of the study and to enjoy their new found camaraderie with others of common ground. While the dinner plans are as yet indefinite, each of the seven interviewees has voiced plans to attend.

The study was conducted in the pacific Northwest in order to minimize transportation costs and maximize ease of contact with respondents and interviewees. The demographics of the Pacific Northwest region are unique to the rest of the United States and may have imposed some Iimitations on the study. In general, fewer people of color reside in the area and their proportion is small relative to the regional population as a whole. Due to these demographics, I explored the possible impact of this dynamic with the review group of people of color who assisted me in formulating my questions, some of whom had moved to the Pacific Northwest from other geographic regions with more diverse populations. Where possible, I also explored this dynamic in the interviews themselves by delving into the subject's family geagraphic history. 
In the Pacific Northwest, people holding some extremist views coexist alongside those with more liberal attitudes. In both rural and urban areas, white supremacist enclaves can be found amid more moderate communities. Communities of people of color, especially in urban and agricultural areas, create pockets of diversity within predominantly white populations. These demographic characteristics afford a rich context for studying the perspectives of people of color living in predominantly white environments. However, due to the demographics of the Pacific Northwest and the ways in which people learn to adapt to them, the findings of this study may not be applicable to people living in more diverse areas.

Throughout the study I remained cognizant of my own race, ethnicity, class, and gender and worried that my own background might prove detrimental to the candor I hoped for. It was certainly conceivable that participants would cautiously edit their responses. I intentionally chose methods to enhance trust and credibility: all correspondence, surveys, and interview questions were critiqued by a review group of men and women of color; a clear statement of the purpose of the research was presented to all participants and offered again whenever anyone asked why I was interested in this topic; and interviews were designed for dialogue, trust-building, and reflection. 
Finally, the level of reciprocity I engaged in with the interviewees was not as full and complete as it might have been. I did not return to the study participants the transcripts of their second interviews for verification. Since the first interviews were more extensive than I had originally envisioned and the second ones were primarily for the purpose of clarification and correction, I decided this adjustment would not adversely affect the study. I shared some of my observations but not my conclusions with the participants. While this leaves open the possibility of some misinterpretation of final comments, I believe this risk to be minimal. I plan to give a copy of my dissertation to each of the interviewees in my study. 
CHAPTER IV

DATA ANALYSIS

"All there is to thinking is seeing something noticeable which makes you see something you weren't noticing which makes you see something that isn't even visible" (Maclean, 1976, p. 92).

In this chapter I describe and analyze the wonderfully rich, reflective data I gathered in this study. I begin by introducing the respondents as they like to present themselves. Next I investigate a key concept in the literature reviewed and in the lives of the respondents, that of being an insider or an outsider, of belonging or not. Subsequently, I explain the ways in which I came to frame an understanding of the respondents' histories at predominantly white institutions through multiple readings of the data collected, the development of codes for narrative elements, the identification of broader conceptual categories, and ultimately the recognition of an emerging thematic pattern among the respondents. Lastly, I consider the respondents' reported opinions of, and experiences with, institutional recruitment and retention efforts in each one's teacher preparation program with an ear toward what each one believes actually made a significant difference. 
The interviews which are analyzed in this chapter stand as the centerpiece of my research study. From 14 taped and transcribed conversations, two interviews each with seven participants, I amassed 600 pages of the respondents' personal and professional chronicles. Using ethnographic methods to study the interviews, I was able to triangulate the interview data with two other sources of the respondents' own words: their surveys and their personal journals. To clarify or emphasize points made during the interviews, three of the respondents also shared papers and lessons they had previously written during their teacher preparation programs. In addition, I had the opportunity to gather empirical material through visits to five of the respondents' classrooms where they are now employed as teachers. As a participant observer in these public school settings, I could see the respondents' ideas translated into everyday interactions with students and colleagues, and I could catalogue the environment for learning which each teacher chose to create. Finally, I enjoyed the unexpected benefit of serendipitous conversations with some of their colleagues, administrators, and former professors in which these other education professionals volunteered comments about the respondents and their work. Combined, these empirical materials enabled me to develop a rich characterization of each respondent--how each one constructs a sense of self, reflects upon past and present experiences, 
and interprets the factors and events which led to his or her successful completion of a teacher education program at a predominantly white higher education institution.

Introducing the Cast: The characters Present Themselves

I believe that the significance of these people's stories lies in their descriptions of the everyday reality of minority-majority interaction which each one experiences. As the interviewees recount their experiences and respond to questions, the threads of their life stories knit together to form enlightening patterns of their individual and group identities.

To more fully appreciate each respondent's perspective and comments, in this section I profile each person interviewed. Since confidentiality was promised to all, I have changed names and masked identities enough to preclude anyone's real identification. However, I have tried to preserve the accuracy of each one's profile to the extent that the descriptive characteristics noted in this study match relevant interview comments. Collectively, the interviewees were selected from a substantial pool of minority students who completed graduate level teacher preparation programs at 10 predominantly white institutions in the Pacific Northwest since 1990. In sum, it is unlikely that anyone who participated in this study could be 
accurately identified; it is more likely that someone might be misidentified.

Each person interviewed was given the opportunity to explain his or her rationale for reporting race and ethnicity as it had been done on the survey, and then each one was asked to provide a synopsis of family history and significant life events until entry into a teacher preparation program. A distinctive note in each interview was the way in which each person chose to construct and present his or her racial and ethnic identity. In the introduction of the study's cast of characters which directly follows, I attempt to honor the respondents' careful, thoughtful selection of detail used to present themselves.

Joe

of mixed Caucasian and Native American racial background, Joe considers his ethnicity to be a blend of Northern European and Mohawk Indian. Joe's relatively new found curiosity about his heritage stems from his exposure to Native American people and culture encountered once he transferred to a large, urban, state university for his undergraduate studies. Learning about his heritage later in life and from non-family members is a situation he finds "ironic."

Joe's education about his Native American background continued during his teacher preparation at a smaller, 
rural, public university with a reputation for excellence and innovation. However, he experienced considerable frustration with other "middle class whites with a fraction of Native American blood who tried to act Indian," so he tended to shy away from the cultural student groups and events he had found supportive during his undergraduate years. Even now, Joe prefers that his study of his heritage remain a private journey.

Prior to his college study, Joe had only a vague acquaintance with his mother's Mohawk history and some knowledge that his grandfather was an elected tribal leader, because his family did not talk openly about his mother's heritage. Despite his grandfather's respected position in the tribe, the promise of good wages as a high steel worker had pulled him to the city long ago and his grandmother "really carried that 'leave it behind you' attitude toward the reservation." According to Joe, his grandmother "wanted to be a middle class American of no particular ethnicity, which is typical of people of their generation. She spoke very, very little Mohawk." His mother also "wanted to be American" and never talked of her past. In fact, if people misconstrued her ethnicity and assumed she was Italian or Jewish or Middle Eastern, she did not correct them. Conflicts over her choice of husband and his drinking damaged her relationships with her family. Joe's mother moved to New York city to dance and "hooked up with a jazz 
musician [Joe's father] whom she never married because she never divorced her first husband," although they have been together for 36 years and raised four children.

Joe believes his father's vocation, jazz musician, and the culture that surrounds it define their family life far more than his father's European ancestry or his mother's Hohawk heritage. He characterizes his family as lower working class, at times quite poor due to a downward spiral resulting from his parents' gambling problems during his middle and high school years. Neither parent graduated from college, although his father attended music school of $f$ and on and was reportedly very talented. Overall, Joe feels "like I'm American, since I was raised in this country . . . and [I'm] working class."

In his iate 205 and newly married, Joe is beginning his own family. He is in the midst of figuring out who he is and where his heritage fits in the explanation of his identity. More than anyone else interviewed, Joe is interested in uncovering the nature of his family background, in deciding what to be proud of and what to minimize or down play. The first in his family to graduate from college and to become a professional (teacher), Joe describes an increasing sense of responsibility to know himself, honor his heritage, convey pride to his children, and mentor his students. The more he discovers aspects of his personality which he can now identify as Mohawk, the 
more he wonders what being an American means and if he needs to choose one ancestry over another or if he can be both.

Ada

Ada is an Asian-American of both Japanese and Chinese ethnicity. When her fourth generation Chinese-American father married her fourth generation Japanese-American mother, the union caused a great deal of consternation on both sides of the family, but they have since "worked it out." Ada sees herself as very much "mainstreamed into the culture," and she distinguishes her family's ethnic traditions as less traditional than most Asian families. "I kind of feel like we hold onto the symbols more than the culture . . . it's hard to explain."

Because Ada looks more Japanese and people often assume that she's Japanese, Ada identifies more closely with that strain of her heritage. Like Joe, Ada learned much about her heritage in college, particularly when she was required to write a cultural background paper: "When I was doing my reading, a lot of the cultural things came out, you know, like the Japanese were the quiet Americans and they really have a sense of respect for their elders." Also in her late 20s, Ada is in the process of figuring out who she is: she reports that she often compares herself to generalizations she hears about Asian-Americans, women, and teachers and she especially identifies with contemporary women's' issues. 
Ada attended a large, urban, state university for her undergraduate studies--a school known to serve a large Asian population and to be sensitive to the widely diverse cultures encompassed within the Asian category. She reports that she felt very much "at home" in her classes and was often in the company of other Asian-American students. For ner teacher education program, Ada switched to a different large, urban, public university in another state. At this university's graduate school of education, the student population seemed "very homogeneous and White" to Ada, although the university as a whole is recognized regionally for its students' racial and ethnic diversity. Ada's family places a high value on education. Both of her parents and even her grandparents graduated from college; both of her parents pursued professional careers in the sciences. According to Ada, it was a given that she would go to college; the only surprise was that she chose teaching over a more lucrative career. She sums up her family's values as: "you know, you respect your elders and you don't talk back, and you work hard, go to school, go to college." While Ada values her ethnic heritage and is reminded of it daily because she obviously looks Asian, inside she feels "just totally mainstream American."

$\underline{\text { Sam }}$

Raised in China, Sam immigrated from Asia over 25 years ago. He views his immigration to the U.S. With pride: "I 
was not a refugee, I was not one to immigrate over here because my relatives are here. No! I came here as a Lone Ranger with $\$ 2,000$ in my pocket, and that was it!" No one in his family had previously attended a college before sam left Hong Kong and traveled, alone and with very little money, to America in search of opportunity and advancement. After graduating from a small, Christian, liberal arts college in the Midwest, sam chose to remain in the United states. While pursuing a career in business, he lived in various locations throughout the U.S., finally settling in the Pacific Northwest. Now married and the father of two children, Sam "feels very American" yet he notices that his children are "even more mainstream" than he. A man who has come to teaching later in life, sam is profoundly aware of his age as compared to other new teachers; he associates both his wisdom and his inflexibility with the fact that he is nearing the age of 50. Sam understands both chinese and English, but he speaks English with a strong accent. His difficulty with English articulation generates mixed feelings for him: he is proud of his bilingual accomplishment, apologetic for his faulted speech, and angry at the discrimination he believes his less-than-perfect English has caused. Sam left China long ago to become an American by choice, yet he finds as he moves through middle age that he feels increasingly drawn to "Chinese values" he minimized in his youth, particularly those for "quiet 
reflection, an appreciation of a broad life circle, and sincere friendship."

Sam lives on the edge of a large metropolitan area and selected a teacher education program which was geographically convenient. His work and family commitments necessitated such a choice. The warmth and common religious values espoused by the small, private, suburban university were compelling reasons for sam to choose to attend its teacher preparation program. Although most of the other minorities in the program appeared to be of Asian heritage, that fact was not initially significant for the "Lone Ranger." He knew he could "make it anywhere."

\section{Maria}

Although Maria describes her race as "white and Black mixed" and her ethnicity as Hispanic, she feels her true heritage is puerto Rican. According to Maria, in the Pacific Northwest such a distinction is less understandable, but "back in New York city where I'm from it makes sense."

Maria goes on to explain:

I think it's very common for people in Puerto Rico that are Black to marry White. They always talk about, if you're too dark, you need to marry somebody lighter! or they say, "you're too light, you need to marry somebody darker!" . . they make jokes about that, it's acceptable to say it - . . here people don't appreciate it. I guess I always knew I was puerto Rican, but like my birth certificate, on it, it says "white." So I think that's interesting. I mean, I didn't make that decision, the people in the hospital wrote that in for race which is funny because my father's not white. . . It's funny 'cause I've 
been at clinics where they write on it for race, Black, and I don't say anything.

Her father who is Black and her mother who is white immigrated to the U.S. When Maria was very young. Neither of her parents had ever finished high school, and both toiled very long and hard hours at their New York factory jobs in order to provide for the family. Maria grew up in a neighborhood where many of her teenage girl friends lived out a stereotype by getting pregnant, dropping out of school, and getting married or going on welfare. Maria was determined to please her parents and herself by completing high school and getting a decent clerical job: she achieved her goal. The stereotype of the poor Hispanic woman is a painful one for Maria to consider, and it is very important to her that she is seen as distinctly different from such a stereotype.

After marrying, having two children, and divorcing, Maria diligently worked and went to urban community colleges in New York and then in the Northwest. Over a period of 15 years, she made incremental yet steady progress toward her goals of a college degree and teaching certificate. She notes with pride that she is the first person, male or female, in her family who has earned a college degree. Now in her late 30 s and remarried, Maria continues to balance school, work, and family--and when a choice must be made, family always comes first. When it came to choosing a teacher education program, Maria chose a convenient and 
affordable public university close to the city neighborhood she calls home.

When looking at Maria, it is difficult to guess her heritage. She reports that people often assume she is Italian, Indian, Greek, or Middle Eastern. Sometimes she corrects them; sometimes she lets it go. What Maria does find "interesting" is the "different way people treat her depending upon their assumptions" regarding her ethnic and racial identity.

Malaika

Malaika's ethnicity, African/Caribbean/American, is very important to her senselof self. | She considers herself Black, and she is quick to draw distinctions between what she identifies as the American Black'experience and her own experiences as a Caribbean immigrant. For this reason, Malaika's mixed accent with flavors of the British west Indies is one she comfortably retains.

Malaika is a single mother in her mid-30s who has been independent her whole life and on her own since she immigrated to New York City'about 15 years ago. Her mother is from saint vincent, and her dad is from Barbados. They met and married in Trinidad, but went: separate ways after their children were of school age. Malaika's father had attended college and worked at what was considered a locally prestigious position as a policeman and driver for the governor. Her mother, forced earlier in her teenage years 
to leave high school to support her brothers and sisters, established her own business and sold food from a stand to support herself and her children once Malaika's father left. Malaika identifies closely with her mother and believes they share a dogged determination to succeed despite difficult conditions.

Malaika scrimped and saved throughout her undergraduate education at a public New York City school; she creatively "took advantage of every opportunity and made things happen when they needed to happen." Once she and her children had moved to the Northwest, Malaika chose another public urban school for her teacher preparation. Her decision was a pragmatic one: the school had work-study opportunities, a support system for minorities, and a convenient location close to her children.

\section{$\underline{\text { Susan }}$}

Susan identifies her race as African American, and she elaborates upon her identity by describing her ethnicity as Native American, Caucasian, and African American. Explaining this mixed heritage is important to susan; she has only recently been able to do so:

My parents tell me about the mix, and I keep threatening to write it down one day, but it's been hammered in my head, you know, by listening to my parents who were born just a jump from slavery. And their grandparents and ancestors were. There was a lot of intermarriage between African-Americans and Native American people in the south. And plantation owners, you know, who would interbreed with their slave women, and that 


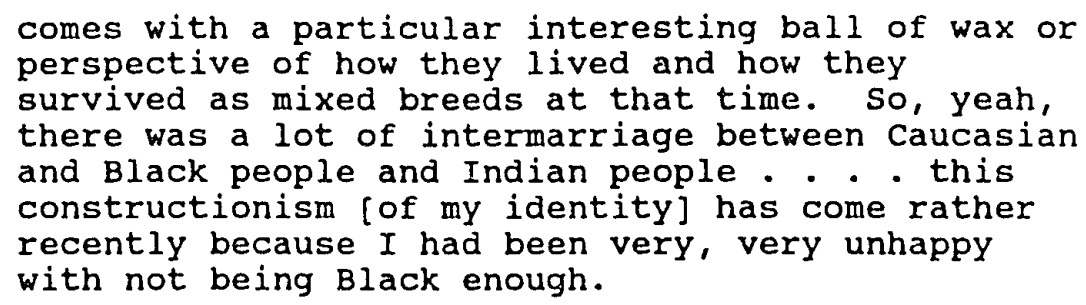

A single woman in her mid-40s, susan went through a career change and extended period of self-reflection prior to entering a teacher preparation program. During this period her parents were quite frustrated with her personal searching and questioning. Neither parent had graduated from college (her father attended trade school to become a draftsman; her mother is a seamstress), and they wanted their daughter to "just get a job." Susan persisted in her quest despite what she perceived as "intense interference and lack of understanding at home" and now she feels proud of who she is and what she is doing.

Susan's undergraduate experiences are varied: she attended private, liberal arts and fine arts schools in the Northwest and the Northeast. When it came to choosing a teacher education program, susan looked for a school with a good reputation and a commitment to urban community problems. She also needed to cut costs by living at home again with her parents in the city. She remains satisfied with the local private university she chose to attend. 
Jonathan

Jonathan describes himself as a young, Afro-American, male elementary teacher who is very aware of "beating the odds and defying the stereotypes that I have to face daily." On his survey, he left "ethnicity" blank because after much thought he felt he was simply American. Fluent in Spanish as well as English, Jonathan learned a second language "to communicate well in this changing culture and because it was required in school, not because I'm Hispanic or anything." Jonathan believes that it is his birthright to choose different ways to describe himself (e.g., Afro-American, African-American, Black), but he also expresses some confusion about which choice to make:

I don't know what I consider myself, to be honest. I wrote Afro-American. If there's a survey that says African-American, I'll circle that. I don't really use the term African-American simply because I've never been to Africa. I realize that I am a descendant, you kinow, historically, but my older sister married an African, a Nigerian. They have two children, so their children are AfricanAmerican by birth. So, to me, it makes it real hard for me to be African-American. Sometimes I can use Afro-American at the beginning of a speech and then [switch] to Black at the end. I don't understand why we have all the different names. And I guess that's kind of strange, to be coming from me, saying that. But I generally go with whatever's politically correct.

Jonathan also finds other ways to name and describe himself. He likes to be the one who controls his description. Once, when reading the newspaper, he came across the term

"intercooled" in an ad. Believing that "intercooled" perfectly describes his talent for remaining calm and moving 
between different White and Black cultures, he has since I adopted the word for his own.

A single man in his mid-20s, Jonathan notices his youth more than any other characteristic. He "hung out" with । other youthful students in his teacher education program land he stands out as one of the youngest members of the faculty at the elementary school where he now teaches. Jonathan attended the same private university for both his undergraduate and graduate education. The urban/suburban school actively recruited him from his suburban high school. The extra effort the school personnel put forth on Jonathan's behalf made a big difference to him and he । remains loyal to the program and its mission of community service.

Jonathan is the first person in his family to graduate from college. His father is retired from a successful : military career which afforded many travel opportunities for his family. They lived abroad in several international locations and his mother often found employment near a military base. Jonathan's family places a strong value on hard work, discipline, and education; Jonathan enthusiastically shares those values.

\section{presentation of Self}

When given the opportunity to present themselves at ithe beginning of the interviews, the participants appeared to carefully select which pieces of information they deemed । 
relevant to truly convey who they are. of particular note is the frequency with which they mentioned having struggled with who they are and how they fit into mainstream American culture. Nothing regarding such a fit had come easily or automatically. Differing parental ancestries, social class, physical appearance vis-a-vis the European-American look, queries of others (e.g., where are you from?), and personal doubts combined to complicate the questions: Who am I? Am I an American? In whose eyes? Do I really belong? Or am I an outsider-within? Perhaps not surprisingly then, a common occurrence during the interviews was the appreciation expressed for the opportunity to define oneself rather than to be defined by others' assumptions and stereotypes and to explain what it is like to grapple with whether or not one is a legitimate member of the culture.

\section{Belonging: An Analysis of the Inside-Outside Concept}

Questions of belonging, of being an insider or an outsider or an outsider-within, arise often in both academic and popular literature addressing issues of minoritymajority relations (Collins, 1992; Morrison, 1993). In a recent interview, writer Michael Dorris who is of French, Modoc Indian and Irish ancestry, related a typical description of feelings which stem from living a life on the margins of mainstream American culture (Aronson, 1995): 


\begin{abstract}
It makes you marginal . . not being a fill
insider in anything, being of mixed blood, makes you watch very acutely to find out how insiders behave. And then you try to understand the behavior. It's like being a foreigner in an odd kind of way, and it's very schizophrenic and painful for a child. You're always looking the wrong way or thinking the wrong way, or you're standing there listening to a group of people telling a joke in which half of your relatives are the butt, and you don't know whether to say anything or not . . . but as for helping you, if you survive the growing up experience intact, it's very useful. (pp. 11-12)
\end{abstract}

After referencing my literature review and analyzing all of my empirical materials, I concluded that the concept of belonging is a pivotal one in the life of a minority who is operating in the world of the dominant culture. It is a primary contextual key unlocking an understanding of the respondents' lives. The importance of the insideoutside/standpoint/fault line construct which/surfaced in this research is congruent with the feminist and ethnic theorists' beliefs about essential elements to grasp if one is to understand the hegemony of the dominant culture.

since the insider-outsider concept received such a high degree of attention in the theoretical literature, I chose to address it forthrightly in the interviews. However, since the concept is so relevant to the respondents' lives, I found that it could not be avoided: it surficed before I mentioned it and arose repeatedly throughout both the first and second interviews. By speaking to the inside-outside concept in a wide variety of ways (usually more indirectly than directly) the respondents often revealed its personal significance for them. Their understanding of the dynamics 
implied in this concept, the impact it had upon them, and their coping responses to it appeared to influence their personal serenity and the degree to which they succeeded in the dominant culture.

Perhaps not surprisingly then, this concept was mentioned very early in the conversations of four of the respondents. Without any prompting from me, they spoke about the ideas of inside, outside, belonging, and their standpoint versus that of the mainstream culture as they sought to make a point, sometimes using those exact words. Whether or not the terms had been mentioned by the respondent, during all seven first-round interviews I drew a diagram and asked each person to indicate with an $\mathrm{X}$ where s/he would place herself/himself on a drawing like the one pictured as Figure 3. In every case, before I had finished speaking the respondent nodded in recognition, commented and started elaborating on the meaning of the location of their $X$ marks. Clearly, this appeared to be an easy concept to grasp. The respondents themselves then proceeded to clarify differences between their perceived locations as children or in their teacher preparation program or in their communityat-large or in the school where they now teach. As they did so, I inquired about their marked locations on the diagram: Could you tell me about this place? What does it feel like? What do you and others say and do when you are here? What are the clues for you that let you know you are here and not over here? 


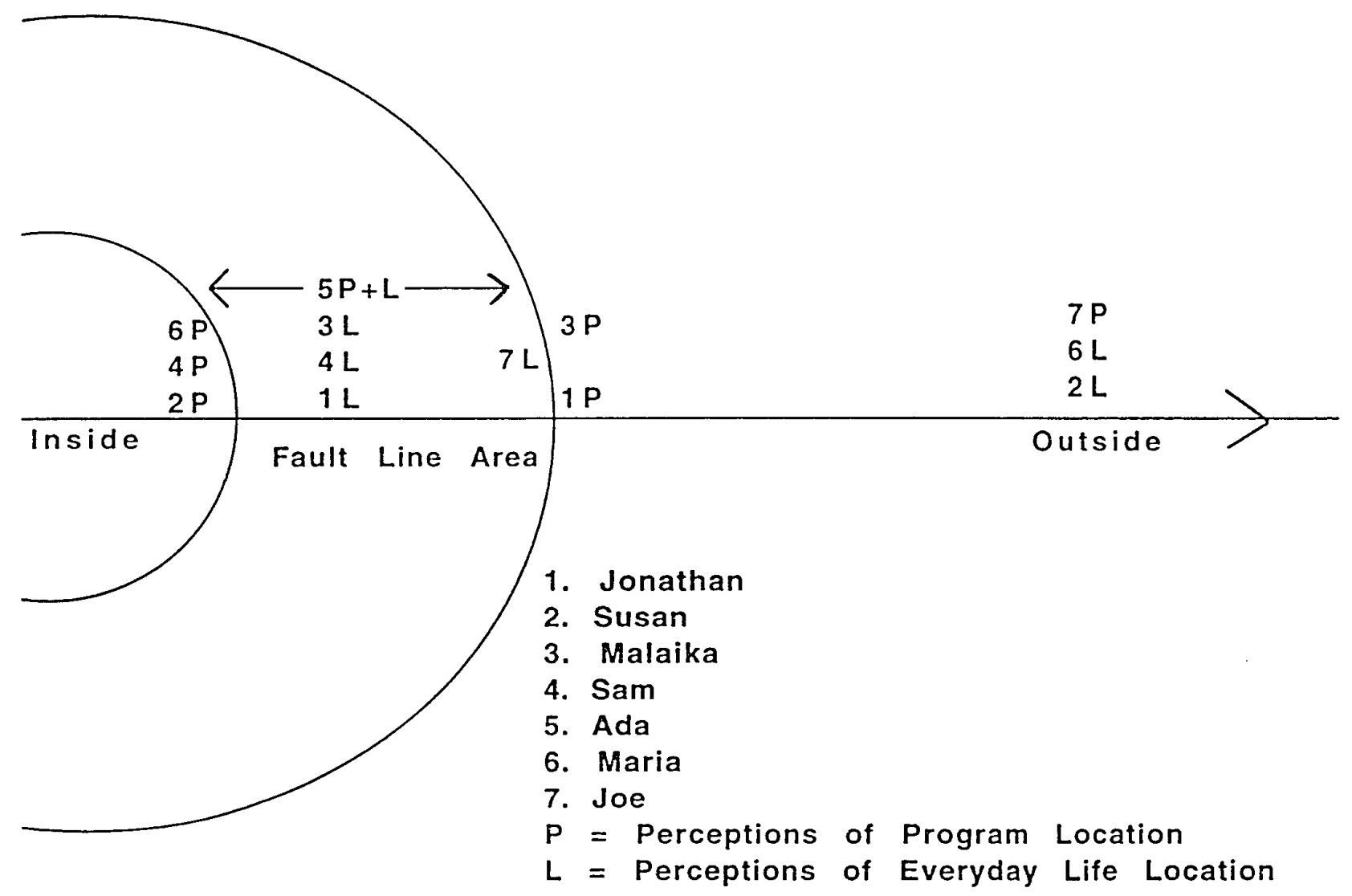

Elqure 3. Interviewees' self-reports of location on inside-outside diagram. 
Throughout the first and second interviews, the respondents commented on their senses of belonging. It appeared to prompt subsequent reflection and insight and more than one person noted that the diagraming and discussion about it gave them a chance to make sense of something they often felt but did not speak about. Interestingly, my mention of the concept served to enhance significantly my credibility with the respondents. The dialogue which ensued from the inside-outside diagramming set the stage for the rest of the interview. Generally at this juncture the tone relaxed more and from this point forward the interviewees volunteered so much information that they often anticipated and answered the other questions I had outlined before I had a chance to ask them.

\section{Being outside}

Neither Maria nor Joe looks like an easily identifiable minority; both report they readily blend into a majority group and, at least on the surface, look like they belong. However, that is not necessarily how they feel internally. Economic disparities seemed to set them apart during their earlier days and weighed upon their confidence. Maria found the inside-outside diagram particularly:

interesting because I spent a lot of my life thinking that I was outside of mainstream, like I didn't fit in with other people... . knowing that my parents didn't have a lot of money, and in growing up I went to school with kids that did, or 
had these big vacations and stuff--I always felt outside.

Joe also cites class differences as the basis for his

outsider feelings:

I decided to become this professional person called a public school teacher. And that was something. . . I just felt like I was out of my league, I felt like I was in above my head. I felt like it just wasn't me.

In contrast to Maria and Joe, Sam's Asian heritage cannot be hidden: visually and linguistically he is clearly Chinese. He believes society "views you on how you look and society doesn't accept me that way." During his 20s, Sam spent several years in a small midwestern college town where he was the only Asian and he fondly reminisces about that time:

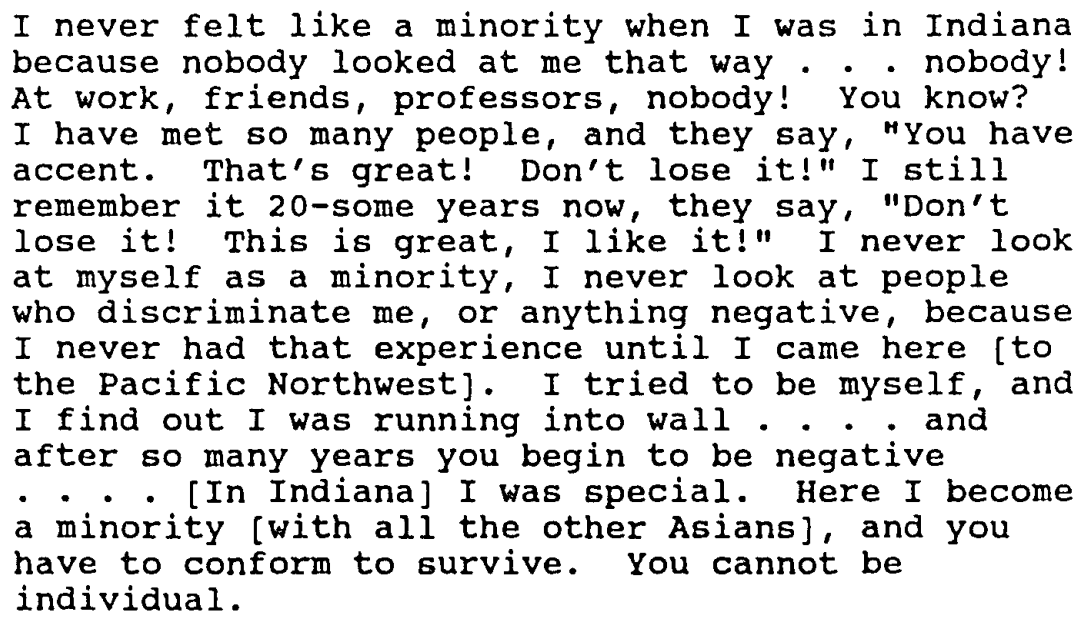

When Sam lived in Indiana he was the only Asian, and he believes this gave him a special status almost like a visiting dignitary. People felt privileged to know him and to have the opportunity to be exposed to a person from 
another culture. Although of different ancestry, he felt included in the community. Once sam moved west and joined the ranks of the Asian-American minority, he felt "less than ordinary because there are so many of us and my beautiful accent became problem."

Even though Ada grew up in the U.S. and has always felt very American, she echoes Sam's stories to a certain extent. She speaks English clearly and articulately, yet her facial features definitely appear to be Japanese, and Ada openly wonders what assumptions members of the majority make when her physical characteristics make it obvious she is not of European-American ancestry. A fifth generation AsianAmerican, Ada relates how "thoughtless, silly" questions from strangers can erode her self-confidence. At least weekly, and sometimes daily, she is asked questions like: "Where are you from? [and after her answer, 'San Francisco'] No really, where are you from? Do you speak English? Gee, you speak English pretty good for a foreigner." Although Ada feels "totally American" and identifies closer with American women today than with Asian-Americans, comments like the former are unsettling to her. Most of the time she ignores them, but occasionally they give her pause to doubt herself and how credible she is to others.

Another visually obvious minority member because of her very dark skin, Malaika reports an interesting insight visa-vis belonging and acceptance for Blacks in America. She 
likes to present herself as an outsider: if her Caribbean British accent does not reveal her heritage to others, Malaika is quick to volunteer an explanation of her Trinidad background. Like Sam's experience with the people in Indiana, Americans of the dominant culture seem to accept her more once she has made it clear that she is an outsider. She finds that people compliment her on her success and then openly wonder how she could prosper here when other Blacks do not. She explains: "I'm more likable by the majority than a Black American. I don't know why. People in the U.S. [of the dominant culture] get closer to me than a Black American."

While they note that being an outsider can have its usefulness, in general the respondents describe the outside as less comfortable. "You are not where you belong," appears to be an equally strong and disabling message whether self-imposed or conveyed by others.

\section{Being Inside}

Being inside can feel good. Relaxing. Safe. Familiar. Equal. When the respondents are inside, they report feeling accepted for themselves, respected as peers, and heard as legitimate members. They do not have to apologize or counter expectations that they are rot where they belong. They can let down their guard and stop scanning the environment for safety. Like the inperfect, much battered toy in The Velveteen Rabbit (Williams, 1983), 
they believe they have become "real" to others and that they

are part of the family.

Maria's descriptions sum up what many other respondents mentioned:

My parents' goal that we would graduate from high school . . they thought that would make me part of society or fit in, whereas they didn't feel like they fit in. And I realized, graduating from high school, I still wasn't inside. And the jobs I had, like I was a secretary or clerical, I was helping or bringing the coffee for the people that were going to have the meeting or the people that were talking and the people that were making the decisions, and I was somebody that needed permission for everything and. . . you know, nothing I had to say, I felt, was important to anyone. Or if I had opinions, people would think, "Well, who's she?" so this in and out idea, this is why I think this is a really interesting question because I haven't discussed this with a soul but I've been finding myself, like, looking around and thinking, "Wow, I'm in here!" [now that I'm a certified teacher]. And I remember for so long feeling like that's never been me. This is interesting that you asked that, as if you knew that there are people who feel that way. At [university], I think after getting my bachelor's, I started feeling like I was "in"..... . for so much of my life I felt like I was outside, and sometimes I'm at a meeting . . or I'm saying something, and then I look around at all the people that I'm with, and I'm saying, "My God, these people are listening to me!". . . like I'm a part of them! And that feels really interesting. That feels different. And it's like I'm waking up and finding myself inside, almost. And for a long time, I never had.

\section{Walking the Fault Line}

Some respondents take pride in their ability to move between the inside and the outside according to their preference at the time. As Ada remarks: 
I'll never quite be on the inside, but I generally don't think about myself as being on the outside. I know that I'm not quite on the inside, but I don't want to be anyway. The people on the inside don't really know what it's like to be on the outside. But I know that it's।like to be on both sides, so I can, from my standpoint, I can kind of move back and forth. Sometimes I choose to be here [inside], sometimes I choose to be out here. Sometimes it just happens to be that I'm outside. so sometimes I feel like I'm above, and I see things that are happening, and I don't have to be involved in those kinds of sturf.

Ada goes on to give an example from /her personal life that

highlights as an asset her confidence in her ability to

negotiate multiple worlds:

I enjoy it [being able to know different worlds].

I feel real comfortable going downtown to

Chinatown, whereas my boyfriend who's Caucasian

has probably been down there maybe twice in his life and that's with me. And $I$ just feel real comfortable going down there. I know what things are and go in a restaurant and know what to order. He just kind of tags along and says, "I'll do whatever you say." But then if I want to go to, say, an art museum, I'm educated in that and I know what I'm looking at. I can appreciate what I see and it seems like I can adjust and whoever I meet I can relate to them at any level--small children or adults. I had to learn that at a young age, I did.

Jonathan opted to draw his own inside-outside diagram,

a Venn diagram schema which emphasizes his facility with

moving into and out of different worlds and specifically

focuses on an area of overlap akin to a fault line (see

Figure 4). Like Ada, he frames his|location positively:

This is a very cool place to be if you're me. Because what you have is, you know, the Black community, I suppose, and then you have mainstream America which may or may not include these [Black] people. And I sort of have the freedom to walk in and out of both of those worlds at my choice. 


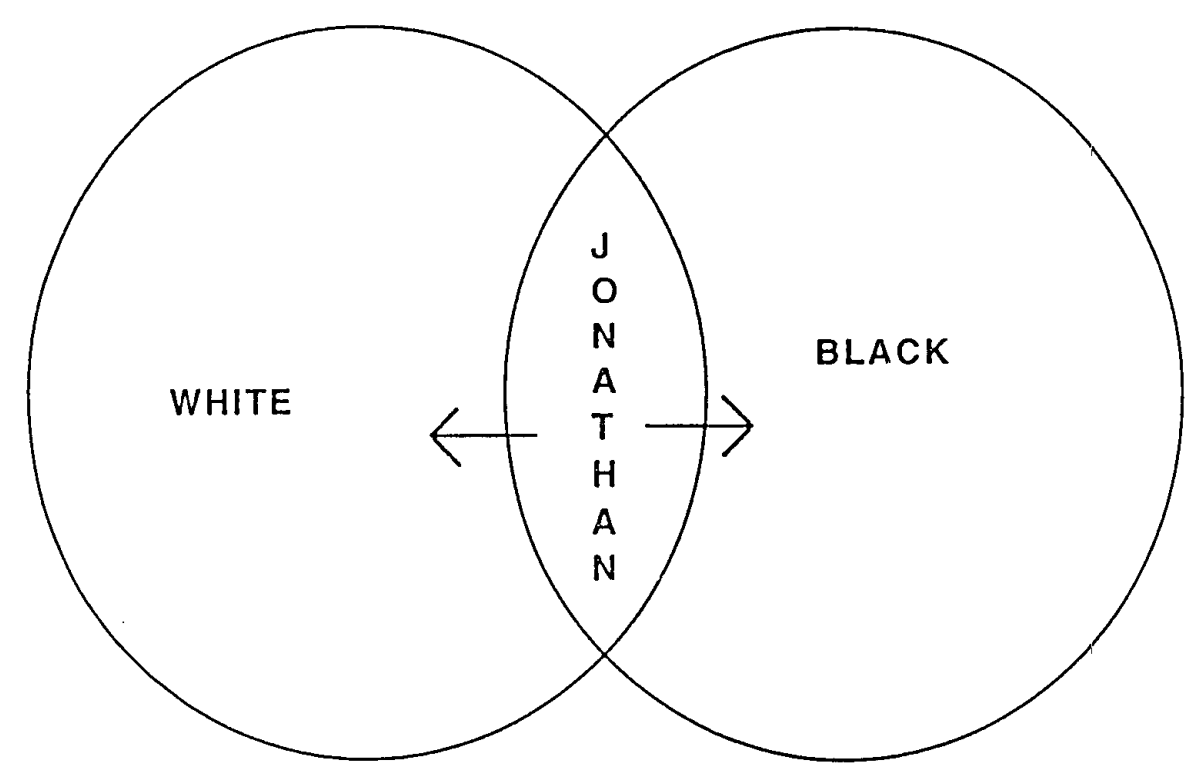

Figure 4. Jonathan's inside-outside diagram.

On the other hand, a sense of belonging can be almost ephemeral for some of the respondents. One abiding story among the interviewees is that of being brought up short by a reminder that they are not really full members, a reminder that invariably arrives just when they have been lulled into a comfortable belief that their membership is finally without question.

In her second interview, Maria tells about an experience she had as a faculty representative from her school. She had been looking at the school "with rose colored glasses" and believed the entire faculty shared her enthusiasm for multicultural education and school reform. Then, she found herself sent to a district-wide bias 
awareness meeting for administrators where she realized she had been selected because she was the only teacher of color on her faculty and would make her school "look good." Initially, Maria felt pride stemming from her belief that the principal had sent her to the meeting because he respected her professionally and shared her concerns: She belonged. Once at the meeting, she was devastated to realize she had been sent as a "thing. . a minority teacher thing." What particularly hurt was her recognition that "nothing was going to change" because she was not empowered to return to her school and provide the necessary leadership to improve the faculty's bias awareness. She was at the meeting to make her school look good, not to do anything further with what she might learn at the meeting. Once again, she was outside. This was particularly difficult for Maria to reconcile and first she was filled with self doubt and blame: "I feel like I was tagged for who I am rather than for what I was doing . . and that's kind of sad. . they used me. . and I don't know what I did to cause that." During her lifetime, Maria has learned to "ignore my own [perspective] and look at [it] as the more ignorant one because it's not the one that's being taught by the people in charge, and I've had to adopt the dominant culture in order to succeed." She is gaining confidence in the legitimacy of her own perspective and finds she is speaking out more, she is beginning to believe her ability 
to appreciate multiple perspectives is an asset, and yet experiences like the bias meeting "knock me back in my old place." Walking the fault line is not easy; for these respondents, there may be rewards but you can never relax.

The inside-outside concept was one I thought would neatly apply to the respondents' experiences in predominantly white institutions. What I did not expect was the ubiquity of the notion. For the minorities I interviewed, belonging is a daily issue in some form. It can raise questions, present challenges, convey messages of competence or incompetence, be a source of pride or embarrassment or curiosity. Their experiences in teacher preparation programs were microcosms of their daily lives. separating a program experience from the rest of life seems much easier for a member of the dominant culture to consider; for the respondents, a program story connected with one from childhood to one in their current teaching assignment. Being a minority within contemporary American culture means living the question of belonging or not in its myriad iterations.

The Emergence of a Profile of Resiliency

As noted previously, the question of belonging is a preeminent one in the lives of the respondents, as ubiquitous as the air they breathe. Consider the air: an essential element which despite its necessity for a person's 
good health, is not always healthful. It can sicken or invigorate. Its danger can be obviously foretold by an acrid, burning taste and smell or insidiously hidden like a colorless, odorless gas. Furthermore, the humans who must breathe it to survive can be physically fit with heart and lungs able to efficiently intake oxygen, or they can be debilitated to such an extent that they cannot avail themselves of the resource although it is obtainable. The categories which emerged from the coding and analysis of the data reveal a wealth of skills and attitudes which enable these particular humans to inhale freely from the air of the dominant culture and to filter both its subtle and obvious pollutants which are injurious to their health. Thus, the categories overall reflect the respondents' personal reactions to, and compensations for, their lives lived as minorities within a dominant culture.

\section{Developing Categories}

The process I followed for data analysis was one of constant comparison. After multiple readings of the interview transcripts and review of other empirical materials, I analyzed the data by searching for distinct conceptual categories which could be coded. Once a multitude of coding categories was identified from the texts, the categories themselves were reviewed to search for emergent themes and patterns. Periodic reflective steps backward helped to establish what seemed to be truly 
important. This constant comparative method enabled me to move from rough categories (e.g., choosing to speak) to higher order narrative elements (e.g., use of laughter after giving examples of unexpected boldness) and to uncover commonalities and disparities.

summarily, four main categories served to divide and organize the codes. Their evolution can be briefly described as follows:

1. Identity. This category includes codes attributable to a construction of self and maintenance of self-esteem. It is a strong theme running throughout the interviews and personal writings of the respondents. It reflects a synthesis of codes like: I try to be me; who I am; naming myself; it's not about me; that surprises people; moving back and forth; my life was different.

2. Interpersonal Interactions. Communication skills and attitudes are central to this category. They are evident in codes like: voice, choosing to speak, talking and not talking, silence, keeping silent, being silenced, permission to speak, cash language, bilingual, understanding, and not being understood. other interpersonal elements closely linked to communication also appear here, especially empathy and sense of humor.

3. Survival. This category involves strategies for success and could easily be renamed problem-solving skills and attitudes. It is entitled "survival" due to the urgency 
associated with its information. Some representative codes which led to this category include: do what you need to do, taking their point of view, I can see it their way too, one class at a time, laughter (after unstereotypic boldness), laughter (after painful reminders), being positive, what I can do, prioritizing, pick your battles, and I never quit.

4. A Higher Calling. Another strong emergent category, this one speaks to the ways in which the interviewees find meaning in their lives and derive a sense of purpose from their efforts. This is their "why" as opposed to the previously described category's "what." In this category, several strands twisted together as references to goals, expectations, realistic optimism, persistence, and dreams wove in and out of the conversations. Representative codes for this category are: for kids to succeed, role model, expecting the best, Quit? No! Never!, and why I teach.

An Emergent Thematic Pattern: Resiliency

After stepping back from my decisions about the categories just delineated, I did some reflective writing and personal questioning. A sense of familiarity rang through the data, but I could not place it. I found myself unintentionally remembering former students from earlier teaching days: teens in drug rehabilitation, a Job Corps youth who turned his life around despite long odds, a 
teenage mother labeled at-risk who graduated from high school much to others' surprise. Something in the data was triggering connections with prior conversations I had had with students who had also survived, succeeded, been resilient.

Resilient: the concept of resiliency seemed an overarching one. A further library search produced some enlightening literature relevant to the concept and to the interview data, specifically Benard's (1991) profile of the resilient child. Her research explores the phenomenon found in studies of human development where some youth are able to survive high-risk situations of severe stress and adversity and go on to lead healthy, competent lives. Instead of a negative focus, Benard and a host of other researchers cited in her studies examine the seemingly protective and empowering factors which somehow allow people in high risk situations to change or work around life stressors. The resiliency profile Benard outlines bears a striking similarity to the categories I had previously determined in the data analysis. Where I had discovered Identity, Benard names Autonomy; for my Interpersonal Interactions, her Social Competence; for my Survival, her Problem-solving Skills; and for my A Higher Calling, her sense of Purpose and Future. The alignment seems exceedingly close, so much so that I used Bernard's markers for the profile of a 
resilient person as an organizing template by which to study much of the interview data.

After analyzing all interview data, I determined that each of the seven interviewees evidenced examples for each of the four categories of a resilient person's profile. I found such alignment remarkable. By applying the resiliency template to the data, I believe a pattern emerges which appears to clarify why the minority interviewees are able to satisfactorily answer their questions of belonging, negotiate their lives on a fault line, and succeed in a predominantly white institutional environment.

In the following sections I offer highlights from the data which typify the manifestations of resiliency profiles in the respondents' everyday lives. I have laid the resiliency template over the four major thematic strands which emerged from my data analysis and I employ the resiliency terms as organizing concepts.

\section{Autonomy}

Each respondent possesses a strong sense of identity which is linked to a surprising commonality of experience running throughout each person's story--a common thread not at all readily apparent from the survey data or easily deducible from a quick biographical sketch. During each person's childhood or youth, the interviewees experienced life in another culture where they either enjoyed a positive 
sense of belonging or learned that they could succeed as an outsider-within.

Jonathan spent his teenage years on a U.S. military

base in Germany. His African-American heritage did not determine his minority status there, because that characteristic "just didn't matter." He was a "good । minority;" he was an American abroad who was helping to protect Europe. Not until he returned to the states in his later teen years did Jonathan confront the negative stereotypes associated with Black males in the U.S. Although he remembers many angry, resentful times then land now resulting from the pressures of such negative expectations, somehow his previously positive minority experience wins out. Jonathan constructs his sense of identity from the "me" he knew and liked in Germany, the positive protector rather than the downtrodden, angry young Black man frequently represented in the media.

Ada also lived overseas during her youth. In fact, she lived in several countries and geographic regions of the U.S. where she attended a variety of types of schools ranging from an Australian one-room, farm school to a sophisticated Los Angeles academy. Ada uses her first hand knowledge of the world's diversity to temper the sting of the questions she often fields as to her place of oxigin, questions arising from her Asian appearance. It allows her to excuse the behavior of those who ask "ignorant, Euro- 
centered questions": they just do not know any better because they have not traveled or seen how diverse the world really is. Ada lived and learned successfully in all of her many homes, and she refers to this record as proof that she can negotiate many environments while others find it more difficult.

Maria, Malaika, and Susan all spent time in New York City where the rich cultural diversity and international flavor made them feel welcome. As susan said, "It was like coming home; everyone belonged." When each one of these women encounters prejudice in the Northwest, she can rationalize that the person who is the source of the prejudice just does not know how big the world really is. Again, if they can explain bias, they can take away some of its sting.

Aside from their common New York times, the three women each enjoyed positive childhood experiences in which they succeeded as outsiders-within. Susan's mixed heritage and consequently lighter skin tone engendered ostracism from her neighborhood friends: she was not black enough to fit in. In an effort to neutralize the taunts of her peers with something more positive, Susan's parents scrounged up the money to send her to an elite music school in the city. At the school, Susan stood out for her talent and selfdiscipline. She found a way to make it in a hostile place, a way to shine. Both Maria and Malaika distinguished 
themselves as academically outstanding students in elementary school. Both girls surprised their teachers who did not believe "girls of their kind" would do so well (Malaika was dark Caribbean and lower class; Maria was Puerto Rican). The women continue to draw on the part of their identity constructed in those early years--the part where they heard the message that they could succeed where others could not, that they could make it when included with the more advanced students.

Sam's story is a bit different, but it still evidences early achievernent and distinctiveness. When Sam left Hong Kong, his "Lone Ranger spirit" carried him to Indiana. The lone scholar and adventurer of his family, he had always seen himself as different and special. His welcome in the Midwest and ensuing status as a visiting dignitary reinforced his siense of self. When Sam encounters difficulties now, he refers to those other times for the proof that what is now occurring is "not right." Lastly, Joe, also had a sig̣nificantrly positive childhood experience. A mediocre student who perceived himself and his family as poorer than most others, Joe had a year of uncharacteristic success in fifth grade. A teacher coached Joe, expected the best from him, and viewed him as a leader. Joe lived up to the expectations and sailed through the year, finding himself the leader of students he had previously looked up to. Interestingly, Joe did not view 
the year as idiosyncratic, but rather as one representative of the "real me."

These early accomplishments of the interviewees and their successful forays into seemingly foreign territory are significant. Although each person tells his or her own story with its own nuances of meaning, one common theme resounds. Each interviewee attributes his or her ability to negotiate the fault line between minority and majority cultures to the lessons learned from these early experiences. In addition, several view the lack of such experience as a very important reason why another minority with a more homogeneous life history might not be able to make it in a predominantly white institution. Other messages of independence emerge from the data. Frequent messages of self-efficacy and positive self-esteem arise. These people are proud--quietly proud--of their accomplishments. They are doers, the ones who get things done. Self-discipline is also evident. Jonathan carefully manages his time; Malaika and Maria set priorities and limit their leisure distractions; Ada plans ahead of time and organizes carefully, e.g., her weekends are often spent in her classroom; and Sam and Susan, conscious of their anger, look for non-destructive ways to express it.

Another critical facet of the Autonomy component of the resiliency profile is the ability to separate. As Malaika says, "I see it, but it's not about me." The ability to 
distance oneself from discrimination is a powerful antidote. The distancing is not one of denial. Rather, it is a conscious choice to maintain a realistic optimism and to recognize that another's assumptions about a category of people need not be true, indeed are not true, for many individuals who belong to that category.

Autonomy usually implies some control over one's environment. For the minorities interviewed, that is seldom the case. Financial and family demands, others' prejudices, and cultural stereotypes interfere randomly. However, several of the interviewees have developed unique ways to exercise control over a small corner of their world. Jonathan keeps his balance through his music: he uses it to soothe, energize, and buffer him. It is so effective that he has learned to incorporate it into his teaching and create a calm climate in his urban classroom. Sam's Christianity and Susan's church provide solace for them. Maria and Malaika pay increasing attention to the nurturing of their spiritual selves. The particular means for environmental control does not appear to matter. As long as it is possible to create a safe space, some resiliency can be rekindled.

\section{Social Competence}

Communication skills and characteristics like flexibility, empathy, and a sense of humor combine to comprise the resiliency category of social competence. When 
a person possesses traits in this category, he or she is generally able to communicate clearly and to get along with others without undue escalation of conflicts. All seven interviewees demonstrate some aspect of Social Competence even in the face of challenging conditions. Communication skills for minorities operating within a predominantly white institution have a slant to them which adds a note of irony to the term social competence. To succeed as an outsider-within, a minority not only needs to communicate effectively (i.e., competently), but he or she also rieeds to know when to communicate overtly and when not to do so. Consequently, the communication skills category seems to incorporate decision making abilities which, according to these respondents, are of real concern for minorities to cultivate, but which are probably less urgent or necessary for members of the dominant culture to consciously recognize or develop. For example, choosing when to talk and when to listen appears to be a critical decision for the respondents to make, because their experiences have taught them that speaking out is often fraught with negative repercussions.

Ada echoes feelings expressed by all respond:-nts when she states:

This is something I've learned . . . I usually don't share my opinions . . . I've learned that when I do say something it's usually misinterpreted, and because. . . I might offend somebody. I don't want to make waves. 
Maria feels that "there's nothing worse than being misquoted" or misunderstood or seen as a "troublemaker." Maria's fears of the negative consequences of speaking inhibit her. Both she and Ada experience guilt and selfdoubt when they keep silent, but both women take it as a given that to get along with the dominant culture you need to consciously decide when to speak and when not to speak. When referring to this dilemma, sam puts it more bluntly: "I kept my mouth shut; I don't say anything." He describes an ongoing problem with differences of opinion between himself and his student teaching supervisor when Sam kept silent and then appeared to agree by saying, "It's a good idea, I'll try that," although he had no intention of doing so. Sam feared the results of even a minor open disagreement with a "white man with power over me":

I don't want to take any risk because I really do not know too well about that person and if I start arguing with him, I don't know what's going to end up.

Sam felt he could politely question, but not argue of disagree; he had seen another minority pay a price for speaking out and he did not want to suffer a similar fate. Susan's comments reflect even more of the anguish in this situation. She worries "because you always feel like they [the majority] never understand and so [you'd] better not make waves." She tries to balance between a "yes person" and one who is more "militant" by "blurring the edges." Fearing confrontation and argument with whikes both 
in her teacher education program and in the culture-atlarge, Susan describes herself as:

like a satellite. You're your own person and you go as far as you can go and you're always wondering, "Did I go too far? Do they really understand me? They're being really nice now, do they really mean that?"

Malaika also describes how "I never said anything and I questioned myself and I questioned myself." Both Malaika and Susan judiciously choose when to speak by weighing the risks and potential benefits.

Although all of the respondents report feelings of self-doubt or criticism regarding their self-imposed silences, they generally agree that keeping silent is necessary, particularly when a minority is outnumbered or vulnerable to arbitrary actions by someone in the dominant culture who has power over them. Keeping silent is a necessity; these respondents describe it in matter-of-fact tones.

In contrast to self-imposed restrictions, silences arbitrarily imposed by others generate more anger. Malaika tells of a time in a teacher education class when she was the only minority present and she asked a complicated question regarding equity for children. The other students in the class did not seem to understand the question's relevancy, perhaps because it required knowledge from a minority standpoint. The professor dismissed the question as unimportant. Another time when Malaika asked a question, the professor|replied brusquely, "That question was asked 
before," and he went on to someone else. Malaika remembers being embarrassed and angfy, she felt confused and disappointed that an educator would model such a stifling of curiosity, and she stopped asking questions.

Susan, like Malaika, also experiences frequent dismissals, and she reports that journal writing has "saved her sanity." susan remembers many interruptions in class when:

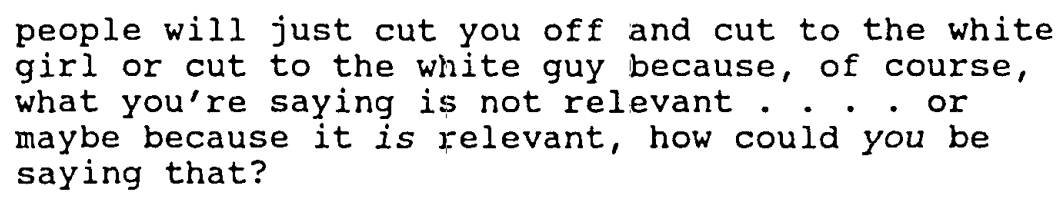


beliefs and opinions do have value. Similarly, Malaika is countering her prior conditioning. Now that she is a teacher, she speaks out loudly and frequently when she is concerned. She trusts her own judgment more and can dismiss others' accusations of her supposedly unchecked selfinterest:

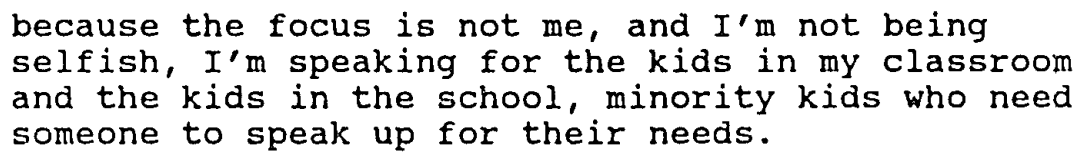

All seven interviewees are able to speak articulately in a one-on-one setting, and all seven possess good writing skills. When faced with the necessity to communicate, each can do so. However, communication in a predominantly white group setting, especially one in an educational context, poses additional difficulties for some of the interviewees which can cause them to be quieter than usual or to speak less articulately than they believe they are able to. Both Ada and Joe report experiencing particular tension in such classroom situations, although they feel that the tension is tempered by their excellent writing skills which allow them to demonstrate competency to their professors by means of an acceptable alternative.

Joe is uncomfortable in a large group discussion. With little prior experience in an open forum either at home or school, Joe feels ill-suited to such a format. His childhood memories are of one-on-one talks which required careful listening; his Mohawk mother rarely engages in other 
than practical, necessary conversation. Not surprisingly

then, in his teacher education classes, Joe felt quite

annoyed and out of place given the premium put on group

discussion. At the beginning of his teacher education

program, he faulted his own inadequacies and believed they

serve to confirm his suspicion that he did not belong in the

program. He resented the ways in which a quarter of the

participants dominated the dialogue. Despite faculty

encouragement to join in, Joe did not see the point and did

not find it useful. However, faced with the threat of

failure if he did not participate more, Joe did start to

talk. His descriptive interpretation of dominant cultural

class discussion shows his perspective:

I started to talk in the seminar, and $I$ found that half of the time people didn't really listen. And that's when I started to figure it out. I started to [understand] that this is really just a series of speeches that we all give. And it isn't really a discussion as I know it. Then I became a little more confident. I thought, "Oh, well if it's just that--if it's not really a conversation where I'm supposed to respond and understand everything you say, well then, no problem. I'll give my little speech if I feel like it, if I feel strongly about it." I didn't understand it before. I thought that they were actually having conversations and that I was too dumb to get it.

All of the interviewees carefully choose when to speak. often their contributions are prompted by majority members' comments about emotionally-laden topics--comments which the interviewees deem incomplete or one-sided. The difficulty inherent in such measured speech is found in the tension between head and heart. The interviewees want to be 
dispassionate in order to be credible to others, but they invariably wait to speak until they feel passionate about a subject. Additionally, when they do share their opinions, they are often viewed as the "alleged authorities" and their comments are "overly weighted."

Despite these conversational challenges, the interviewees collectively demonstrate social Competence. They empathetically look through others' eyes and work to see how someone might come to a different understanding. They question themselves. They adapt. And they laugh. To a remarkable degree, these interviews are punctuated with laughter. It is a laughter which arises in three distinct situations and serves three distinct purposes. When the respondents tell of instances where they have stepped beyond what might be considered the boundaries of their "place" in the shadow of the dominant culture, they laugh loudly and at times with a tinge of nervousness. When they recall incidents of pain, embarrassment, and humiliation, they laugh briefly (almost swallowing it) and look away. Finally, during the second round of interviews when some camaraderie and apparent understanding had developed between myself and the interviewees, they relaxed and laughed at a moment of shared insight. Such ready laughter seems a powerful tool in the resiliency tool kit, one which serves the interviewees well when they are minorities in a predominantly white environment. 


\section{problem-Solving Skills}

Benard believes resilient people view challenges as problems to be solved, not reasons to excuse inaction or to justify hopelessness. She attributes one's ability to think reflectively and to be flexible as essential ingredients for problem solving. The Survival Skills category which I developed during the data analysis includes many examples of the problem solving ingredients mentioned by Benard. This category also includes examples of attitudes which complement resilient problem solving behaviors. As in the examination of the other categories, examples of these resiliency characteristics are evident in each of the interviewees stories.

Among the interviewees, Jonathan offers the best examples of resilient problem solving. In one instance, he recalls a painful account of an everyday manifestation of the fear which members of the majority often feel toward Blacks. One day while walking to a college class, he and four other boy and girl friends (some White, some Black) "were all kind of hanging out and just walking, in broad daylight, across the street." A woman who had stopped at a light saw Jonathan, caught his eye, and "quickly reached up and locked her car door just as [he] came near." Jonathan's reaction to this seemingly small act of fear demonstrates his resilient problem solving:

I'll never forget that. I can tell you the car, I can tell you the color, I can tell you what she 
looked like. I will never forget that image. And I just thought, "That is too funny.". . . I've learned... I take situations like that and I think, well, it's not about what do I need to do to change that, it's about--wow, it must be a scary life to live like that, to always be looking for something. It must be really scary, and I just don't know if I have enough energy to be paranoid all the time. And it's kind of funny when I look at it like that . . . . it's sort of an empowering thing. And, psychologically it does a little something for me... . you've got to pick and choose your battles.. . and just worry about what you can do.

When Jonathan is dressed professionally in a suit and carrying his briefcase, people smile and lact politely. When he is dressed casually:

they will make eye contact with me, sort of, from about six or seven feet away, just in terms of bearing. . okay, where is he? Where am I? And then they get that "walk like you mean business" look, and they put their eyes down and kind of just get right through there. And you can kind of become numb to it. Not in a bad way numb, but like you don't notice it because it happens so much. And it doesn't just happen to me... . or even just to Black men. It happens when you're in a situation that you view as confrontational for whatever reason. I just have to process it... [and tell myself]. . . Oh well! I didn't do anything, I didn't say anything, I didn't give you an impression. So the best thing I lcan do is just sort of let you get out of the way before you do something that hurts both of us.

Jonathan is a master at figuring out what can be done and letting the rest go. He can distance himself, pick his battles, reframe a difficult situation in a positive light, ask questions, and apply multiple perspectives to a problem. All of these strategies are conscious; he chooses when it is in his best interest to use them. 
Jonathan tells another enlightening story about "being used" by his former teacher education institution. Being one of a handful of Black men who has completed the program, Jonathan was asked to pose for the cover of the school's recruiting brochure. He reports his thought processes at the time of the request as a series of personal questions: "You have to decide. Is it comfortable? What are they getting from this? What are you getting from this? If it's a comfortable trade-off, then go for it." Jonathan figured that the brochure would soon be outdated, but his degree would last a lifetime. He traded the photo for some institutional good will he chose to "bank for a later date just in case I might need it." smiling and noting that the institution got the benefit of his "incredible good looks," it did not escape him that his school needed one of its only success stories to prove its urban commitment.

Jonathan's strategies for personal problem solving extend to his teaching. He explicitly teaches his students how to use the very same processes he has come to know and depend upon. Throughout his room are charts and slogans; students memorize inspirational poems. You have to work hard to be a victim in Jonathan's class. He has "no time for it."

Jonathan's embodiment of resilient problem soluti:y skills is exceptional among the interviewees. Each employs some of the skills, but Jonathan uses them all. Among the 
other interviewees, the most common strategy used is that of the consideration of multiple perspectives. They seek to understand by looking at situations from others' points of view. As Maria says,

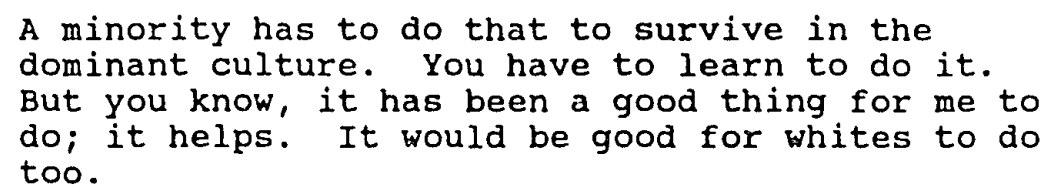

Another common emphasis among the interviewees is in

the teaching of problem solving skills to their students.

In each classroom I visited, I observed whole class and

individual lessons where problem solving skills were modeled

and discussed. Malaika comments reflect those of the

others: "You need these skills to make it, especially if

you are a minority. I can't teach them to the children. I

have to prepare them, to make them strong."

\section{Sense of Purpose and Future}

The final category of the resiliency profile is almost an exact match with the one I named A Higher calling.

Embedded in this category are the interviewees' heart and strength of will--the "why" which impels them to walk the fault line when the pressure intensifies. It is here that they talk of goals, expectations, persistence, hopefulness, and the meaning of their work.

As newly trained teachers, the interviewees are well versed in the power of expectations and self-fulfilling prophecies. As minorities, they know the damaging effects 
of low expectations. The four women are especially tuned to their anger around this topic. Susan vehemently despises the way "they [former school teachers] expected nothing of me--Nothing!" Maria, Malaika, Joe, and Jonathan viscerally recall the power of self-fulfilling stereotypes and the energy it took to combat them. Every interviewee intentionally works to set high, challenging expectations for his or her students. They do not want to be a party to another imposition of limits on their minority students. Along with a plan to expect the best of others, each interviewee tries to expect the best of him or herself. At times these self-imposed demands seem unrealistic. Jonathan, Ada, Susan, and Malaika lean toward perfectionism, and they acknowledge needs to "lighten up" on themselves if only to model forgiveness to their students. Each person interviewed possesses incredible persistence. When asked if they ever considered quitting the teacher education program, to a person they answered, "No! Never!" While the answer was not surprising, the vehemence of the reply was. For these persisters, the idea of quitting was too negative to be given any mental or emotional space whatsoever. Although program completion was not always accomplished in the standard manner or timeline, it was accomplished by one and all through the implementation of various strategies. For Maria, a long range view was too overwhelming. She reports that she took 
it one class at a time. Milestones like an Associate's degree served as markers for her, as concrete evidence of achievement which could not be stolen or withdrawn. Malaika speaks of her "focus": she would not let her aim at her target be pulled away from its mark. Jonathan speaks of "doing what you got to do." He keeps his diplomas on his hall table just to remind himself of all he has already done--and when necessary, to nudge himself on when the going gets difficult. Each one of these interviewees possesses a determination to succeed once they make a decision. Such determination is a source of pride and strength: it is a well from which each draws energy.

Becoming a teacher is not easy; becoming a minority teacher through a predominantly white educational institution is even less so. Yet as these new teachers reflect back on their often difficult program experiences, they smile when relating why they chose to teach. A heartfelt commitment to teaching and progress toward personal goals to empower children and youth seem to make the struggle worthwhile for the interviewees. Several express annoyance for the seemingly cavalier way some middle class whites choose to enter teacher training. The contrast between "having something to do once the kids are in school" or "keeping myself interesting for my husband" and the minorities' determined desire "to make a difference for all 
children" is incredibly annoying to Malaika. Ada, Jonathan, Joe, and Maria echo similar frustrations.

For these interviewees teaching represents far more than a job or a paycheck. Joe likes being a role model. He is a person to his students. Now teaching in an Indian school, Joe feels privileged to help his students gain a pride in their heritage and learn how to make it in both the Indian and white worlds. Maria knows not everyone has a choice even though "the white middle class always assumes you do." She wants to reach out to students and their parents. She knows firsthand that some parents cannot come to school even though they'd like to support their children; "the white assumption that they [the minority parents] don't care is simply wrong." Maria teaches the value of multiple perspectives every day. She is anxious to share what she has learned with others, especially Hispanic females. Ada refers to her "mission to be a role model and to give my students a better understanding of the world and the different kinds of people in it." For Malaika, fun is reaching a child. She elaborates, "I respect them. MY class is like a family. And you know today's children need a caring family with all they have to contend with."

All seven of the interviewees share a belief in the value of minority teachers, and all are proud to have joined the profession. They are also acutely aware of the low number of minority teachers. Often during their teacher 
preparation programs, and now as certified professionals, they are asked to provide leadership and represent minority views. Often they are asked to explain "why so many other [minorities] didn't make it." Consequently, when Jonathan sums up a sentiment commonly expressed in the interviews, that of support for the positive focus of this study, it is not surprising. Jonathan comments: "It's almost like, for lack of a better term, that unsung hero story almost . . . not that I think I should be on a pedestal, but nobody's paid attention to why we did make it." Jonathan also notes that "it couldn't just be the school situation... it's got to come from within [ourselves]." Returning to the hero idea again, Jonathan clarifies that a hero implies something almost superhuman and that is not who he is. Rather, he sees himself as blessed with some special experiences, support, and skills which he gained early in life--talents which enable him to move between the majority and minority cultures. Jonathan assumes that although he does not know the other interviewees,

I'll bet they sound just like me . . . they have to because it's got to come from within and from what you've learned to do. We can move back and forth [between cultures]. We are the vanguard, the ones who are able to go first, but we are not the norm for minorities--not yet anyway.

Jonathan's concept of a "vanguard" of minorities who possess skills due to experiences atypical for most minorities is a provocative one. Each of the interviewees does fit the resilient profile; to do so requires the 
acquisition and everyday application of an unusual combination of traits. Each interviewee gained some measure of success as an outsider-within during his or her youth, and that earlier success appears to empower them to negotiate the ins and outs of the dominant culture with greater facility than minorities with more homogeneous cultural experiences might demonstrate. If the vanguard concept possesses some legitimacy, it raises implications for retention programs. Before considering those implications, I next explore the interviewees'|personal experiences with their institution's retention|programs in an effort to understand the interviewees' perceptions of program impact.

\section{Institutional Retention Efforts:} What Made a Difference?

The design of many retention programs stems from an intent to increase a minority's sense of belonging and is based on the belief that a student's sense of inclusion will support academic success. Often a program operates from the premise that a minority who feels like a legitimate member will succeed, and it also is organized under the tacit assumption that a minority in a predominantily white environment will feel or be treated like an outsider unless something is done proactively.

Much of the retention literature reviewed in earlier chapters attributes minority students' academic success to 
positive programmatic interventions, whereas students' failures are blamed on their personal deficits. The correlations with resiliency mentioned earlier in the chapter suggest that the minority students' successes examined in this study may be linked to positive personal characteristics at least as much, if not more than, programmatic interventions. However, I feel it is also important to explore the minority students' perceptions of their teacher education program components and the degree to which the students perceive those components as helpful in their academic achievement. Using the categories delineated in Love's (1993) national investigation of effective existing retention programs, I asked each respondent to comment on his or her experience with related program elements. Love described each of the catalogued factors known to correlate with student retention as follows:

1. White Racism. Also known as institutional racism, this factor reflects the historical development of higher institutions to meet the needs and interests of white, middle class students and to deem normal the values, behaviors, and attitudes of the white, mainstream American culture. The degree to which white racism or embedded privilege is acknowledged and addressed by an educational institution correlates positively with minority student achievement. 
2. Institutional Leadership. This factor refers to the degree to which institutional officials understand racism and are willing to publicly advocate its elimination. Lack of leadership in this area can be interpreted on the part of faculty and majority students as an institutional tolerance or permission to act out one's prejudice, and is consequently detrimental to a minority's sense of safety and inclusion.

3. Finances. Funding a college education is increasingly difficult, especially for those students who are first generation attendees or who belong to the lower or working classes. This critical factor incorporates the efforts of an institution to assist with financial aid, e.g., locating available resources and/or offering grants, loans, financial information and counseling.

4. Social Interaction, Cultural Dissonance, Environmental Incongruence. Generally, this factor refers to a range of issues relating to a student's sense of belonging to the institutional culture as a whole. Issues of inclusion, isolation, friendship, and community surface here.

5. Faculty-student Interaction. This factor, found to be a significant variable in academic achievement and retention, is associated with the quality of interaction between minority students and their faculty and the ways such interactions compare with those of majority students 
and their faculty. It is influenced by quality of communication patterns, levels of equitable participation and opportunity, students' perceptions of faculty sensitivity or a lack thereof, positive or negative expectations, and trust.

6. Student Services. This is a broad category incorporating the existence of, and access to, traditional student services or a lack thereof including services for academic support, personal assistance, and social and recreational needs.

7. Student Characteristics. This category includes individual student characteristics which allow the student to deal effectively with the institution. Resiliency traits surface in this category. In order to succeed in a predominantly white institution, minority students must demonstrate different personality traits than white students due to the existence of differing expectations for student achievement and requirements for the minority student to adjust to the mainstream cultural values of the institution. In the interviewees conversations about these categories, the most remarkable insight I discerned was completely unanticipated: while aspects of retention programs were certainly helpful to the respondents, their enthusiasm for them is at best lukewarm. In contrast to the animation of other sections of our conversations, respondents speak of program impact in polite, matter-of- 
fact tones. When I asked about programmatic issues, the respondents veered off topic to discuss other events which seemed to matter more. This pattern was repeated frequently until I realized that I was assuming a retention program's value which the interviewees apparently do not share. Primarily, the respondents' animation appeared when discussing category seven, student characteristics. They told stories of their adaptations to the institution-stories of individual creativity and persistence. Five of the interviewees expressed strong opinions that in order to succeed in their teacher education program, they unilaterally had to adapt to the white, middle class norms and values reflected in the institution's atmosphere and practices. These five respondents also perceived category one, White Racism, at their institutions to be an obvious, everyday fact of life. All seven participants had previously honed strengths and abilities that enabled them to make the adaptations necessary in a predominantly white environment.

The two interviewees who noted a mutual adjustment between themselves and their institution were Ada and Jonathan. Both explain their characterization of a mutual adjustment by noting their own lesser needs to adapt to the institution due to personal strengths or earlier experiences. Ada equates her minimal need for adjustment with her professional family background and familiarity in 
such environments. Jonathan attributes his ease to his talent for moving between different worlds which he initially explained when drawing his Venn diagram. Jonathan and Ada also share the opinion that white racism was not apparent at their different teacher preparation programs. Their comments emphasize that they personally did not experience discrimination and that their individual talents enabled them to $\mathrm{fit}$ in easily,

Category two, Institutional Leadership, and category six, student Services, are non-issues for these respondents. Although services were available, the students' needs for them were minimal. References to leadership indicate that students notice what leaders say but perceive little impact from such declarations. The seven respondents indicate widely differing opinions about efforts by their institution's leaders to establish inclusive, equitable practices; their tone when discussing the leaders is nonchalant and detached.

Everyday interactions between faculty and with other students assume a position of prominence in the respondents' lives. Categories four and five address the nature and impact of such interactions. All seven respondents readily identify at least one faculty mentor who took a personal interest in their welfare and academic success. For Joe, Malaika, Maria, Sam, and Jonathan a faculty member intervened at a critical point and found a specific way to 
encourage their continuation in the program or assist in their academic achievement. These students remember the details of such scenes: the day and time, the weather, their feelings, exactly what was said or done. Faculty interventions represent being taken seriously, being respected, being seen as capable, being seen. Joe recalls a difficult period when he had not yet found a way to enter class discussions. A faculty member noticed his reticence to participate and encouraged him to share openly his valuable thoughts--thoughts Joe had written articulately in papers. Even though Joe responded minimally at the time, the teacher's intervention meant a lot and eventually helped to move Joe to join more in classroom interactions.

Faculty interactions are typically described as unrelated to a program. Rather, they are seen as exchanges initiated by individually acting, caring teachers who operate outside the norms of the program or institution. A contrast exists between the interviewees private, individual experiences with faculty and their experiences when they are part of a class of predominantly white fellow students. Several interviewees tell stories where they were publicly discounted, ignored, embarrassed, or put down by majority students and no one intervened. Then, later and in private, the teacher attempted to rebuild rapport with the minority and criticize the actions and ignorance of the white students. 
These stories indicate a challenge for some faculty at predominantly white institutions: how can they facilitate equitable discussions, maintain credibility with the majority students, and advocate for minority students? Actions by the faculty often serve to maintain the status quo and yet they are simultaneously charged with shifting it by incorporating more inclusive methods. The interviewees hold faculty responsible for creating an equitable classroom community despite the fact that they may not have ever personally experienced such an atmosphere during their own education. Five of the interviewees note differences in their public and private interactions with faculty. Ironically, they also offer rationalizations for the differences and speak with empathy about the challenges inherent in the faculty member's position. They are able to do so by viewing the situation from the faculty's standpoint as well as their own.

Category four, Social Interaction, Cultural Dissonance, and Environmental Incongruence, plays a significant role in the respondents' experiences. Joe and Malaika experienced strong perceptions of "being where [they] didn't belong." Their references cite class differences more than race or ethnicity whey they explain their "outsider" feelings. Likewise, Ada and Jonathan indirectly reference class indicators when they report that they blended harmoniously with fellow students. They take their academic competence 
and abilities to blend with students and relate to faculty for granted.

The most emotional responses to program questions surfaced with regard to Finances, category three, and affirmative action, a topic which cuts across several categories. Five of the respondents received financial aid. In each instance, the aid was earmarked for minorities in general or for students of a particular race or ethnicity. These five respondents could not have attended or completed their teacher education programs without such assistance. outstanding undergraduate loans, extended family commitments, lack of extended family resources, and fears of future debt weigh heavily on the minds of the respondents. Only Ada and Jonathan attended without receiving financial aid: she worked 10-20 hours per week throughout her program and her parents also helped fund her education and he worked approximately 30 hours per week. The other five respondents organized various combinations of work study, grants, scholarships, and outside employment in order to pay for their teacher preparation. Jonathan raises another financial issue for future teachers. His African-American male friends openly challenge and mock him for entering teaching bec 1.4 se it is a relatively low paying profession. Consequently, he endures considerable peer pressure to demonstrate his financial as well as his professional accomplishments. Even now Jonathan 
works part-time to supplement his teaching salary. Although he loves teaching, he believes he must enter an administrative track in order to maintain a decent life style and earn respect in his community.

Finally, the issue of affirmative action casts a long shadow over these interviewees. To a person, each minority respondent tells a tale of experience with affirmative action which undermined self-confidence. Usually the story involves the following scenario: the minority applicant successfully interviews and is offered a teaching job; the minority applicant believes his or her success is the result of hard work and demonstrated excellence in teaching; either a teacher education faculty member or a fellow student makes a comment which assumes the job is a result of affirmative action, a favor to one less competent; and the minority person feels a wave of anger, self-doubt, and pain wash over him or her. During the telling of these stories, jaws tighten and tears well up in the respondents' eyes. They talk of what they wished they might say and what they actually could say. They understand that many of the comments are offered as complimentis or in appreciation of the value of "hiring more minorities." Nevertheless, the sting lasts a long time.

In general, the interviewees report that they entered their teacher education programs with the understanding that minorities are outsiders. They brought low expectations for 
program support based on their past life experiences with mainstream institutions, and they knew that they must absolutely expect the best from themselves in order to succeed in a predominantly white teacher education program. They did not expect their program to differ significantly from the challenges they experience daily in the rest of their lives. According to these respondents, their expectations proved accurate. 
CHAPTER V

DISCUSSION, CONCLUSIONS, AND RECOMMENDATIONS

In this chapter, I review my study of minority graduate students who finished programs at predominantly white teacher preparation institutions, consider the significance of the study, and analyze its implications for leaders of institutions who want to attract and increase their retention rates of minority students as well as its implications for the students themselves and those who work closely with them. First, I review the rationale for my study. Subsequently, I re-examine the design of the investigation and its unfolding during the course of the research. A discussion of the results and conclusions logically follows: I reiterate what happened and what was learned from this study and follow up with a further identification of its limitations. This review of the study sets the stage for the next section of the chapter where I consider the implications of the study and its findings. Finally, I make recommendations for further research which will likely enable us to gain a better understanding of the experiences of minorities striving to act effectively in institutional contexts traditionally normed by the values of the American white middle class. 
Review of Research Questions

The goal of this research was to expand our understanding of the perspectives of minority students who have succeeded in predominantly white educational environments, specifically graduate level teacher preparation programs in the Pacific Northwest. The study was prompted by the disturbing numerical disparity between the decreasing number of minority $\mathrm{K}-12$ teachers in the United states and the increasing number of minority schoolage children, and it was grounded in the hope that a deeper understanding of a minority teacher's preparation will aid in the efforts to reverse these demographic trends. According to U.S. government reports, relatively few minority students do succeed in predominantly white environments (ACE/ECS, 1988; Carter \& Wilson, 1992). Despite the individual recruitment strategies and retention programs used at many colleges and universities, students of color are not enrolling or graduating in numbers representative of current demographic figures. In order to learn how to improve the number of successful minority students, considerable attention has been paid to those students who fail to complete their programs of study. From these deficit model studies and the few other studies which have investigated successful students, researchers have enumerated conditions likely to support minority students (Attinasi, 1989; Cibik \& Chambers, 1991; Martinez et al., 
1992). In fact, the factors believed to contribute toward environments of support for minority students are well documented (ACE/OKHE, 1992; Garibaldi, 1989; Martinez et al., 1992; Noel-Levitz Centers, Inc., 1992). With minor variations, the consistency is remarkable. Unfortunately, knowing what to do to increase persistence has not yet translated into doing it.

After reflecting upon this phenomenon, I decided to reject the frequently chosen deficit model of analysis and instead chose to focus upon those students who had succeeded in predominantly white educational environments. I sought to keep the interplay between members of the minority and majority in focus and I wanted to hear the minorities tell their own stories about how and why they believe they finished their programs and what they think enhanced or hindered their efforts. In keeping with this intent, three broad research questions guided this study:

1. What are the experiences of students of color at predominantly white graduate schools of education?

2. What do these students of color perceive to have been contributors or hindrances to their academic persistence and subsequent program completion?

3. What, if any, commonalities of experience or interpretation of experience exist among these students?

These three simple questions remained at the heart of the study throughout its evolution. At times the urge for 
greater certainty and less ambiguity made a diversion to look at program analysis, more straightforward quantitative data, or comments by retention authorities quite tempting. However, by keeping the guiding questions in mind, I kept the minorities positioned as the experts who know, to the best of their recollection, what happened in their teacher education programs and what it meant to them.

Review of Research Design

To establish a strong, comprehensive theoretical scaffolding, and in the hope of hearing the whole of what was happening in the minorities' stories of their teacher preparation, I combined feminist and ethnic interpretive perspectives with a critical analysis. In this way, I attempted to recognize multiple voices while simultaneously committing to a political perspective. By combining the theoretical perspectives, this study addresses the ironic contradiction between the typical research emphasis on minority race and ethnicity as marked categories which are used to explain phenomena and the de-emphasis of the minority point of view.

Together the feminist, ethnic, and critical perspectives did provide high-powered lenses with which to view the problem of under-representation of minority teachers. These combined philosophical principles created a means by which to explore the lived experiences and self- 
understandings of racial and ethnic minorities who have succieeded in predominantly white institutional programs; locate the fault lines they negotiate; maintain collaborative, caring, non-oppressive relationships between myself and the respondents; and seek to understand how race, class, and gender influence this problematic situation of under-representation in order to interrupt and equalize it. From this theoretical base, I designed a study employing components drawn from ethnographic methodology. After determining the size of a potential sample of informants who were regionally accessible to me, I initially explored the social phenomenon of minority success in a majority environment through a written survey. Respondents then formed a pool of potential informants from which I selected a small number to study in detail.

Respondents' survey comments guided the development of the question outlines used for the loosely structured interviews subsequently conducted. Triangulation within three different sources of respondents' own words--survey, interview, and personal journal--enriched the information received. Field observations in the classrooms where they now teach and content analysis of papers written previously for graduate coursework or for their current teaching positions added a legitimizing authenticity to their stories. Finally ethnographic methods incorporating constant comparative analysis were used to categorize and 
cluster the empirical materials in order to better understand the informants' lives and the meanings they attributed to their successes in majority environments.

\section{Subject Recruitment}

Subject recruitment for this study proved to be especially challenging. I personally contacted fourteen Pacific Northwest institutions with igraduate level teacher preparation programs; collectively these schools prepare the majority of the new teachers in the region. Three reported that no students of color had finished their programs since 1990. At one large urban university, with a reportedly high percentage of Asian-American students in the teacher preparation program, the administrators required that an additional human subjects' research review be conducted at their institution as well. Unfortunately, time constraints eliminated that university's population from the study. Summarily, 10 Pacific Northwest institutions with graduate level teacher preparation programs agreed to participate in this study. They represent: urban, suburban and rural locations; public and private funding and governance structures; and religious and sepular philosophies. All 10 institutions are situated in close proximity to urban areas of Oregon and Washington, graduate very small numbers of minority students relative to their majority populations, and possess both elementary and secondary teacher preparation programs. Since 1990 , a total of 85 minority 
students had finished teacher preparation programs at these 10 institutions.

All minorities who had finished their teacher preparation programs were surveyed; $72 \%$ returned the surveys $(\underline{N}=61) ;$ and of those who responded, $83 z(\underline{N}=51)$ asked to be contacted for an interview.

After analyzing the survey respondent pool to determine its descriptive characteristics, a representative group of 10 potential interviewees was selected. This interview group matched the relative proportion of the survey respondent pool, as self-reported by the respondents, with regard to: race/ethnicity, knowledge of languages other than English, social class, receipt of financial aid, participation in part-time employment, age, gender, and selection of elementary or secondary teaching specialization. Great care was taken to match the selected interviewees to the total sample population, and I believe the correlations are representative.

Although I only intended to interview six, I identified 10 possible participants in case of problems with unavailability or attrition. The three people who were in fact unavailable for interviews were: a Native AmericanHispanic woman, an Hispanic man who had immigrated from Latin America, and an Hispanic woman born and raised in the Northwest. All three of these people declined to be interviewed due to their extensive community involvements, 
travel or work conflicts, and concerns to preserve adequate family time. Collectively these three represent a mix of lower and upper working classes, age categories of the $20 \mathrm{~s}$ and 30s, elementary and secondary teaching certification, and part-time workers who received financial aid. Thus, when factoring in the unavailability of these three people, the primary loss of perspective from the final interview group stems from a lack of multiple Hispanic voices.

I decided to interview all of the seven remaining candidates. The final demographic make up of the interviewees represented the following characteristics: four women and three men; African-American, Asian-American, Hispanic, Native American, and mixed backgrounds; English only and multi-lingual speakers; age ranges in the 20s, 30s, and 40s; lower working, upper working, middle, and upper middle/professional classes; scholarship and financial aid recipients and non-recipients; attenders from 5 of the 10 participating institutions; and those who worked during their program and those who did not.

\section{Discussion of Results and Conclusions}

One of the first findings of the study arose from the written survey return rate itself. Given the constraints necessary to meet each institution's obligation to maintain student privacy, the survey was sent out only once without any reminder notice or follow up request to participate. 
Nevertheless, 728 returned the surveys and $83 \%$ of those indicated a willingness to have an interview. The respondents' interest was confirmed by their comments scrawled in the survey margins, comments of appreciation for my interest in the topic and indications of their personal desires to open the dialogue about their experiences.

A second interesting finding also stems from survey data. The wide ranging variety of personal descriptions of race and ethnicity reported on the survey (51 unique descriptions out of a possible 61 respondents) suggests a complexity of racial and ethnic heritage among the minorities participating in this research study. Confirmation of this survey finding occurred when the participants elaborated on their complicated individual identities in their individual interviews. It is not possible to generalize this finding to minority populations at large, but it does seem indicative of these minority teachers recently trained in the Pacific Northwest.

The racial and ethnic variety of the sample may or may not be linked to another significant finding, but it seems to be worth further exploration. One of the major outcomes of the interviews was a confirmation of the legitimacy of the concept of the outsider-within to describe a minority's perception of his or her position in a predominantly white institution. The minorities interviewed reported an intellectual and a visceral understanding of the notions of 
being inside, being outside, and walking on the pressurized fault line between the two places. These concepts are real to the people with whom I spoke. For the minorities, a consideration of whether or not they belong, whether or not they are legitimate members, is ever present--and, in contrast, it is a consideration with which majority members rarely have to contend or even think about.

The standpoint of a minority person vis-a-vis a predominantly white institution and its majority members frames his or her experience. The interviewees often referred to the difficulty they had separating teacher education program experiences from the rest of their lives. They explained many ways in which their prior cultural experiences shaped the expectations they brought to their university. Also, the interviewees described how everyday encounters outside the institution and public school field experiences where at times they met with prejudice, discrimination, misunderstanding, or exclusion spilled over into their feelings and thoughts in teacher education classes. Clearly, questions of belonging and their answers create a significant contextual factor for minorities negotiating a predominantly white environment.

Another finding which stands out from the analysis of the data is the interviewees' common exhibition of traits equated with a psychological profile of resiliency. All seven of the interviewees related stories indicative of 
resilient behavior and attitudes, and they also demonstrated them in interpersonal exchanges with me which occurred during the course of the study. It is plausible that the seven interviewees in my study happen to be unique individuals with life histories that especially equipped them to succeed in predominantly white institutions, life histories which supported the development of their resiliency. However, that would be an incredible coincidence given the systematic way in which the sample was selected. Resilient behaviors and attitudes appear to be the way a minority can cope with the challenges inherent in their outsider-within status and succeed in a predominantly white environment.

other information culled from the empirical materials relates to interviewees opinions of a retention program's impact. When the interviewees discussed their experiences in their teacher preparation programs, financial assistance was unanimously named as a critical factor and financial problems were reported to be of paramount concern for most of the interviewees. The minority students' interactions with faculty also made a strong impact upon them. When an institution had a lack of minority faculty or other minority students, the interviewees reported a debilitating sense of isolation. Extra outreach efforts by a faculty member and his or her personal recognition of a minority student's strengths mattered a lot, and at times the attention 
influenced the student's decision to continue in a program. The students also noted frequent occasions when faculty deferred to white middle class norms and values in class, although they would express support for minority viewpoints in private. The interviewees reported that another important aspect their teacher education programs was the relationship between minority students and other mainstream students. Peer interactions could have a powerful, emotional impact either positively or negatively for the minorities. Lastly, five of the seven interviewees viewed the institution as driven by white middle class values and styles which the minority students needed to embrace in order to achieve. comments from the interviews like, "I just had to think white to make it once I got in," represent the minority students' perceptions that they needed to adjust and adapt. Few faculty or fellow students from their institutions conveyed a message to these students that their minority ways were also acceptable.

When a minority student perceived that a school program operated with singular respect for white middle class norms and values, his or her sense of being an outsider-within was heightened. The interview conversations began to uncover the everyday ways in which this message was communicated. overt discrimination or rude comments were seldom mentioned. In their interviews the participants of fered examples that reflect the embedded nature of white privilege where acts 
are subtle to those who are insiders and obvious to those who are outsiders. Interviewees reported conversations in which they were interrupted and where their white listeners looked around or acted distracted when the minority student had a chance to speak. When the interviewees attempted to speak up in class, several recalled times when university faculty discounted their questions or ignored them, leaving their questions unanswered. Another reportedly frequent experience of the interviewees involved the receipt of comments from faculty or other students implying that the minority student would need help with something. These assumptions were often accompanied by unrequested offers of help from majority members. For the minority students, these situations implied white competence and minority incompetence. According to the stories they told during some of the interviews, these offers of assistance from members of the dominant culture, although made politely and with apparently good intentions, proved to be especially awkward for some of the minority students to handle. Finally, the interviewees spoke vehemently and with frustration about times when members of the dominant cuiture evaluated whether or not an individual minority person did or did not fulfill the stereotype for their racial or ethnic group. Several perceived it as a no-bin situation and a confirmation of being an outsider-within. 
of particular note is the frequent mention of the confusion generated by the private support of a minority student by a faculty member versus his or her public indications of agreement with the views of the majority. When confronted with a classroom situation in which the students are predominantly white, apparently it can be difficult for some faculty to openly express their beliefs in the importance and legitimacy of minority viewpoints which they have privately validated. The interviewees also described classroom experiences where faculty did not intervene or manage a classroom discussion; they allowed put downs and other indications of majority members' disrespect for, or ignorance of, minority members' opinions and experiences to occur. The interviewees who described such experiences also indicated their powerful impact: confusion and self-doubt arose as the minority student questioned his or her ability to assess safety, belonging, and authentic support.

Such mixed messages are additionally significant to the minority student because of the important role which can be played by a single faculty member. One teacher can convey messages of competence and legitimate belonging to a minority in a predominantly white environment, messages critical to that minority student's belief in his or her ability to succeed. If that same teacher behaves differently in public and in private, the results can be 
extremely disappointing and disorienting to the minority student.

The positive impact of individual faculty members surfaced repeatedly during the interviews. No one mentioned a school-wide attitude of inclusion of minority members where their competence was assumed, but individual teachers and administrators who did so were often credited with making a difference for the minority student. Generally these individuals were seen as operating outside of the norms and in spite of the prejudices embedded in a program.

When a teacher preparation program had a minority faculty member, his or her presence established a strong symbol of the legitimate presence of minority students in the program. It also indicated a generalized respect for multiple perspectives, or at least the possibility that that might be true within the program as a whole. Not surprisingly, the reverse was also true. If no minority faculty taught in a program, the minority students reported they received a strong message that they were "on their own." This message of isolation was emphasized even more if there were few or no other minority students in the programs.

Not all of the interviewees shared the same level of concern with issues of belonging or needs for minority faculty role models and advocates. Their different attitudes seem to stem from that juncture where the 
categories of race and ethnicity intersect with those of social class. The two people who report the least concern with fitting in and adapting to white middle class norms and values are the two whose backgrounds can best be described as middle to upper middle class. They experienced minimal needs to adjust to the environment. They attribute their ease to their prior experiences and family upbringing which prepared them to operate adroitly in mainstream organizations. On the other hand, the five interviewees who did experience discomfort with the established institutional norms and values identified themselves as members of the working class or as immigrants "moving up from nothing."

\section{Limitations}

The limitations enumerated in chapter III generally proved to be relevant during the course of the study. The number of minority students who had completed a teacher preparation program in the Pacific Northwest was, and remains, of concern; it limited the size of the sample I could survey. However, the $73 \%$ response rate for the survey indicated that the study participants did represent a significant number of the minority teachers trained in the Pacific Northwest since 1990.

Differences between public and private institutions did not appear to pose the problems I initially anticipated. Yet, I continue to question the ways in which students' 
experiences and opportunities might be different at the two types of schools. Since the study relied to such a large extent on the subjects' own words, Iit was difficult to explore the possible effects of the public or private nature of an institution's funding and governance structures.

The overlap between the interviewees teacher education programs at their institutions and their field placements at public schools did complicate an understanding of the subjects' experiences. The minority candidates did have to navigate two predominantly white institutions, both the universities and the public schools, where two opportunities for support or interference existed. With regard to this added wrinkle, I attempted to keep track of what was what. Nevertheless, for the minority student teachers, a clean separation between the university program and the public school seemed artificial. It all happened in their world.

My worries about the likelihood of the participants' candor were for naught. I had no trouble engaging them in a dialogue about their experiences. Joe echoed a common sentiment when he said, "It was so huge a transcript and yet I feel like I wasn't done. I have lots more to say." Joe's comment does raise a limitation of the study. For the purposes of the research study, I limited the interview rounds to two. By doing so, I stopped the conversations, not the respondents. There is much more to hear and learn from these successful minority teachers. 
Another insight I learned in the process of doing this research relates to the difficulty the subjects had in writing about their thoughts and feelings. Although five of the participants made use of the journaling opportunity, most mentioned how difficult and often emotionally draining it was to write things down. One suggested that a hand held tape recorder might have been easier than writing. Another explained that life as a minority person in America and the experience of being a minority in a predominantly white institution are impossible to separate. The two constantly overlap and intertwine and to separate them creates an artificial understanding of the minority experience. Thus, the breadth of this phenomenon combined with the personal nature of the narratives can make it difficult for some to write alone in a journal. For some participants, knowing an interested listener wanted to hear and understand made it easier to discuss their experiences.

The unique demographics of the Pacific Northwest did limit this study. I believe this study is representative of the region but I do question what a researcher who conducts a similar study in a different location might find.

\section{Implications}

The implications inherent in this study are difficult to unravel. Depending upon one's political perspective and wherewithal to address today's thorny racial and ethnic 
issues, the information gleaned from the interviews could be used to support very different courses of action. For this reason, I cautiously approach this section of the chapter. The findings of this study are clear: the seven minority subjects interviewed needed to exhibit a high degree of personal resiliency to finish their programs in predominantly white teacher preparation institutions. While resiliency traits like positive attitudes, problem-solving skills, self-efficacy, social competence, healthy expectations, and goal directedness generally correlate with success regardless of whether one is a minority or a member of the mainstream American culture, the study's subjects had to demonstrate a very high degree of these resiliency characteristics, and they had to do so in the face of what, for many, was an often unwelcoming, alien environment. According to the interviewees, their personal resiliency primarily explains their academic achievement and program success, although program interventions intended to increase retention of minority students did have some positive effects. Based on the interviews, it is fair to characterize their explanations of their successes as roughly $90 \%$ personal effort and $10 \%$ program support. I believe that those faculty and administrators invested in retention programs, particularly those who have not investigated the perspectives of the minority students themselves, tend to attribute minority success in a 
predominantly white environment to percentages reflecting the reverse of those previously indicated, i.e., $10 \%$ personal student characteristics and 908 program supports. Love's (1993) research about minority retention programs nationwide appears to corroborate this belief.

A minority student's resiliency, then, becomes his or her individual antidote to the hegemony of mainstream American culture acting to preserve the status quo in a predominantly white educational institution. The outcomes derived through resiliency aliow a minority student to circumvent problems of inequity rather than to rectify them. Here lies the crux of the matter with regard to the application of the study's findings to a mainstream institution's policy and practice. If an institution's leaders want to improve their numbers of retained minority students while not rocking the boat, then the answer is simple: devise a means to screen for applicants' resiliency. Such an interpretation of the findings would be a gross misdirection of the intent of the study and it would negate the value of its findings. A far more critical question for institutional leaders to address is: in what ways can institutions construct policies and practices which decrease the amount of resiliency required of a minority student who succeeds? To confront this question, institutional leaders must be resolute and honest. They must also face the likelihood that, despite many well- 
intentioned retention efforts, predominantly white institutions and the members of the majority who operate within them continue to perpetuate an insider's culture where insiders are advantaged. While appreciating the resiliency of successful minority students, institutional leaders need to direct the focus of future actions to the root causes of the situations which denand such resiliency. Another mare's-nest to unravel is/that of the representative quality of the interviewees. This study was not intended to produce generalizable information; the sample was too small, and the method was designed to elicit deeper understandings of individuals' experiences. Therefore, the seemingly common evidence of mixed racial/ethnic heritage among the survey respondents and interviewees is difficult to interpret: The descriptions of mixed backgrounds contradict common cultural assumptions about the clear separations between racial/ethnic groups and raise questions as to their ongoing validity in our increasingly pluralistic American culture. I wonder to what extent the profiles of the respondents/are indicative of the society at large--and to what extent they describe those minority individuals able to succeed in a predominantly white environment. Does experience coming to terms with a mixed heritage somehow enable one to negotiate other mixed environments? Are the generalizations which describe purer racial/ethnic categories valid distinctions? Were they once 
accurate, but are they now outdated? Are they constructions of the dominant culture which seeks to organize and separate minority populations? Are they helpful ways for minority groups to establish identity? Are they oversimplified descriptions? And, does this study's investigation of people of mixed backgrounds somehow negate its relevance to people who would more clearly identify wholly with one racial/ethnic group? I believe many implications exist in these questions, implications which arise from the misunderstandings and false assumptions which exist between members of minorities and those of the dominant culture, implications which need to be thoughtfully considered.

A true surprise which emerged from the data analysis of the interviews was the degree of commonality among the respondents. When designing this study, I expected to hear seven unique stories of different people, and I anticipated that the interviewees' distinct racial/ethnic backgrounds and personal characteristics would provide the means to differentiate their portraits. Throughout the data analysis I fought my assumptions and expectations of difference; I kept trying to apply a template that just did not fit. Although each person interviewed told a wonderfully idiosyncratic and rich personal history, the similarity of the themes of being an outsider-within and of resiliency which wove throughout the lives of all of the participants seemed remarkable. Consequently, I believe that the 
uniqueness of a minority member's personal history is subsumed by the common experiences encountered by most minorities who enter and act within a predominantly white environment.

Lastly, minority participants went out of their way to say they appreciated the concerns for confidentiality in my study, but they were not worried and in fact they wanted to be heard. They made comments like: "It's the way life is; it's out there, so let's start talking about it; it's a relief to talk about it; and what's to be afraid of?" of more importance to the respondents was their new found recognition that they were not alone, that others shared similar experiences, understandings, and stories. The participants expressed the desire to gather for a dinner and meet each other. They would love to combine their stories into a book that might help other minorities in similar circumstances. The contrast between minority and majority attitudes toward opening this dialogue causes me to question who benefits from the previous silence about this topic.

\section{Recommendations for Future} Research

This small, regionally limited study should be expanded. I believe it raises many legitimate questions which prompt more qualitative as well as quantitative studies. Minority voices need to be central to any further investigation about the under-representation of minority 
teachers. This study only begins to uncover understandings of minority students' experiences in predominantly white environments and what those experiences mean to individuals. In addition, I recommend an investigation of the perspectives of majority faculty and students to better understand what it means to members of the dominant culture to experience the organizational changes which stem from the increasing diversity of the American population.

Another valuable research approach to the phenomenon indicated by the under-representation of minority teachers might be to compare perspectives within a single situation. An analysis of minority students' reports of experiences and their interpretations contrasted with those of majority students in the same program, their faculty, and the quantifiable relevant program data could provide enlightening information.

Finally, I suggest pausing to reflect upon the unsettling information indicated by my research study, i.e., that a minority person in a predominantly white environment functions as an outsider-within and the resiliency necessary for him or her to succeed there may be far greater than is typically acknowledged. If this is true, what does it mean? The implications reach far beyond individual programs. Further study that places|programs and institutions within their larger cultural context seems an apt next step. 


\section{Epilogue}

During the final week of writing the documentation of this study, several seemingly small news events and । experiences caught my attention. The fact that I noticed them may be indicative of my absorption in this project, akin to the way you notice how many cars like your own are on the road immediately after you buy a new one. However, these items may also be indicative of the timeliness $\mid$ and pervasiveness of the issues raised in this research. I The mixed bag of attention grabbers includes:

1. A nationaly televised interview with Tiger/Woods (April 8, 1995), a young minority player in the U.S. Masters golf tournament. Probably working from the assumption that his appearance reflected his ethnicity, an interviewer asked Woods how he felt as a young Black golfer, and woods replied, "I can't really answer that because to speak about just being Black would ignore other parts of me. You see I'm also part Asian and part Native American and those parts of me are equally important to honor and represerit." Not only did the interviewer inadvertently ask woods to select which heritage was more legitimate, but he also reminded the young golfer that he was an outsider-within. . . that his participation was atypical. What do reminders of one's proper place do to one's self-confidence? What benefits accrue when one receives positive place messages (e.g., "Of 
course you are right where you belong") or one does not have to consider the question of legitimate membership at all?

2. On public cable access television (April 4, 1995), a "Grassroots News" segment featured a conference for Pacific Northwest youth of color investigating opportunities at historically-black colleges and universities (HBCUs). The people of color leading the discussions presented a strong case for the benefits gained by a minority student who attends an HBCU, and they emphasized the risks incurred and extra strengths demanded of those young people of color who opt to attend predominantly white institutions. Perhaps most meaningful was the matter-of-fact tone of the discussion: these people of color know what it is like to be "welcomed home"l and what it is like to go where "you are suspect and must prove yourself and your right to be there every day." I wonder if members of the dominant culture are as acutely aware of these differences.

3. At an American Association of Higher Education conference in Washington, DC, Professor Ronald Takaki of San Francisco State College (March 1995) told a story of his undergraduate education at an elite liberal arts college in the Midwest. After growing up in Hawai, he felt totally American. However, when in the predominantly white culture of middle America, his Asian features caused him to stand out from the crowd. For his entire four years at college and despite his explanations that he was American, the 
college administrators repeatedly invited him to the hospitality dinners for foreign students. Takaki is not sure exactly what effect the invitations had, but: to this day he remembers them with mixed feelings.

4. One of the interviewees called to ask how the research was progressing, and more important, when could he have dinner with the other study participants. He just wanted me to know how much he was "looking forward to meeting other people who have been through the same stuff and who also care abuut teaching."

What members of American minority groups know and what members of the mainstream culture know is not the same. Our different experiences and our different interpretations of those experiences generate untoward conditions which hamper communication. We have a long way to go to realize the equities our culture espouses. Listening to minority voices and questioning our taken-for-granted assumptions are ways to help move us along the path; we need to do more of both. 
REFERENCES

Adams v. Richardson, 480 F.2d 1159 (D.C. Cir. 1973).

Agar, M. (1986). Speaking of ethnography: Quafitative research method series. Newbury Park, CA: Sage Publications.

American Council on Education/Education Commission of the States (ACE/ECS). (1988, May). One-third of a Nation: A report of the Commission on Minority Participation in Education and American Life. Washington, DC: Author.

American Council on Education/office of Minorities in Higher Education (ACE/OlHHE). (1992). Environments of support. Washington, DC: Author.

Aronson, D. (1995, Spring). Heroic possibilities. Teaching Tolerance, pp. 11-15.

Atkinson, P., \& Hammersley, M. (1994). Ethnography and participant observation. In $N$. Denzin \& $Y$. Lincoln (Eds.), Handbook of qualitative research (pp. 248-261). Thousand Oaks, CA: Sage Publications.

Attinasi, L. (1989). Getting in: Americans' perceptions of university attendance and the implications for freshman year persistence. Journal of Higher Education, 60(3), 247-277.

Bean, J., \& Metzner, B. (1985). A conceptual model of nontraditional student attrition. Review of Educational Research, 55(4), 485-540.

Belenky, M. (1985). Finding our voice. Boston University Journal of Education, $167(3), 12-22$.

Belenky, M., Clinchy, B., Goldberger, N. \& \& Tarule, J. (1986). Women's ways of knowing: The development of self, voice, and mind. New York: Basic Books, Inc., Publishers.

Bell, D. (1992). Faces at the bottom of the well: The permanence of racism. New York: Harper collins Publishers, Inc. 
Benard, B. (1991). Fostering resiliency in kids: protective factors in the family, school, and community. San Francisco: Far West Laboratory for Educational Research and Development.

Bogden, R., \& Biklen, S. (1982). Qualitative research for education. Boston: Allyn and Bacon, Inc.

Bohmer, S., \& Briggs, J. (1991, April). Teaching privileged students about gender, race, and class oppression. Teaching Sociology, 19(2), 154-163.

Brown v. Board of Education of Topeka, 347 U.S. 483 (1954).

Carnegie Forum on Education and the Economy. (1986). A nation prepared: Teachers for the 21 st century. New York: Author.

Carter, D., \& wilson, R. (Eds.). (1992). Minorities in Higher Education: Eleventh annual status report. Washington, DC: American Council on Education.

Christensen, L. (Ed.). (1992). Rites of passage: A literary magazine. Portland, OR: Jefferson High School.

Cibik, M., \& Chambers, S. (1991, Winter). Similarities and differences among Native Americans, Hispanics, Blacks, and Anglos. NASPA Journal, 28(2), 129-139.

Civil Rights Act of 1964, 78, 241-268 (1964).

Clewell, B. (1987). Retention of Black and Hispanic doctoral students. Princeton, NJ: Educational Testing Service.

Collins, P. (1989). The social construction of black feminist thought. Signs: Journal of Women in culture and Society, 14(1), 745-773.

Collins, P. (1992). Learning from the outsider within. In M. Frow \& J. Cook (Eds.), Beyond methodology: Feminist scholarship as lived research (pp.|35-59). Bloomington: Indiana University Press.

Conciatore, J. (1990, July 19). Shortage of minority teachers leads some to look to majority. Black Issues in Higher Education, $I(13), 8-9$. 
Denzin, N., \& Lincoln, Y. (1994). Entering the field of qualitative research. In $N$. Denzin \& Y. Lincoln (Eds.), Handbook of qualitative research (pp. 1-17), Thousand Oaks, CA: Sage Publications.

Devault, H. (1990). Talking and listening from women's standpoint: Feminist strategies for interviewing and analysis. Social Problems, $37(1), 96-115$.

di Leonardo, M. (1991). Introduction: Gender, culture and political economy. In M. di Leonardo (Ed.), Gender at the crossroads of knowledge: Eeminist anthropology in the postmodern era (pp. 1-48). Berkeley: University of California Press.

Dilworth, M. (Ed.). (1992). Diversity in teacher education: New expectations. San Francisco: JosseyBass.

Eliot, T. (1950) The cocktail party. New York: Harcourt, Brace, and World, Inc.

Freire, P. (1970). Pedagogy of the oppressed. New York: continuum.

Fontana, A., \& Frey, J. (1994). Interviewing: The art of science. In N. Denzin \& Y. Lincoln (Eds.), Handbook of gualitative fesearch (pp. 361-376). Thousand Oaks, CA: Sage Publications.

Garibaldi, A. (Ed.). (1989). Teacher recruitment and retention with a special focus on minority teachers. Washington, DC: National Education Association.

Gilligan, C. (1982). In a different voice. Cambridge, MA: Harvard University Press.

Gosetti, P., \& Rusch, E. (1993, April). The lens of privilege: Re-examining educational leadership. Paper presented at the annual meeting of the American Educational Research Association, Atlanta, GA.

Grant, C. \& sleeter, C. (1988). Race, class, and gender and abandoned dreams. Teachers College Record, 90 (1), 20-40.

Gray, C., Hernandez-Gravelle, H. Lewis, J., \& Warren, I. (1992). Race in the classroom: The multiplicity of experience. Boston: Harvard University Press. 
Guba, E. \& Iincoln, Y. (1994). Competing paradigms in qualitative research. In $N$. Denzin \& $Y$. Lincoln (Eds.), Handbook of qualitative research (pp. 105-117). Thousand Oaks, CA: Sage Publications.

Harding, s. (1990). Feminism, science, and the antienlightenment critiques. In L. Nicholson (Ed.), Feminism/postmodernism (pp. 83-103). New York: Routledge.

Harding, s. (Ed.). (1987). Feminism and methodology. Indianapolis: Indiana University Press.

Hirsch, E. (1987). Sultural literacy. Boston: Houghton Miffiin.

hooks, b. (1990). Yearning: Race and gender, and eultural politics. Boston: South End Press.

Johnston, W. (1987). Workforce 2000: Work and workers for the 21 st century. Indianapolis, IN: Hudson Institute.

The Kerner report updated: Report of the 1988 Commission on the citjes, Race and Poverty in the united states today. (1988). Paper presented at the national conference, sponsored by the Johnson Foundation Wingspread Conference Center, Racine, WI.

Kincheloe, J., \& McLaren, P. (1994). Rethinking critical theory and qualitative research. In $N$. Denzin \& $Y$. Lincoln (Eds.), Handbook of qualitative research ( $P$ p. 138-157). Thousand Oaks, CA: Sage Publications.

King, J. (1991). Dysconscious racism: Ideology, identity, and the miseducation of teachers. Journal of Negro Education, 60(2), 133-146.

King, S. (1993). The limited presence of African-American teachers. Review of Educational Research, 63(2), 115149 .

Kinnick, M., \& Ricks, M. (1992, May). student retention: Moving from numbers to action. Paper presented at the annual forum of the Association for Institutional Research, Atlanta, GA.

Kreisberg, S. (1986). Transforming power: Toward an understanding of the nature of power in the experience of empowerment. Unpublished doctoral dissertation, Harvard University, Cambridge, HA. 
Ladson-Billings, G. (1994). The dreamkeepers: Successful teachers of African American children. San Francisco: Jossey-Bass Publishers.

Lewis, M. (1978). The culture of ineguality. New York: New American Library.

Lincoln, Y. (1992). I and thou: Method, voice, and roles in research with the silenced. In D. McLaughlin \& W. Tierney (Eds.), Naming silenced lives (pp. 29-47). New York: Routledge.

Love, B. (1993). Issues and problems in the retention of black students in predominantly white institutions of higher education. Equity and Excellence in Education, $26(1), 27-36$.

Maclean, N. (1976). A river runs through it and other stories. Chicago: University of Chicago Press.

Martinez, R., Durham, R., Philbrick, P., \& Melenez, D. (1992). Minority graduate education: An encouragement program. Equity and Excellence in Education, 25(2-4), $31-34$.

McGuire, J. (1991). Factors and barfiers impacting Black students in choosing teaching as a career. Unpublished doctoral dissertation, Colorado State University, Fort Collins, co.

McIntosh, P. (1988). White privilege and male privilege: A Personal account of coming to see correspondences through work in women's studies (Working paper no. 189). Wellesley, MA: Wellesley College, Center for Research on Women.

Mestas, J. (1990). Reflections on ethnic underrepresentation in higher education. Philadelphia: PEW Charitable Trusts Higher Education Research Program.

Metzner, B., \& Bean, J. (1987). The estimation of a conceptual model of nontraditional undergraduate student attrition. Research in Higher Education, 27(1), 15-37.

Middleton, E., \& Mason, E. (Eds.) (1988). Recruitment and retention of minority students in higher education. Dubuque, IA: Kendall/Hunt.

Monteblanco, c. (1994). Multicultural philosophy: Personal reflective writing. Unpublished manuscript. 
Morrison, T. (1993). Playing in the dark: Whiteness and the literary imagination. New York: Random House.

National Advisory Commission on Civil Disorders. (1968). Report of the National Advisory Commission on Civil Disorders, otto Kerner, Chairman. Washington, DC: Government Printing office.

Nieto, S. (1992). Affirming diversity: The sociopolitical context of multicultural education. New York: Longman Publishing Group.

Noel-Levitz Centers, Inc. (1992). A compendium of successful, innovative retention programs and practices. Iowa City: Author.

O'Brien, A. (1993). Persistence influences on the minority student attending a predominantly white postsecondary institution: The student perspective. Unpublished doctoral dissertation, Portland State University, Portland, OR.

Ogbu, J. (1978). Minority education and caste: The American system in cross-cultural perspective. New York: Academic Press.

Ogbu, J. (1992, November). Understanding cultural diversity and learning. Educational Researcher, 21(8), $5-24$.

O'Hanlon, R., \& Washbrook, D. (1992). After orientalism: Culture, criticism, and politics in the third world. Comparative Studies in Society and History, 34(1), 141167.

Olesen, V. (1994). Feminisms and models of qualitative research. In N. Denzin \& $Y$. Lincoln, (Eds), Handbook of qualitative research (pp. 158-174). Thousand Oaks, $\mathrm{CA}$ : Sage Publications.

Ornstein, A., \& Levine, D. (1989, September/October). Social class, race, and school achievement: Problems and prospects. Journal of Teacher Education, 40(5), 17-23.

Pascarella, E., \& Terenzini, P. (1990). How college affects students. San Francisco: Jossey-Bass.

Pasch, M., Krakow, M., Johnson, C., Slocum, H., \& Stapleton, E. (1990, July). The disappearing minority educator-No illusion: A practical solution. Urban Education, $25(1), 207-218$. 
Plessy v. Ferguson, 163 U.S. 537 (1896).

Quindlen, A. (1993, January 28). Familiarity breeds content, self-esteem. New York Times, p. B6.

Ranbom, S., \& Lynch, J. (1988, Fall/winter). Timeline: The long, hard road to educational equality. Educational Record, pp. 16-21.

Ravitch, D. (1990, Spring). Diversity and democracy: Multicultural education in America. American Educator: The Professional Journal of the American Federation of Teachers, 14(1), 16-20, 46-48.

Regents of the University of California v. Bakke, U.S. $76-811(1978)$.

Rodriguez, R. (1982). Hunger of memory: The education of Richard Rodriquez. New York: Bantam-Doubleday.

Rose, P. (Ed.). (1993). The Norton book of women's lives. New York: W. W. Norton and Company.

Schwandt, T. (1994). Constructivist, interpretivist approaches to human inquiry. In $\mathrm{N}$. Denzin \& $\mathrm{Y}$. Lincoln (Eds.), Handbook of qualitative research (pp. 118-137). Thousand Oaks, CA: Sage Publications.

The Secretary's Commission on Achieving Necessary skills (SCANS). (1990). Executive summary of the commission's report. Washington, DC: U.S. Department of Labor.

Simonson, R., \& Walker, S. (Eds). (1988). Multicultural literacy: opening the American mind. st. Paul, MN: Graywolf Press.

Smith, D. (1987). The everyday world as problematic: A feminist sociology. Boston: Northeastern University Press.

Spradley, J. (1979). The ethnographic interview. New York: Holt, Rinehart, and Winston.

Staff. (1995, February 13). What color is black? Science, politics, and racial identity. Newsweek, 125(7), 62-72.

Stanfield, J. (1994). Ethnic modeling in qualitative research. In N. Denzin \& Y. Lincoln (Eds.), Handbook of qualitative research (pp. 175-188). Thousand Oaks, CA: Sage Publications. 
Steele, C. (1992, April). Race and the schooling of black Americans. The Atlantic Monthly, 269(4), 68-78.

Terrell, M., \& Wright, D. (Eds.). (1988). From survival to success: Promoting minority student retention (Monograph Series, Vol. 9). Washington, DC: National Association of Student Personnel Administrators, Inc.

Thomas, J. (1993). Doing critical ethnography. Newbury Park, CA: Sage Publications, Inc.

Tierney, W. (1992). An anthropological analysis of student participation in college. Journal of Higher Education, $\underline{63}(6), 603-618$.

Tinto, V. (1987). Leaving college. Chicago: The University of Chicago Press.

Tukufu, D. (1991, October). Diversity in the workplace: success through mutual adjustment. Keynote speech at the annual conference of the Pacific Northwest Personnel Managers Association, Portland, OR.

Voting Rights Act of 1965, 79, 437-446 (1965).

U.S. Department of Education. (1992a). Digest of education statistics 1992. Washington, DC: National Center for Education Statistics.

U.S. Department of Education. (1992b). Trends in enrollment in higher education by racial/ethnic category: Fall 1982 through fall 1991. Washington, DC: National Center for Education Statistics.

Valli, L. (1983). Becoming clerical workers: Business education and the culture of femininity. In M. Apple \& L. Heis (Eds.), Ideology and practice in schooling (pp. 213-233). Philadelphia: Temple University Press.

West, c. (1993). Race matters. Boston: Beacon Press.

williams, M. (1983). The velveteen rabbit. New York: Alfred A. Knopf.

Zweigenhaft, R., \& Domhoff, G. (1991). Blacks in the white establishment? A study of race and class in America. New Haven, CT: Yale University Press. 
APPENDIX A

HUMAN SUBJECTS APPROVAL 


\section{OFFICE OF RESEARCII AND SPONSORED PROJECTS}

DATE: May 31,1994

TO: $\quad$ Leslie Rennie-Hill

FROM: Jer Martha Balshem, Chair, HSRRC, 1993-94

RE: i HSRRC Waived Review of Your Application titled "Perceptions by Students of Color of Their Schooling at Predominantly White Graduate Schools...."

Your proposal is exempt from further HSRRC review, and you may proceed with the study.

Even with the exemption above, it was necessary by University policy for you to notify this Committee of the proposed research and we appreciate your timely attention to this matter. If you make changes in your research protocol, the Committee must be notified.

c. Ofrice of Graduate Studies : 
APPENDIX B

CORRESPONDENCE 


\section{Portand State Lniversity}

David Krug

Dean, School of Education

Ponland State University.

POBOA 751

Portland. OR 97207

April 26. 1994

To Whom li May Concern:

This letter serves to signify my suppon of Leslie Rennie-Hill's research. After working "wh her for over five years. I can vouch for her personal and professional integrits.

Her topic of studs is important: Perceptions of Students of Color of Their Schooling at Predominantly White Graduate Schools of Education: What Contributed to Persistence and Achievement? W'iat Didn't? As stipulated by the Human Subjects Research Reriew Committee. standard procedures will be followed: Subjects participation will be voluntan: their confidentiality will be ensured: personal information will be destroved when no longer needed. The research will include only survey procedures and interviews.

Subjects for the study will be recruited from a pool of people of color who have satisfactorily completed teacher preparation programs at araduate schools of education. This study should enhance our understanding of the experiences of these minorities in our institutuns. Resisting the deficit orientation. it will explore what makes a positive difference. Most imponantly, its core will be the voices of the people of color themselves. I

Leslie plans to offer a summary of the results and findings to all cooperating institutions. I anticipate such information could prove useful in an accreditation repon.

I know Leslie will appreciate your help ohtaining address lists of people of color who have completed your graduate teacher preparation program since 1991. I aiso encourage your cooperation and thank you for your willingness to devole a few extra minutes in this issue

Sincerel!.

David Krug

Deiall 
Leslie Rennie-Hill

3528 NE U.S. Grant Place

Portland, OR 97212

DATE

Institutional Ally's Address

Dear Institutional Ally,

Thank you very much for your willingness to assist with the distribution of these surveys. I appreciate your support for the effort.

When I received approval from the PSU Human Subjects Research Review Committee in May, they saw no problems with the study. The other 9 institutions have found this distribution method to work out ok. I hope you do too.

Each envelope is ready to go: an address label will complete each packet. If you would like to include your personal letter of support, please feel free to do so. I've enclosed a sample which some of the other schools have used as a model.

When we last talked, you noted approximately $\mathrm{N}$ students of color have completed your graduate teacher preparation program since 1990. I've included $N$ survey packets; if you need more, just let me know.

One last request: once the mailing is out, would you send me a copy of your letter if you decide to add one, the total number of surveys mailed, and the date of mailing? That way, my records will be complete and I'll have some idea of when to look for responses. I hope to be able to analyze the survey data and begin some selected interviews by August 1st.

If you have any questions, please don't hesitate to call me at home (503) 282-8036 or work 725-4657.

When the study is completed (hopefully next fall), I'll send you a summary of results. Until then, many thanks again for your help - especially when extra time is at such a premium.

sincerely,

Leslie Rennie-Hill 


\section{DRAFT DRAFT DRAFT}

Letter from Institutional agent to completers of institution's post bac. teacher preparation program 1990 to present.

Dear

I write to you today to encourage your participation in the research study described in this mailing. The topic of study is an important one; the focus is upon the experiences of graduate students of education who are considered to be a minority within a majority population.

The faculty of $X Y Z$ Institution maintains a strong desire to support the professional success of nur minority students beginning with their successful completion of our teacher education program. Information which deepens our understanding and candidly presents students' perspectives will help us to improve our efforts. I believe the results of this study will do just that.

This particular study will pool information from 10 graduate level teacher preparation programs in the Pacific Northwest. since the schools share many characteristics, it seems valid to aggregate the data. The Dean's office will receive a summary report of the study which can be shared with the faculty of the school of Education.

All information relative to the study will be kept confidential. No one at XYZ Institution will learn the content of any of your responses or even if you complete the survey or participate in an interview. pue to the large number of schools participating, it will be easy to mask all participants' identities and ensure total confidentiality.

Please give this request your thoughtful consideration. And, thank you for your willingness to devote a few extra minutes to this issue. 


\section{Leslie Rennie-Hill \\ 3528 NE U.S. Grant Place \\ Portland, OR 97212 \\ (503) $282-8036$}

Date

\section{ADDRESS}

\section{Dear NAME,}

Greetings! Now that fall is here, I plan to work long and hard on this project for the next few months. I look forward to reconnecting with you and continuing our dialogue.

Enclosed is a transcript from our first conversation. Reading it may seem strange at first; sometimes it is difficult to recognize a transcribed conversation as the one that occurred. I ask you to read and react to the transcript. We need to assure that it is accurate. Feel free to make notes on the pages. After your review, would you then make some notes in your journal? Some ideas to consider are: How did I feel about this interview? Did I get across what I wanted to? If you choose to, you could write me a paragraph about the interview as a whole and what it meant to you.

I will call you to set up a brief second interview. I hope we can find a time convenient for you between now and the first of the year.

At the second interview, we can go over your journal and clarify any confusions from the first conversation. We can also talk about anything we've missed that you believe should be included.

At this point I've completed seven interviews - seven wonderful, important stories. After talking with you and the other folks, I am more convinced than ever that we are onto something significant. Your contribution is really helping to clarify what it is like to succeed in a predominantly white institution. Thank you once again for your willingness to be a part of this effort.

When I think of our last conversation, I smile at the warmth, connections, and insights. I'm glad we'll be talking again soon. In the midst of your hectic life, I am grateful you can fit this into your schedule.

Sincerely, 
APPENDIX C

SURVEY 
Leslie Rennie-Hill

3528 NE U.S. Grant Place

Portland, OR 97212

July 8,1994

Dear Fellow Teacher;

Recent reports from the American Council on Education (1988) tell us that by the year 2000, one-third of all school age children will be children of color. Unfortunately, the percentage of all teachers who are teachers of color is expected to shrink from $12 \%$ to less than $5 \%$ by that same year.

For the past five years, I have taught in a graduate-level teacher preparation program in an urban, predominantly white university. These recent professional experiences have added a realism and at times put a human face on the statistic cited above. Therefore, with a personal as well as an academic interest in the problems posed by the lack of teachers of color, I write to you today.

I expect that you too may be deeply concerned about these statistics and their implications. Based on my belief that the U.S. public schools need more teachers of color now and in the future, I am doing a doctoral research study. I hope you will choose to join me in this study.

According to Dr. $\mathrm{XYZ}$ at $\mathrm{ABCDE}$ College, you are a person who has successfully completed a teacher preparation program at a predominantly white institution. You are one of the experts I'm searching for because you've lived the experience that this study is about. You, and only you, know why and how you completed your graduate program.

It is my hope that by listening to your story and then by letting others understand your experiences - what helped and what didn't - we can move ahead to make it possible for others to follow in your footsteps.

Finding people who meet the background qualifications for this study has been extremely difficult. Far too few people have achieved what you have. While you may not receive any direct benefit from this study, by sharing your knowledge, you will make an invaluable contribution that may help others in the future.

The survey will take about 15 minutes to complete. All survey data will be collected anonymously and beld confidential. No one at the graduate school you attended will know whether or not you ever completed the survey. If you have questions about the survey or the entire study, please call me at (503) 725-4657. this wolk.

I recognize that your time is valuable. Thank you for devoting some of it to

Sincerely,

Leslie Rennie-Hill 


\section{SURVEY: COMPIETERS OF GRADUATE TEACHER ED. PROCRAMS}

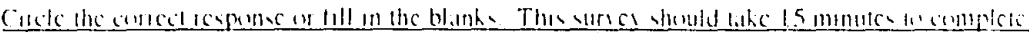

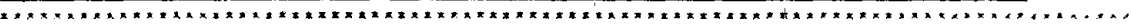

I. Gender: Male Fenale

2. Age: $\quad 21.29 \quad 30.39 \quad 40.49 \quad 50.59$

?. Race:

4. Finnicin.

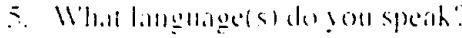

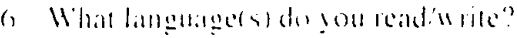

- Dil pour hather attend college? yes no Didhegraduale? yes no

8. What is sour fahter"s occupation?"

9. Did your mother atlend college? yes no Didshegraduate? yes no

10. M'hat is sour molher"s occupation?"

11. Did am! of gom gramdparents allend college? yes mo

12. Has or is ang one of you parents generalion in your family a teacher? !es 176

1?. Ilas am! one of your grandparens generation in your family a teacher? yes me

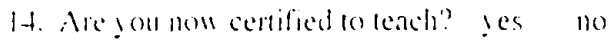

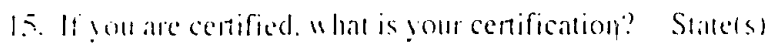

Cindelends : Subjects

Sprovil Endursements

10. Are got employed now as a public school teacher? yes no

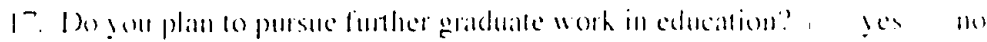

18. What was your overall undergraduate grade point average (GPA)?
$(-1.0 .3 .5)$
$(3.4-3.1)$
(3.0.2.6)
$(2.5 \cdot 2.1)$
(less than 2.(0)

19. What was your overall graduate (iPA in the teacher preparatlon progemon?
$1+.0 .3 .5$
$(3.4+3.1)$
(3.0.2.6)
12.52 .1
(less thath 20)

(1) (1) 
20. Did !ou receive a scholarship or grant while in the teacher prep. program? yes no 11 :es. " hat kind"?

21. Were you employed while attending the teacher preparation program? yes no

22. If les. hom man! hours perweek did you work?

less (han 5 hrs 5.10 hers $11-15 \mathrm{hrs}$ 16-20 hrs $21-30$ hrs more than 30 hrs

23. Did fou tahe out a sudent loan while in the teacher prep. program? yes no

2-4. Bo gou halle other student loans from your undergraduate studies? yes no

25. Dhal you receive a graduate teaching assistantship or other worhisud! assistance whike in lle keacher prep. program?

26. Did rom fultill ans regulat personal communits service obligation

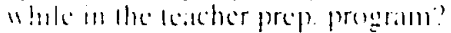

27. II !on alle commilled to on going community volunteer work. pleare describe hriells:

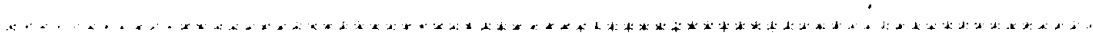

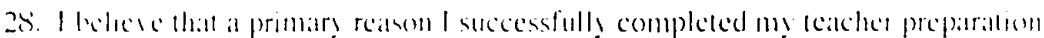
program is hecaluse

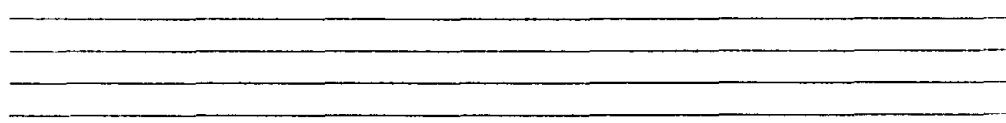

20. Ifelt that the bigegest obstacle which interfered with my work in and completion of the eacher preparation progeram was

30. If you are willing 10 consider participating in a follow up intervieu. please indicate the hest was to contact you:

Nimlo

Address

Phü

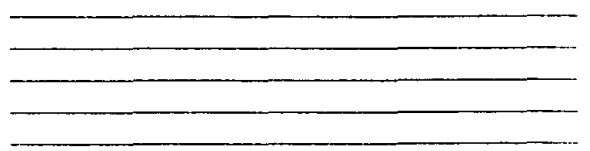


APPENDIX D

INTERVIEW QUESTIONS 
INTIRVIFW QUESTIONS (as of $8 / 2 / 9+$ )

\section{CONSTRLCTION (OF: SELF}

1. Here you are mon. a certified leacher. Whate the focus of this study is en your aperiences at $X X X X$. I magine that time is not separate from the rest of your life. Hould youlell me how you an to where you are today?

ilicten for family of oregn. schoolina. fasorite adults. messages, values?

W'bat gualines do sou balate most about gourself"?

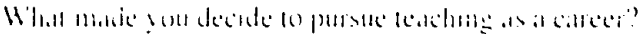

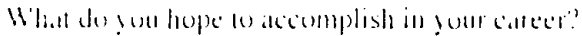

2. Talh abou lusideré(ousder concept and shom diagram.

Locale bour sell on this diagram. Describe what that place looks. sommds. fech like. Are daily life and program locations the same or different?

1

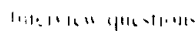

$x: 1.4$ 


\section{THACHIR IOLUCATION PROGRAM EXPERIENCE}

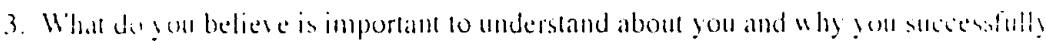
completed the progrim?

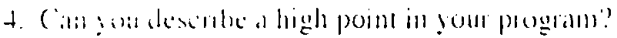

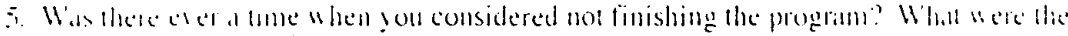
presputante factors? Why did jou conlintec"?

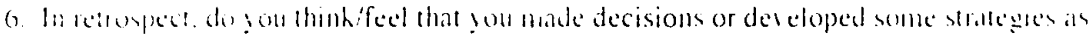

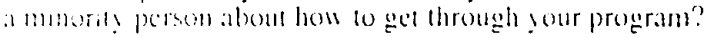

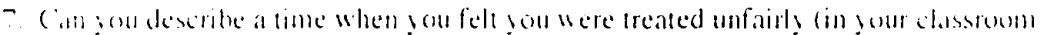

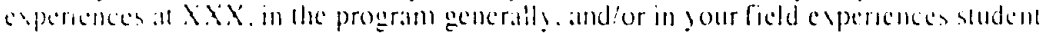
[alshin!?

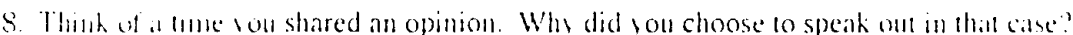

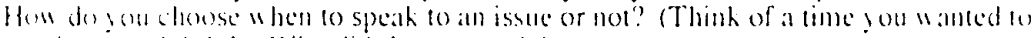

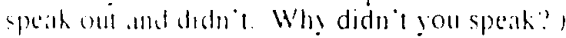

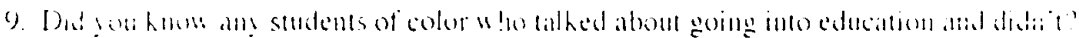
(outd for comment on that?

1(1. Du :ou hmom an! students of color who didn t complete your teacher preparation

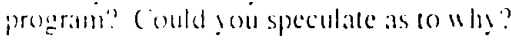

11. What ad ke "w und you give a friend of color who is entering the leateler prepanation progrim! som allended?

12. Show charl of Love's seven dimensions of programs for minorities enrolled in predominamly white instilutions. Rate your program based on your personal eyperiences.

1.3. If you " were lo design a leacher education program. what would you include". teanc' (1)11?

2

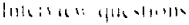

$\therefore: 14$ 


\section{R()IE OIF THE TEACHER}

14. Non l'd like ! oun to thinh hach on your own K-12 schooling. Were the re practices by acachers or the system that particularly worted for ?ou??

Were there practices whel were damaging or which limbed yot?

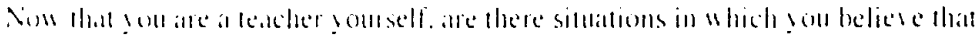

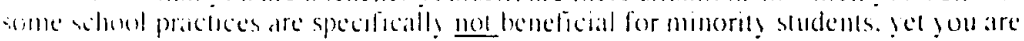
"epeced on do them ambas?

Wund you describe these simations and how you handle or plan wo handle heme"

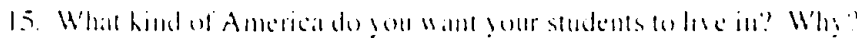

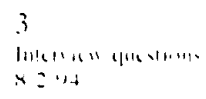

